\title{
PHENOLOGICAL ANALYSIS OF THE LAST GLACIAL VERTEBRATES FROM THE TERRITORY OF MORAVIA (THE CZECH REPUBLIC) - CONTINUITY AND CHANGE IN FAUNISTIC COMMUNITIES
}

\author{
RUDOLF MUSIL \\ Department of Geological Sciences, Faculty of Science, Masaryk University, Kotlářská 2, 61137 Brno, the Czech Republic; \\ e-mail: rudolf@sci.muni.cz.
}

Musil, R. (2018): Phenological analysis of the Last Glacial vertebrates from the territory of Moravia (the Czech Republic) - Continuity and change in faunistic communities. - Fossil Imprint, 74(3-4): 199-236, Praha. ISSN 2533-4050 (print), ISSN 2533-4069 (on-line).

\begin{abstract}
Due to the vertical zonality of the studied area, its environment varied greatly over a relatively short distance within the same time span. It is possible to distinguish the following different types of environment:

(1) Alluvial floodplains around larger water flows. I assume in the Last Glacial there was continuous coniferous forest, with occasional sporadic occurrences of thermophilous deciduous trees in favourable locations mainly in south Moravia.

(2) Lower foothills up to about $300 \mathrm{~m}$ a.s.l. along the floodplains, probably the most widespread type of environment in the studied area. Open grasslands with isolated trees and shrubs were predominant.

(3) At the higher altitudes of the hills (ca. 300-500 m a.s.1.) there was only steppe.

(4) The highest parts of highlands and the mountains (500-1,400 $\mathrm{m}$ a.s.l.). During the cold and dry events these areas were mostly without grassy vegetation.

The boundaries of the above mentioned environments fluctuated throughout the whole of the Last Glacial.

A series of new investigations of Last Glacial Moravian sites took place over the recent decades. The result was a relatively large amount of fossil vertebrate findings, from karst areas (caves), and from open air sites. All findings were assigned to precisely defined layers which were in most cases radiometrically and/or archaeologically dated. It allowed association of the fauna communities with stratigraphical events and therefore produced a clearer picture of changes during the entire Last Glacial.

The study showed that the species structure of the communities was not stable during the Last Glacial. The changes did not exhibit gradual linear development. The time span of the individual communities varied greatly. In two cases a total species change occurred very rapidly. In other cases the changes occurred over a longer period of time and may have involved penetration of new species into existing communities to a significant extent.

The changes of communities associated with single stratigraphical events were palaeoecologically evaluated. In comparison with changes in the environment, I can conclude that both changes occurred simultaneously. I am therefore convinced that the primary impulse for community change was induced by environmental change.

The Eemian communities of regions east of Germany differ from coeval communities of Western and the west part of Central Europe. This difference was driven by variation in precipitation, a more humid climate in the West and continental climate in the East. We have therefore two different Eemian provinces in Central Europe, the more humid west (oceanic weather) and the drier east (continental weather).

The first half of the Last Glacial, about $40 \mathrm{ka}$ from its beginning, had a wide range of climatic oscillations of different intensity. In layers of Moravian localities with interglacial species, the numbers of finds are always limited (small number). They were previously assigned to the Eemian. The earlier stratigraphic scale of the Late Pleistocene corresponded with this view. According to recent opinion, however, the rare finds of interglacial species in these localities are not from the Eemian interglacial, but from the first interstadials of the Last Glacial.

Larger temperature oscillations occurred only in the second half of the Last Glacial and the most significant cooling was at the very end of this time.

In the first occurrence of the typical Holocene assemblage in the Moravian Karst there are still some species which are typical for the Last Glacial (reindeer and lemmings). Lemmings died out first, but reindeer survived up to the Neolithic age.

This area had, and still has today, differing environments within a relatively short distance caused by vertical zonation. There was a significantly colder climate in the deep and relatively narrow valleys. The upper part of the insolation slopes was mainly covered with grass and the average annual temperature there was much higher than in the valleys. This was reflected of course in the fauna.

The in-migration of animals was not only via a meridional route. Migration was not only caused by oscillation of the average temperature or rainfall, but also by the need to find the best conditions for living. Seasonal migration was caused mainly by annual changes in the energy value of the food plants.
\end{abstract}

Key words: Moravia, Last Glacial, vertebrates, changes in assemblage diversity, migration, palaeoecology, environment 


\section{Introduction}

Phenology deals with seasonal climate shifts and their impact on the changes in flora and fauna. A summary of the environmental requirements of each species serves as the basis for environmental interpretation. The environmental interpretation of extinct species is based on knowledge of living species. It may not always exactly correspond with the past. It should be added that data on the characteristics of modern-day animals are sometimes extremely different, sometimes even diametrically dissimilar (Musil 1985, 1992, 1993, 1994a, 2010a). In these particular cases those which the author viewed as the most convincing are listed. It is assumed that not all of the species from an individual Pleistocene genus are known. A number of species have not been identified because there was no comparative material or because it was difficult to distinguish every single species on the basis of skeletal material. For most genera, there is a much higher number of possible species than is suggested in existing publications.

Moravia, the eastern part of the Czech Republic, borders with Poland to the north, with Slovakia to the east, with Bohemia to the west and to the south with Austria. It measures approximately 200 kilometers from north to south, and around 155 kilometers from east to west. Moravia is therefore a relatively small territory which is, however, extremely important for the possible migration of flora and fauna between northern and southern Europe. This region is surrounded for the most part by various high mountains (up to $1,400 \mathrm{~m}$ a.s.1.), it opens up fully only to the south, towards the Danube region. To the north it is connected to the relatively narrow Moravian Gate. All Moravian streams flow north to Poland, and south to the Danube region. The morphology of the vertically extremely rugged terrain has an effect on the climate which is quite varied over a relatively small area. There are also climatic differences between the northern and southern parts of this territory. The mountains (Českomoravská Highlands, Jeseníky, Beskydy, Carpathians) enclose not only Moravia but also extend further to the east and west. Moravia is therefore the only possible north-south connection between the north and south of the eastern part of Central Europe. As a result of these north-south migrations, there are a large numbers of vertebrate findings. Many karst regions (Moravian Karst, Javoříčko Karst, Zbrašov Karst and others) with a large number of caves (Moravian Karst has approximately 2,000) contribute to the major occurrences of the findings.

The territory of Moravia, from the viewpoint of the high concentration of animal findings, was extremely suitable for inhabitation by Palaeolithic hunters and therefore a large number of Palaeolithic sites were identified here (e.g. Musil 1955, 1957, 1962, 2003a, b, c, d, Valoch 1988, Svoboda et al. 2000b, 2003b, Škrdla 2002, Svoboda 2003a, b). My analysis can therefore be based, not only on the findings of naturally dead animals (mainly in caves), but also on the game hunted by Palaeolithic men (Musil 1999a, b, c). Another important source of knowledge is the rich history of Pleistocene research in Moravia which extends far back into the $18^{\text {th }}$ century (Musil et al. 1999).

Although it has long been known that the climate of the Last Glacial was not uniform, but was subject to major miscellaneous oscillations, the assemblages of large mammals throughout the entire Last Glacial were still considered as being more or less identical. This was usually a consequence of the fact that the study of these sites did not cover the entire period. However, all of this is possible within the territory of Moravia. This paper therefore evaluates not only the relationships between biota and the environment, but also the substantial changes occurring over the course of the studied period.

\section{Time divisions used}

I have divided the whole time period of the Last Glacial into different stages - events (events 1-14). Single events of various time spans can also include several short climatic oscillations that do not play a decisive role on the type of vegetation cover and fauna (Stewart et al. 2003). The time span of events is, to a certain extent, influenced by the number of sites in a given period. The basis for this division was mainly based on previous publications (Musil 2003b, c, 2005a), the findings from the papers of "The Stage 3 Project”, Cambridge University's interdisciplinary project (van Andel and Davies 2003).

The Palaeolithic cultures are mentioned only for those sites, where they were actually present. Individual taxa according to the zoological system are not presented. From an ecological viewpoint it is much better to consider the whole community, and the proportions of each species. The split between large and small animals also has its justification. Larger animals have a much greater home range area over which they travel than small animals. Ecological analysis is therefore dependent on the size of the area of vegetation cover in each biotope, which may even change within a short distance.

\section{Event 14, MIS 1}

Subrecent to Recent. Neolithic, Bronze Age and younger.

\section{Event 13, MIS 1}

10-8 ka BP. Early Holocene, Mesolithic Age.

\section{Event 12, MIS 1}

12-10 ka BP. From this time we recognise the Epimagdalénian culture.

\section{Event 11, MIS 2}

14-12 ka BP. Late Glacial, Magdalénian (13.93-11.45 ka BP) (Valoch 1988, 1996).

\section{Event 10, MIS 2}

19-15 ka BP. The end of LGM (sensu lato), Epigravettian (18.89 ka BP, 18.92 ka BP, 19.38 ka BP, 15.06 ka cal BP) (Brandtner 1996, Musil 2002b).

\section{Event 9, the end of MIS 3 and the beginning of MIS 2}

Time range $31.93 \mathrm{ka}$ cal BP up $26.46 \mathrm{ka}$ cal BP (according to van Andel and Davies 2003). 
LGM (sensu lato): 27-15 ka BP, MIS 2, 27-16 ka BP, Gravettian (Pavlovian, Moravia), time range 29-27 ka BP.

Pavlovian Interstadial (Moravia) 30-22.5 ka BP according to Svoboda (2003a).

\section{Event 8, MIS 3}

Early Cold Phase, 37-27 ka BP (the time length for all events according to van Andel and Davies 2003, Musil 2005a).

Younger stage of MIS 3: 38-29 ka BP and an early cold stage (greater number of cold periods, only three slightly warmer).

The younger stage of Middle Pleniglacial. Interstadials: Hengelo (39-37 ka BP), Shapurovo Interstadial (36-29 ka BP, Belarus).

Warm periods 9 and 8: Denekamp (32-28 ka BP), Briansk Interstadial (32-24 ka BP, Russia), Borisov Interstadial (28 ka BP, Russia).

MIS 3, Pod Hradem Cave, Moravian Karst, 28.8-35.3 ka BP (Musil 1965b), 28.9-37.9 ka BP (Neruda and Nerudová 2013), 33.3-28.2 ka BP (Lisá et al. 2018).

\section{Event 7, MIS 3}

Middle stage of MIS 3, 44-38 ka BP and the transitional phase, 44-37 ka BP (according to van Andel and Davies 2003, Musil 2005a).

The middle stage of Middle Pleniglacial (three warm periods with a few cold breaks and a final warm period between 38-37 ka cal BP).

Turov Interstadial (44 ka, Belarus).

45-35 ka BP, Bohunician, Aurignacian, Szeletian, Moravia, 34.9-40.0 ka BP (Neruda and Nerudová 2013), Šipka Cave, Moravia, 40.1-44.0 ka BP, Čertova Díra Cave, Moravia, 42.0-45.0 ka BP (Neruda and Nerudová 2013).

\section{Event 6, MIS 3}

Older stage: 59-44 ka BP, Stable Warm Stage (according to van Andel and Davies 2003). Stable warm period broken by a cold phase around $47 \mathrm{ka}$ cal BP.

The middle stage of Middle Pleniglacial. Aurignacian.

Warm periods 17, 16 (Oerel Interstadial, 58-55 ka BP), 15, 14 (Glinde Interstadial, 51-46 ka BP), 13. $60 \mathrm{ka}$ $\mathrm{BP}$, Goulotte Interstadial (France), Polotsk Interstadial (Belarus), Moershoofd Interstadial (50-43 ka BP).

MIS 3, 59-45 ka BP, Kůlna Cave, Moravian Karst, layer 6a, 52.7 ka BP, Kůlna Cave (Micoquian), layer 7a, 4.6-4.3 ka cal BP (Micoquian). All dates from Musil (1970) and Neruda and Nerudová (2013).

\section{Event 5, MIS 4}

Younger stage of MIS 4: 66-59 ka BP, between 68-60 ka BP the First glacial maximum (FGM) in Northern Europe (according to van Andel and Davies 2003).

Middle stage of Middle Pleniglacial, late stage of the Middle Palaeolithic, Mousterian - Micoquian.

Sloboda event (Belarus).

\section{Event 4, MIS 4}

Older stage of MIS 4: 74-66 ka BP.
Table 1. Overview of warm oscillations (interstadials) in the Last Glacial, their names and submission to MIS, inclusive of radiometric data (Musil 2005a).

Tabelle 1. Stratigraphie der Letzten Eiszeit mit den Namen der warmen Interstadialen.

\begin{tabular}{|l|c|c|}
\hline \multicolumn{1}{|c|}{ Climatic oscillations } & MIS & cal ka BP \\
\hline Heinrich event 1 & MIS 2 & $15.5 \mathrm{ka}$ \\
\hline Late Glacial & MIS 2 & $\mathbf{1 5 - 1 0 ~ k a}$ \\
\hline Heinrich event 2 & MIS 2 & $21 \mathrm{ka}$ \\
\hline Pavlov Interstadial & MIS 2 & $25 \mathrm{ka}$ \\
\hline Late Pleniglacial & MIS 2 & $\mathbf{2 5 - 1 0 ~ k a}$ \\
\hline Heinrich event 3 & MIS 3 & $28 \mathrm{ka}$ \\
\hline Pod hradem Interstadial & MIS 3 & $30 \mathrm{ka}$ \\
\hline Denekamp Interstadial & MIS 3 & $34-29 \mathrm{ka}$ \\
\hline Heinrich event 4 & MIS 3 & $35 \mathrm{ka}$ \\
\hline Hengelo Interstadial & MIS 3 & $38-37 \mathrm{ka}$ \\
\hline Hasselo Stadial & MIS 3 & $41-38 \mathrm{ka}$ \\
\hline Bohunice Interstadial & MIS 3 & $42-38 \mathrm{ka}$ \\
\hline Moershoofd Interstadial & MIS 3 & $50-43 \mathrm{ka}$ \\
\hline Henrich event 6 & MIS 3 & $50 \mathrm{ka}$ \\
\hline Glinde Interstadial & MIS 3 & $53-52 \mathrm{ka}$ \\
\hline Oerel interstadiál & MIS 3 & $58-53 \mathrm{ka}$ \\
\hline Middle Pleniglacial & MIS 3 & $\mathbf{6 0 - 2 5 ~ k a}$ \\
\hline Henrich event 6 & MIS 4 & $65 \mathrm{ka}$ \\
\hline Early Pleniglacial & MIS 4 & $\mathbf{7 2 - 6 0 ~ k a}$ \\
\hline Odderade Interstadial & MIS 5a & $72-60 \mathrm{ka}$ \\
\hline Rederstall Stadial & MIS 5b & $84-72 \mathrm{ka}$ \\
\hline Amersfoort-Brörup Interstadial & MIS 5c & $92-84 \mathrm{ka}$ \\
\hline Herning Stadial & MIS 5c & $104-92 \mathrm{ka}$ \\
\hline Early Weichselian & MIS 5a-d & $\mathbf{1 1 0 - 7 2 ~ k a}$ \\
\hline Eemian & MIS 5e & $\mathbf{1 2 6 - 1 1 0 ~ k a}$ \\
\hline
\end{tabular}

Early Pleniglacial (74 ka BP).

Warm interstadial 21 (Saint Germain Interstadial, France 2), West Dvina 2 Interstadial (Belarus), warm period 20, 19. MIS 4, 74-66 ka BP, Kůlna Cave, 69 ka BP (Musil 1970).

\section{Event 3, MIS 5b}

Taubachian (Valoch et al. 1970, Valoch 1988), in Kůlna Cave in the underlying bed of event 4 . The first significantly warm event of the Last Glacial, with sporadic interglacial species, warm to very warm climate. A greater number of forest species with greater thermal demands. Cold climate species slightly increased (Musil 1970, 1988a). Without time date.

\section{Event 2, MIS 5c}

In the Kůlna Cave in the underlying bed of event 3 . Slightly warm period. Without time date.

\section{Event 1, MIS 5d}

A sudden cooling, the Greenland Stadial 25 (between 109-107 ka BP). Only on the basis of superposition of layers. In the Kůlna Cave in the underlying bed of event 2, cold climate. Without time date. 


\section{Summary of the climatic characteristics of the studied period}

Climatic oscillations in the Last Glacial were basically adapted from the publications cited in this article. The basic climatic characteristics come from GISP 2 ice core. The numbers used in the studied periods indicate markedly warm events (Tab. 1) in the Last Glacial (Meese et al. 1987, Huntley and Allen 2003, Musil 2003c, 2005a). An overview and temporal distribution is presented in Musil (2005a).

In this section I utilised previously published papers concerned with the environment in the Last Glacial (Musil 1980, 1988b, 2000a, b, 2008, 2010a, 2011a, b).

The first half of the Last Glacial, about $40 \mathrm{ka}$ from its beginning, has a wide range of climatic oscillations of different intensities, but there was still on average a warm or temperate climate. For this reason, the first part of this time period was previously classified as the Eemian interglacial. A detailed overview of the Last Glacial is shown in Textfig. 1. Larger temperature oscillations occurred only in the second half of the Last Glacial and the most significant cooling was at the very end of this time period (van Andel and Davies 2003, Musil 2003a, b, c, 2005a).

129-116ka BP (Eemian, MIS 5e) and transitional periods leading to the Last Glacial (117-109 ka BP)

\section{9-107 ka BP (MIS 5d)}

Abrupt cooling, Greenland Stadial 25.

\section{7-98 ka BP (MIS 5c)}

Two significantly warm events separated by short-term cooling. A temperature similar to the Eemian interglacial.

\section{6-88 ka BP (MIS 5b)}

Decrease of average temperatures, but still relatively warm. The typical Arctic climate had not yet developed.

\section{8-66 ka BP (MIS 5a and older phase of MIS 4)}

Warm climate with cold oscillations.Warm events: 21, 20, 19 (Huntley and Allens 2003).

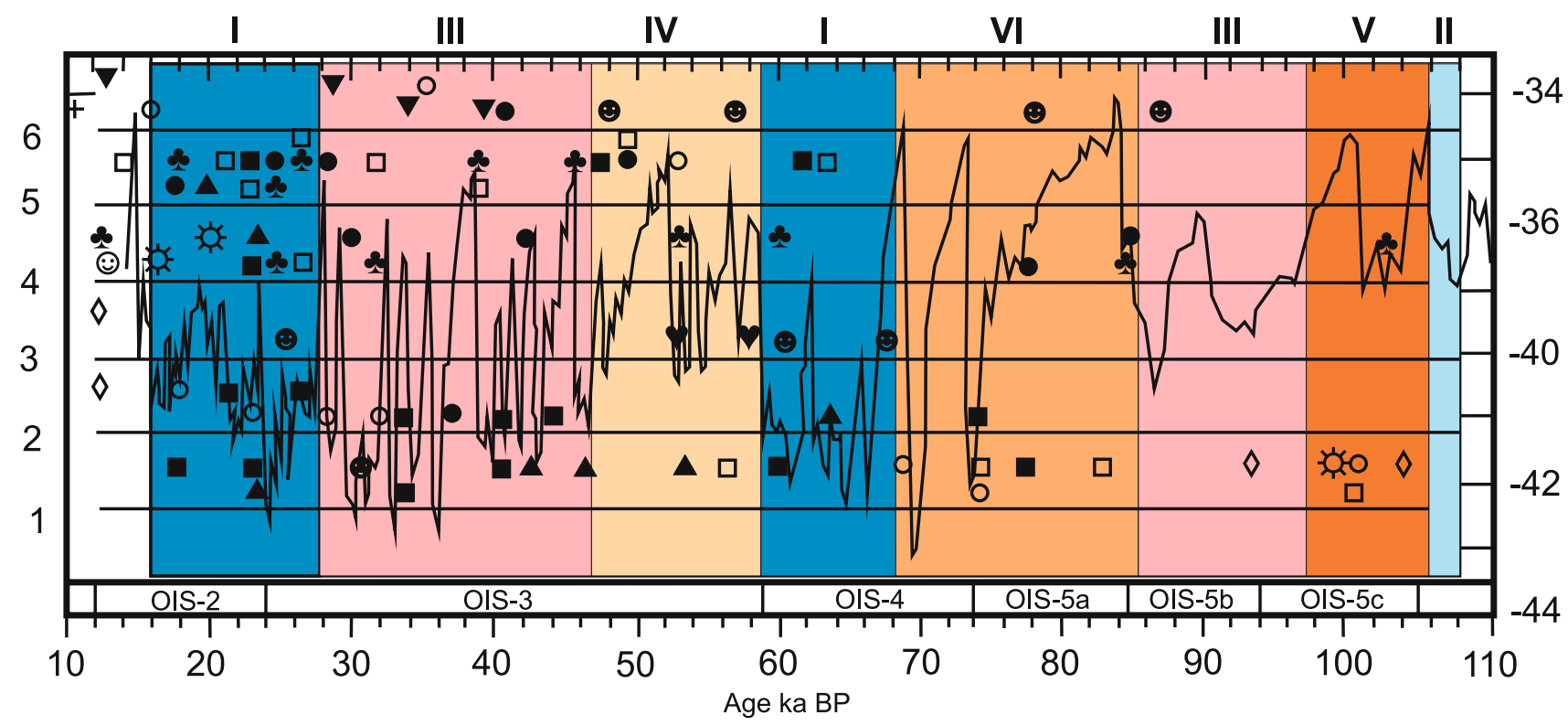

1 stadial

20 interstadial

$3 \square$ paleosoil horizon

4 loess layer

$5 \Delta$ gley (pseudogley) horizon, arktic brown soil
6 - glaciation, permafrost, frost wedges

7 birch - coniferouus forest with sporadic deciduous trees and open areas (steppe)

8 하 deciduous forest

$9 \vee$ deglaciation
$10 \diamond$ tundra with shrubs

$11 \nabla$ dry climate

$12+$ the latest finds of mammoths

13 ) aeolian sands

Text-fig. 1. Temperature changes in the Last Glacial based on the Greenland glacier. Climatic oscillation GRIP as the basis according to van Andel and Davies (2003). The different colours correspond roughly to the average temperatures for that time period. The blue shades indicate cold events, different shades of red colours warm events. For clearer orientation, the chart above shows Roman numerals, number I indicates the coldest event, number VI the warmest event.

Abbildung 1. Temperaturänderungen in der Letzten Eiszeit. Auf der Grund des grönländischen Gletschers. Klimatische Oszillations GRIP nach van Andel und Davies (2003). Die verschiedenen Farben entsprechen beiläufig den durchschnitlichen Temperaturen für gegebene Periode. Blautöne zeigen einen kalten Zeitabschnitt, verschiedene Farbtone von roter Farbe warme Zeiträume. Zur besseren Orientierung zeigt das Diagramm oben die römischen Nummern, die Zahl I die kälteste Zeit, die Zahl VI dann die wärmste. Erläuterungen: • Stadial, ○ Interstadial, 口 Paleoboden, — Löss, \ Gley (Pseudogley) Horizont, arktische Braunerde, ๑ Vergletscherung, Permafrost, Frostspalten, \& Birken - Nadelwald mit sporadischen Laubbäumen und

Steppeninseln, $*$ Laubwald, $\vee$ Abschmelzen, $\diamond$ Tundra mit Sträuchern, $\nabla$ trockenes Wetter, + die letzten Funde von Mammuts, ;) Flugsand. Die Plazierung der Symbolen entspricht der Zeitperiode, von der sie stammen. 
Recapitulation: This period, lasting ca. 40,000 years (107-66 ka BP), corresponds with a significantly warm climate with a larger number of temperature fluctuations of variable intensity. At the beginning (MIS 5c), there was a sudden increase in average temperatures.

\section{8-60 ka BP (MIS 4, younger phase)}

Warm event 18 . Not until this time did the Scandinavian mountain glaciers descend into the lowlands and extend south to the north coast of the Baltic Sea. In the Alps the expansion of mountain glaciers did not occur (van Andel 2003). The First Glacial Maximum (FGM) lasted ca. 8,000 years. The first significant and sudden climate change. Arctic conditions, the origin of typical Mammoth steppe (Musil 2005a).

\section{8-28 ka BP (MIS 3)}

Two climatically distinct relatively warm stages (58-46 ka BP, older phase: Oerel, Glinde; 46-28 ka BP, younger phase: Hengelo, Denekamp) broke through the cold oscillations. While the average temperature of warm events throughout both stages is very similar, the two stages differ in the intensity of the greatest cold oscillation. In the older stage, between 58-46 ka BP, there were not any significant cold oscillations, in the second younger stage, between 4628 ka BP, cold oscillations were already significantly cold.

\section{8-16 ka BP (MIS 3/MIS 2)}

The deterioration of the climate and the greatest cooling in the Last Glacial. The continental ice-sheet crossing the Baltic Sea extended deep into Germany and Poland. Its biggest expansion, however, had a relatively short duration, only about 9,000-10,000 years. The Last Glacial Maximum (LGM) represents the greatest cooling during the whole of the Last Glacial. Between 25-10 ka BP, a gradual collapse of the ecosystem connected with the Last Glacial occurred and it continued until the onset of today's. The next warmer events were between 20-17.5 ka BP.

\section{6-10 ka BP (MIS 2)}

A whole series of brief cold oscillations with sudden warm events. A warmer event occurred around $14 \mathrm{ka} \mathrm{BP.}$ At about $15 \mathrm{ka}$ BP the North part of Europe (Rügen and Lithuania) was already without any glacial cover. During the time span 10,900 and 9,200 cal BP the north part of Scandinavia $\left(66^{\circ} \mathrm{N}\right)$ was also without glaciation.

\section{Faunistic assemblages of individual events}

In this section I consider the faunistic diversity of the individual events and the resulting appearance of the environment. With regard to the composition of the faunistic community, I utilised all the cited publications concerned with the area of Moravia (details in the bibliography). All the published vetebrate species from the main Moravian sites are listed in this section.

The first stratigraphic events $1-4$ are to a certain extent problematic. They were recognised initially on the basis of the superposition of layers and then on the diversity of the assemblage.

\section{Event 1, MIS 5d}

Between 109-107 ka BP, a sudden cooling (Greenland stadial 25). Classification of Kulna Cave only on the basis of superposition of layers and of the composition of the assemblage (Šroubek et al. 1996).

Palaeocenosis: Microtus gregalis.

Kůlna Cave, Northern part of the Moravian Karst, layer 14, Middle Palaeolithic, Levallois technology.

Small mammals: Ochotona pusilla, Arvicola amphibius, Dicrostonyx torquatus, Lagurus lagurus, Microtus arvalis/ agrestis, Microtus gregalis (dominant) (Musil 1958, 1988a).

According to the assemblage either from MIS 5d (more likely) or from the preceding glacial (MIS 6a). The trees were identified from sporadic charcoal finds: conifer, Fraxinus excelsior, cf. Quercus (Opravil 1988).

Significant cold and steppe assemblage (event 1). After event 1, a rapid faunistic turnover occurred. In the following assemblage, the beginning of the constantly increasing number of interglacial species can be recognised (events 2 and 3 ).

\section{Event 2, MIS 5c}

The time allocation was calculated according to the stratigraphy of the layers and the structure of the faunistic assemblage. Middle Palaeolithic (Amersfoort Interstadial).

Palaeocenosis: Ursustaubachensis-Equus taubachensis.

Kůlna Cave, Northern part of the Moravian Karst, layers $13 \mathrm{a}, 13 \mathrm{~b}$.

Large mammals are absent in layer 13a, the microfauna and gastropods suggest a warmer climate. While larger mammals in layer $13 \mathrm{~b}$ are thermophilic and known from the humid part of the Last Interglacial, the microfauna in this layer tend to reflect more strongly a steppe environment: Pitymys subterraneus (dominant), Lemmus lemmus (sporadic), Microtis gregalis (many).

Larger and medium-sized fauna, layer 13b: Aves gen. et spec. indet., Canis lupus, Ursus taubachensis, Elephas sp., Equus taubachensis, Cervus elaphus, Capreolus capreolus, Alces alces, Bovidae (Musil 1970) (species in bold are typical for Eemian or are species typical for the Holocene).

Notes: The species found are not classified systematically, but only as a community which is divided into large and small mammals. This is because their palaeoecological evaluation may be different for each class size. Large animals cover a much larger region than smaller animals during their migration and, therefore, the analysis of environment use for the two groups may differ. Indeed, the environment may not always be the same over a larger distance.

\section{Event 3, MIS 5b}

The time submission is based on the stratigraphy of the layers and the composition of the assemblage. The Taubachian findings according to Valoch (1988) should be considered as Last Interglacial (Eemian interglacial). In my opinion, it should be Brørup interstadial. 
Palaeocenosis: Equus taubachensis-Mammuthus primigenius.

This event was published in an earlier paper (Musil 1988a) as the Last Interglacial. The significantly warm stages of the Last Glacial Brørup and Odderade in Kůlna Cave with sporadic fauna and flora findings of the Last Interglacial were formerly classified as the Eemian interglacial (see Textfig. 3). The species typical for the Last Interglacial appear sporadically in our country in these stages (MIS 5b and 5c). These species were not limited by the current concept to the Eemian interglacial, but continued to survive for some time after this interglacial.

Kůlna Cave, Northern part of the Moravian Karst. Layers 11a, 11b, 11c, 11d, dark gray sandy sediment, Taubachian. Charcoal indicate coniferous forests and a colder and wetter climate (Opravil 1970).

Larger and medium-sized mammals: Capra ibex, Rupicapra rupicapra, Alces alces, Cervus elaphus, Capreolus capreolus, Saiga tatarica, Bovidae indet., Mammuthus primigenius, Elephas sp., Equus taubachensis, Stephanorhinus kirchbergensis, Coelodonta antiquitatis, indeterminable rhino, Canis lupus, Ursus sp., Ursus taubachensis, Castor fiber, Panthera spelaea, Crocuta crocuta spelaea (Musil 1970) (species in bold are typical for Eemian or for the Holocene).

Forest species with greater thermal demands predominate. Continuous forests with steppe islets. Cold climate species only slightly admixed.

Small mammals: Arvicola cantiana-terrestris, Lemmus lemmus, Lagurus lagurus (dominant, 69.2 \%), Pitymys subterraneus, Microtus arvalis/agrestis, Ochotona pusilla (Musil 1988a, 1997b).

Bohunice (open-air site), Central Moravia, brickyard, chernozem soil.

Larger and medium-sized mammals: Castor fiber, Canis lupus, Meles meles, Ursus sp. (arctoid), Equus taubachensis, Capreolus cf. süssenbornensis, Bison priscus (Musil 1960b) (species in bold are typical for Eemian or for the Holocene).

Vratíkov, No. 4 Cave, Central part of Moravia, complex of loam layers, only a probable time allocation (Musil 1967).

- Layer 1 - reposited terra rossa (lowermost layer).

Larger and medium-sized mammals: Equus sp., Rangifer sp., Bos primigenius, Canis lupus, Ursus sp.

Small mammals: Cricetus sp. or Spermophilus sp., Apodemus sp., Microtus arvalis/agrestis, Myodes cf. rufocanus.

- Layer 2 - the brownish-yellow loam in the roof of layer 1 .

Small mammals: Sorex araneus, Myotis sp., Cricetus cricetus, Myodes sp., Microtus arvalis/agrestis, Microtus gregalis (Musil 1967).

- Layer 3 - no findings.

- Layer 4 - cocoa brown to dark brown loam.

Larger mammals: Ursus sp. (arctoid).

Small mammals: Glis glis, Apodemus sp., Cricetus cricetus, Myodes sp., Microtus arvalis/agrestis, Microtus gregalis, Arvicola amphibius.
Birds: Pyrrhocorax sp.

- Layer 5 - brown loam.

Larger mammals: Ursus sp. (arctoid).

Here the increased number of interglacial species ends (event 3 ). In the next event there are only possible interglacial findings (rhino and some $E$. taubachensis). Due to the complicated cave conditions, a different explanation can not be excluded. Generally however an assemblage with sporadic steppe and species typical for Holocene.

\section{Event 4, older stage of MIS 4}

Classification according to the stratigraphic superposition of layers and composition of the assemblage: 74-66 ka BP.

Palaeocenosis: Cervus elaphus maral.

Note on Cervus elaphus maral: These were not a sporadic find. There were relatively many findings and they differed markedly from the size of a typical C. elaphus. Therefore this difference should be published. The size clearly corresponds with the maral and therefore I determined these findings as such. The maral is today considered to be only a subspecies of C. elaphus.

Kůlna Cave, Northern part of the Moravian Karst, layers 9, 9a, 9b, brown loam, ESR 70-55 ka BP, Micoquian, Eemian interglacial according to Valoch (1988). $71.3 \mathrm{ka} \mathrm{BP}$, according to the present author it is Amersfoort.

Larger and medium-sized mammals: Equus sp., Equus (Asinus) hydruntinus, ?Stephanorhinus kirchbergensis, Coelodonta antiquitatis, Alces alces, Cervus elaphus, Rangifer tarandus, Bovidae indet., Mammuthus primigenius, Canis lupus, Crocuta crocuta spelaea, Panthera spelaea, Ursus ex gr. spelaeus, Ursus taubachensis, Lepus sp. (Musil 1970). One finding of a rhino and a few findings of bear. Another event can not be excluded.

Small mammals: Lagurus lagurus (dominant, $73.5 \%$ ), Microtus gregalis (16.7 \%), Microtus arvalis/agrestis, Microtus subterraneus, Lemmus lemmus, Chionomys nivalis (Musil 1988a).

Some species of larger fauna require a warmer climate and a forest environment, the microfauna is intermediary and steppe.

Šipka Cave, Karst of northern Moravia, complex of layers IV, Micoquian III, IV (a greater number of layers with brown to almost black color, probably this age or older (event 3?) (Musil 1965a).

Larger and medium-sized mammals: Panthera spelaea, Cuon europaeus, Vulpes vulpes, Panthera pardus (very abundant), Canis lupus, Ursus ex gr. spelaeus, Crocuta crocuta spelaea, Cervus elaphus maral (very abundant), Capreolus capreolus, Saiga tatarica, Ovibos moschatus, Rupicapra rupicapra, Bos primigenius, Bison priscus, Sus scrofa, Castor fiber, Coelodonta antiquitatis, Equus mosbachensis-abeli, E. (Asinus) cf. hydruntinus (species typical for the Holocene are in bold).

Small mammals: Dicrostonyx torquatus.

Birds: Aquila chrysaetos (Musil 1965a).

Švédův stůl Cave, Southern part of the Moravian Karst, layers 10-14, Mousterian, probably this age or older (Musil 1962). 
Larger and medium-sized mammals: Lepus sp., Crocuta crocuta spelaea, Canis lupus, Vulpes vulpes, V. corsac, Meles meles, Ursus ex gr. spelaeus, Mammuthus primigenius, Coelodonta antiquitatis, Equus mosbachensisabeli, E. germanicus, E. (Asinus) hydruntinus, E. cf. gmelini, Cervus elaphus maral, Alces alces, Rangifer tarandus, Bos primigenius, Bison priscus, Rupicapra rupicapra, Ovis sp., Capra sp., Marmota sp. (bold: species typical for the Holocene).

Recapitulation: For some sites it is not possible to exclude an older age, however, an objective verification is absent. The present faunistic assemblage consists of steppe landscape species (a semi-arid climate), species typical for a warm climate are only sporadic (Sommer and Nadachowski 2006). The finding of Stephanorhinus kirchbergensis is not quite certain. This period is characterized by the findings of the large deer species Cervus elaphus maral. The species had not been previously found before this event.

Sudden fundamental change in community (between the end of event 4 and the beginning of event 5), the start of a glacial steppe assemblage with sporadic Holocene species (events 5 and 6).

\section{Event 5, MIS 4, younger stage}

The classification is in accordance with the stratigraphic superposition of layers and the composition of the community, 66-59 ka BP, First Glacial Maximum (FGM).

Palaeocenosis: Rangifer tarandus-Cervus elaphus.

Notes: In the Last Glacial, there appear very rare finds of bears with arktoid marks. They are determined as Ursus arctos. At the end of the Last Glacial, species typical for the Holocene gradually migrated along the river Danube to Central Europe from the Mediterranean Sea region. Among them are present-day brown bears which are not connected with the earlier Ursus arctos priscus. In my opinion, it is necessary to distinguish between the two groups of bears, the earlier group (Ursus arctos priscus) and then those coming to the region from the Mediterranean Sea area such as Ursus arctos arctos.

Kůlna Cave, Northern part of the Moravian Karst, layers 8, 8a, 8b, Micoquian, reddish-brown loam, much debris and large sized boulders. It is not impossible that one of the layers is older than event 5 . On the basis of the charcoal and mollusc findings (without a determining layer), a mild to moderate cold climate (Opravil 1970, Kovanda 1970).

Larger and medium-sized mammals (Gravettian (Pavlovian), research 1997) (Musil 2003b, c): Panthera spelaea, Canis lupus, Vulpes lagopus, U. arctos priscus, Ursus ex gr. spelaeus, Mammuthus primigenius, Coelodonta antiquitatis, Equus sp., E. scythicus, Alces alces, Cervus elaphus, Rangifer tarandus, Saiga tatarica, Rupicapra rupicapra, Lepus sp. (Musil 1970) (bold: species typical for the Holocene).

Small mammals, layer 8b: Pitymys subterraneus (very many), Microtus gregalis (very abundant), Lagurus lagurus (abundant), Microtus arvalis/agrestis (abundant), Myodes glareolus (sporadic), Arvicola amphibius (sporadic), Ochotona pusilla (sporadic) (Musil 1988a).
Small mammals, layer 8a: Lagurus lagurus (many), Dicrostonyx torquatus (many), Microtus gregalis (sporadic), Pitymys subterraneus (sporadic), Chionomys nivalis (sporadic) (Musil 1988a).

Recapitulation: Layer 8a with steppe fauna tends to correspond with a colder climate, layer $8 \mathrm{~b}$ is somewhat warmer. According to Valoch (1988), layer 8 was deposited at the end of the Eemian interglacial. At this time, however, according to van Andel (2003) there was the First Glacial Maximum (FGM) with the first distinctly Arctic climate of the Last Glacial.

There was a sudden change in the structure of the community in comparison to event 4 and simultaneously a reduction in its faunistic diversity.

\section{Event 6, MIS 3, older stage}

Time submission by stratigraphic superposition of layers and composition of the assemblage, 59-44 ka BP.

Palaeocenosis: Rangifer tarandus-Cervus elaphus.

Kůlna Cave, Northern part of the Moravian Karst, layer $7 \mathrm{~d}$ (the basis of layer 7), dark brown loam.

Larger and medium-sized mammals: Castor fiber, Lepus sp., Gulo gulo, Crocuta crocuta spelaea, Ursus ex gr. spelaeus, $U$. arctos, Mammuthus primigenius (dominant), Coelodonta antiquitatis, Equus sp., Rangifer tarandus (dominant), Alces alces (sporadic), Cervus elaphus, Capreolus capreolus, Bovidae indet. (sporadic), Ovis sp. (Musil 1988a) (bold: species typical for the Holocene).

On the basis of the charcoal, it was a closed forest with a slightly cold climate (Opravil 1970). Components of a warmer climate.

It can not be excluded that the individual layers $7 \mathrm{a}, 7 \mathrm{~b}$, 7c, 7d represent separate climatic fluctuations.

Kůlna Cave, Northern part of the Moravian Karst, layer $7 \mathrm{c}$, dark brown loam.

Larger and medium-sized mammals: Lepus sp., Canis lupus, Vulpes vulpes, V. lagopus, Gulo gulo, Crocuta crocuta spelaea, Ursus ex gr. spelaeus, U. arctos, Mammuthus primigenius (many), Coelodonta antiquitatis (sporadic), Equus sp., Rangifer tarandus (sporadic), Alces alces, Capreolus capreolus, Cervus elaphus, Bovidae indet., Saiga tatarica, Ovis sp., Capra ibex (Musil 1970) (bold: species typical for the Holocene).

On the basis of the charcoal, it was a closed forest with a cool climate (Opravil 1970). According to the fauna, it was steppe with a warm forest element, and warm climate fluctuation. Interstadial Kůlna (Valoch 1988; Moershoofd).

Kůlna Cave, Northern part of the Moravian Karst, layer $7 \mathrm{~b}$, solifluction, dark brown loam, Micoquian.

Larger and medium-sized mammals: Ursus ex gr. spelaeus, Mammuthus primigenius (many), Coelodonta antiquitatis, Equus sp., Rangifer tarandus (abundant), Alces alces, Bovidae, Saiga tatarica (Musil 1970).

Analyses of the charcoal showed deciduous trees and a climate similar to that of today (Opravil 1970). From the composition of the fauna (layers $7 \mathrm{a}$ and $7 \mathrm{~b}$ ), it was steppe and a cool climate despite the charcoal findings. 
Notes: The stated findings are not ecologically the same and therefore, at first glance, it seems that it is not possible for them to have originated from a single layer. The Moravian Karst and the karst areas in general usually have an entirely different plant biotope over a short distance. While on the sunny slopes high above the valleys there was steppe plant cover, it was different in the valleys. In this case, there is also the surrounding landscape to consider because the Kůlna cave does not lie inside the Moravian Karst, but on its border (floodplanes). Even the temperature differences between the deep valleys and the surrounding high slopes are significant. While the valleys were cold all year round, even in the summer, the slopes had in contrast always a considerably warmer climate. These temperature differences are apparent even today. Therefore, the deep valleys of the Moravian Karst also served at the beginning of the Holocene as a typical glacial refugium for many typical glacial species.

Ecological variation in a single layer, therefore, is higher due to the diversity of vegetation cover over a short distance.

Kůlna Cave, Northern part of the Moravian Karst, layer 7a, brown to dark brown loam, Micoquian, Neanderthal finding.

Dating: ESR 56-44 ka, $50 \pm 5.0 \mathrm{ka}$ cal BP (mean of ESR, Rink et al. 1996); $48 \pm 3.2 \mathrm{ka}$ cal BP $(45,660+2,850 /$ - 2,002 BP) (Mook 1988, Musil 2000a).

Kůlna Interstadial (sensu Valoch 1988; Moershoofd). Analyses of the charcoal indicated deciduous trees and a similar climate to today's (Opravil 1970).

Larger and medium-sized mammals: Canis lupus, Vulpes lagopus, V. vulpes, Gulo gulo, Crocuta crocuta spelaea, Ursus ex gr. spelaeus, Equus sp. (sporadic), E. (Asinus) hydruntinus, Coelodonta antiquitatis, Mammuthus primigenius (abundant), Rangifer tarandus (abundant), Alces alces, Bovidae indet. (sporadic), Saiga tatarica. From the cave, probably from the same layer, Cervus elaphus, Capreolus capreolus (Musil 1970) (bold: species typical for the Holocene).

Small mammals (layer 7, without an exact distinction): Microtus arvalis/agrestis (NISP 52), Chionomys nivalis (NISP 4), Microtus subterraneus (NISP 495), Lemmus lemmus (NISP 222), Dicrostonyx torquatus (NISP 204), Lagurus lagurus (NISP 693; 29.9 \%), Microtus gregalis (NISP 1446; $41.1 \%$ ), Arvicola amphibius (NISP 5), $A$. cantiana-terrestris, Apodemus sp. (NISP 11), Ochotona pusilla (NISP 20) (Musil 1988a, 2003c).

Birds: Aves, undetermined.

Šipka Cave, Karst of Northern Moravia, complex of layers III, Mousterian, greater number of brown coloured layers, most likely of this age (event 6). They could not be younger, only older (Musil 1965a).

Larger and medium-sized mammals: Marmota sp., Cervus elaphus, Bison priscus, Bos primigenius, Equus mosbachensis-abeli, E. (Asinus) hydruntinus, Coelodonta antiquitatis, Crocuta crocuta spelaea, Vulpes vulpes, Ursus ex gr. spelaeus, Panthera spelaea, P. pardus, Canis lupus, Gulo gulo, Mammuthus primigenius (Musil 1965a).

Barová Cave, Central part of Moravian Karst, reddish brown bedded loam, the probably age corresponding to event 6 (Musil 1960a).

Larger and medium-sized mammals: Ursus ex gr. spelaeus (MNI $67 \%$, of which $42 \%$ juvenile animals),
Crocuta crocuta spelaea (MNI $8.5 \%$ ), Canis lupus (MNI $11.4 \%$ ), Panthera spelaea (MNI $6 \%$ ), Capra ibex (sporadic find), Equus sp. (sporadic find).

Recapitulation: Event 6 contained nearly the same faunistic assemblage as event 7 , but event 6 differs significantly due to the presence of species typical for the Holocene (always only sporadic findings). This includes mammoths, reindeer, with cave bears as the predominant find, remarkably only a few horses. Therefore, even though this is probably an open steppe landscape, it cannot be compared to event 7 with the occurrence of forest species. In this case, it probably reflects a warm oscillation, which was recognised as Interstadial Kůlna (Musil 1970). Individual layers 7a, 7b, $7 \mathrm{c}, 7 \mathrm{~d}$ can represent various separate oscillations.

Change in the composition of the community (between events 6 and 7). In event 6 glacial fauna with sporadic occurrence of species typical for warmer periods (such as Cervus elaphus, Capreolus capreolus). In event 7 only glacial fauna, species typical for the Holocene are absent.

\section{Event 7, MIS 3, middle stage}

44-38 ka BP. Transitional climatic stage (three warm events with a few cold oscillations and the ultimate warm event between 38-37 ka cal BP.

Palaeocenosis: Mammuthus primigenius-Rangifer tarandus.

Kůlna Cave, Northern part of the Moravian Karst, layer 6a, Micoquian (Valoch 1988).

Time data for this layer are very contradictory. The original data for this layer was relatively low $41 \pm 1.0 \mathrm{ka} \mathrm{cal}$ BP $(38,600+950 /-800$ BP) (Musil 2003c). Valoch (1988) as supporting and precise date take not until the layer $7 \mathrm{a}$ and it dates to $45,000 \mathrm{BP}$ and the layer $6 \mathrm{a}$ based on $\mathrm{U} / \mathrm{Th} \leq 50 \mathrm{ka}$ (Valoch 2002). Only the newer data are higher and layer 6a was cited as 52,700 \pm 230 BP (Neruda and Nerudová 2013). But in Nejman et al. (2011) data was cited as (by mistake assigned to layer 7a) $38,600+950 /-800 \mathrm{BP}, 45,660+2,850 /-2,200$ BP, 44,000 + 12,000/- 5,000 BP, 50,000 $\pm 5,000$ BP. People familiar with the problems in determining the boundaries of the individual layers in cave sediments, know how difficult this may be. In this case, it is only the fauna associate on which clearly distinguishes the adjacent layers.

Larger and medium-sized mammals: Lepus sp., Equus sp., Coelodonta antiquitatis, Canis lupus, Vulpes lagopus, Crocuta crocuta spelaea, Ursus ex gr. spelaeus, Mammuthus primigenius (dominant), Rangifer tarandus (dominant), Bovidae, Saiga tatarica.

Small mammals: Microtus gregalis (NISP 94), Microtus arvalis/agrestis (NISP 4), Dicrostonyx torquatus (NISP 180), Chionomys nivalis (NISP 8), Microtus subterraneus (NISP 38) (Musil, 1970, 1988a).

Birds: Undetermined birds present.

Stránská skála (open-air, Central Moravia), lower palaeosol, $43 \pm 2.9$ ka cal BP $(=41 \pm 3.0$ ka BP) (Svobodová 1987), 38,500 + 1,400/- 1,200 BP and 38,200 $\pm 1,100 \mathrm{BP}$, Bohunician (Svoboda 2003b).

Stránská skála III (open-air, Central Moravia), layer 4, brown loam, Bohunician, $43 \pm 2.9 \mathrm{ka}$ cal BP $(=41,300+$ 
3,100/- 2,200 BP) (Svobodová 1987, Svoboda 2003b, c), 41,300 $\pm 3,100 \mathrm{BP}$ (age range 40,674-50,000? cal BP (Nejman et al. 2011)), $40 \pm 1.3 \mathrm{ka}$ cal BP $(=38,500+$ $1,400 /-1,200 \mathrm{BP}), 40 \pm 1.9 \mathrm{ka}$ cal BP $(=38,500 \pm 1,700 \mathrm{BP})$ (Svoboda 2003b, c), Bohunician (Svoboda 2003b, c).

Larger and medium-sized mammals: Mammuthus primigenius, Rangifer tarandus, Coelodonta antiquitatis, Bos sp. seu Bison sp. (Musil 1976).

Bohunice (open-air site, Central Moravia), a base of brown loam, PK II, Bohunician. Dating: 41,250 \pm 450 BP (Valoch 2008), 44.9-38.0 ka cal BP; $45 \pm 2.0 \mathrm{ka}$ cal BP (= $42,900+1,700 /-1,400 \mathrm{BP}), 43 \pm 2.1 \mathrm{ka}$ cal BP $(=41,400$ + 1,400/- 1,200 BP) (Mook 1976, Musil 2003b), $38 \pm 1.1$ ka cal BP (Switsur 1976, Musil 2003c), 40,173 $\pm 1,200$ BP (Switsur1967), $42 \pm 2.6 \mathrm{ka}$ cal BP (40,173 $\pm 1,200$ BP, Musil 2003c).

Larger and medium-sized mammals: Equus sp., Mammuthus primigenius (Musil 1976).

Recapitulation: Typical glacial species such as in event 8 can also be found during this time period. Events 7 and 8 have only glacial fauna, the species diversity remains the same, only the number of individuals of some species changed. The dominant species (mammoths and reindeer) occur in the open countryside, on the dry steppe and in a cold climate (Musil 1997b). During this event forest species completely disappeared.

\section{Event 8, MIS 3, younger stage}

38-29 ka BP. Early cold stage (many cold events, only three slightly warmer).

Palaeocenosis: Ursus ex gr. spelaeus.

Pod Hradem Cave, Northern part of the Moravian Karst, layer 9, brown loam: Szeletian. Dating: $35 \pm 1.7 \mathrm{ka}$ cal BP $(33,300 \pm 1,100 \mathrm{BP}), 35 \pm 1.2 \mathrm{ka}$ cal BP $(33,100 \pm$ 530 BP), 29,400 \pm 230 BP, 28,200 \pm 950 BP (Musil 2000, 2003a).

Larger and medium-sized mammals: Vulpes lagopus, Ursus ex gr. spelaeus, Mammuthus primigenius, Coelodonta antiquitatis, Rangifer tarandus, Bison sp.

Small mammals: Mustela cf. putorius, Spermophilus citellus, Cricetulus sp., Myodes glareolus, Microtus arvalis/ agrestis.

Birds: Lagopus lagopus, L. mutus (Musil 1965b, 2002a).

Pod Hradem Cave, Northern part of the Moravian Karst, layers 10-19, a layer complex of brown loams (event 8 , maybe even earlier).

Larger and medium-sized mammal: Lepus sp., Panthera spelaea, Crocuta crocuta spelaea, Canis lupus, Vulpes vulpes, V. lagopus, Ursus ex gr. spelaeus (dominant), U. arctos priscus, Mammuthus primigenius, Coelodonta antiquitatis, Equus sp., Sus scrofa, Rangifer tarandus, Bison priscus, Bos primigenius, ?Saiga tatarica, Rupicapra rupicapra, Capra ibex.

Small mammals: Mustela cf. putorius, Spermophilus citellus, Cricetulus sp., Myodes glareolus, Microtus arvalis/ agrestis.

Birds: Dafila acuta, Tetrao tetrix, Lagopus lagopus, L. mutus, Strix aluco, Garrulus glandarius (Musil 1965b).
Švédův stůl Cave, Southern part of the Moravian Karst (fireplace), Aurignacian.

Larger and medium-sized mammals: Crocuta crocuta spelaea, Ursus ex gr. spelaeus, U. arctos priscus, Coelodonta antiquitatis, Equus mosbachensis-abeli, Rangifer tarandus (Musil 1962, 1997b).

Recapitulation: Typical glacial species were found during this event. The species typical for warmer periods are absent (with the exception of two species). It is also the last time cave bears were found in large numbers in Moravia.

The end of the completely glacial assemblage (event 8). The beginning of a glacial assemblage with sporadic finds of species typical for the Holocene (event 9).

\section{Event 9, end of MIS 3 and start of MIS 2}

At the end of this event the LGM occurred (ice core GISP 2, sensu lato, 27-15 ka BP), which led to large scale cooling. The LGM period sensu stricto between 25-23 ka BP represents the coldest time during the Last Glacial (Barron et al. 2003).

Palaeocenosis: Mammuthus primigenius.

Kůlna Cave, Northern part of the Moravian Karst, layer $6 \mathrm{~b}$, gray-brown reddish loam, Gravettian.

Dating: $25 \pm 0.2 \mathrm{ka}$ cal BP $(22,990 \pm 170 \mathrm{BP}), 24 \pm$ $0.3 \mathrm{ka} \mathrm{cal} \mathrm{BP}(21,630 \pm 160 \mathrm{BP}), 24 \pm 0.2 \mathrm{ka} \mathrm{cal} \mathrm{BP}(21,750$ $\pm 140 \mathrm{BP}), 23 \pm 0.3 \mathrm{ka}$ cal BP $(21,260 \pm 140 \mathrm{BP})$ (Valoch 1988).

Larger and medium-sized mammals: Bos sp. or Bison sp., Alces alces, Cervus elaphus, Rangifer tarandus (6\%), Equus sp. (92\% of all of the findings), Mammuthus primigenius (bold: species typical for the Holocene). Total number of bone fragments represents about 50 specimens (Seitl 1988).

Small mammals: Dicrostonyx torquatus, Microtus gregalis, Microtus oeconomus, Chionomys nivalis (abundant), Ochotona pusilla (Musil 1988a, 2002a).

Pod Hradem Cave, Northern part of the Moravian Karst, layer 7, yellow-brown loessic loam $(26,830 \pm 300$ BP, fireplace) (Musil 1965b).

Larger and medium-sized mammals: Canis lupus, Crocuta crocuta spelaea, Vulpes lagopus, Ursus sp., Rangifer tarandus.

Birds: Lagopus sp., Anas acuta (Musil 1965b, 2002a).

Šipka Cave, Karst of Northern Moravia, Gravettian (Musil 1965a).

Larger and medium-sized mammals: Mammuthus primigenius (dominant), Coelodonta antiquitatis (dominant), Equus germanicus, Panthera spelaea, Canis lupus, Vulpes lagopus, Ursus sp., Gulo gulo, Rangifer tarandus, Bos primigenius, Bison priscus, Rupicapra rupicapra, Capra ibex, Lepus sp.

Small mammals: Dicrostonyx torquatus.

Předmostí (open-air, Central Moravia), Gravettian (Pavlovian) (Svoboda et al. 2001a, c, Svoboda 2001a).

Dating: $27 \pm 0.8 \mathrm{ka}$ cal BP $(25,040 \pm 320 \mathrm{BP}), 29 \pm 0.9$ ka cal BP $(26,870 \pm 250$ BP) (Svoboda et al. 2001a, Musil 2003b), 24,340 $\pm 120 \mathrm{BP}-26,870 \pm 250 \mathrm{BP}$ (Bocherens et al. 2015). 
Table 2. Larger and medium-sized mammals from Předmostí (Musil 2008) (bold: species typical for the Holocene). NISP number of identifiable specimens, MIN - minimum number of individuals.

Tabelle 2. Große und mittelgroße Säugetiere aus der Lokalität Předmostí (die Arten typisch für Holozän fett gedruckt). NISP - die Anzahl der identifizierbare Stücke, MIN - Mindestanzahl der Individuen.

\begin{tabular}{|l|c|c|}
\hline \multicolumn{1}{|c|}{ Species } & NISP/\% & MNI/\% \\
\hline Mammuthus primigenius & number unknovn & $\geq 1.000$ teeth/72.05 \\
\hline Canis lupus & $4.143 / 43.32$ & $103 / 7.42$ \\
\hline Vulpes lagopus & $2.250 / 23.47$ & $96 / 6.52$ \\
\hline Lepus sp. & $912 / 9.51$ & $86 / 6.0$ \\
\hline Rangifer tarandus & $890 / 9.28$ & $36 / 2.59$ \\
\hline Gulo gulo & $581 / 6.06$ & $12 / 0.86$ \\
\hline Equus germanicus & $194 / 2.02$ & $5 / 0.36$ \\
\hline Ursus arctos & $315 / 2.5$ & $10 / 0.72$ \\
\hline Coelodonta antiquitatis & $5 / 0.05$ & $1 / 0.07$ \\
\hline Megaloceros giganteus & $13 / 0.13$ & $1 / 0.07$ \\
\hline Alces alces & $13 / 0.13$ & $2 / 0.14$ \\
\hline Castor fiber & $4 / 0.04$ & $2 / 0.14$ \\
\hline Crocuta crocuta spelaea & $4 / 0.04$ & $1 / 0.07$ \\
\hline Panthera pardus & $1 / 0.01$ & $1 / 0.07$ \\
\hline Panthera leo & $1 / 0.01$ & $1 / 0.07$ \\
\hline Bison priscus & $25 / 0.25$ & $2 / 0.14$ \\
\hline Bos primigenius & $9 / 0.09$ & $1 / 0.07$ \\
\hline Meles meles & $23 / 0.24$ & $2 / 0.14$ \\
\hline Capreolus capreolus & $2 / 0.02$ & $1 / 0.07$ \\
\hline Capra ibex & $2 / 0.02$ & $1 / 0.07$ \\
\hline Ovibos moschatus & $4 / 0.04$ & $1 / 0.07$ \\
\hline
\end{tabular}

Notes: The species Panthera spelaea could be found in Moravia throughout nearly all the Last Glacial. The species Panthera leo appeared at the very end of this glacial period, with other species typical for the Holocene also appeared, in particular from the regions around the Mediterranean Sea.

Larger and medium-sized mammals: See Table 2.

Small mammals (NISP/\% - MNI/\%): Lemmus lemmus (15/0.2 - 3/0.25), Dicrostonyx torquatus (16/0.17 - 4/0.29), Talpa europea (25/0.26 - 2/0.14) (Musil 2003b, c, 2008, 2010a).

Pavlov (open-air site, Southern Moravia), Gravettian (Pavlovian), research 1997 (Musil 2003b, c).

Dating: $27 \pm 0.8 \mathrm{ka}$ cal BP $(25,020 \pm 150 \mathrm{BP}), 27 \pm 1.1$ ka cal BP $(25,160 \pm 170 \mathrm{BP}), 28 \pm 0.5 \mathrm{ka}$ cal BP $(25,530 \pm$ $100 \mathrm{BP}), 28 \pm 0.6 \mathrm{ka}$ cal BP $(25,840 \pm 290 \mathrm{BP}), 29 \pm 0.6 \mathrm{ka}$ cal BP $(26,620 \pm 230 \mathrm{BP}), 29 \pm 0.7 \mathrm{ka}$ cal BP $(26,730 \pm 250$ BP) (Svoboda 2003a).

Larger and medium-sized mammals: Lepus sp. (MNI $23 \%$ ), Vulpes lagopus (MNI $17.7 \%$ ), V. vulpes (MNI $3.0 \%$ ), Canis lupus (MNI $13.9 \%$ ), Ursus arctos arctos (MNI $0.4 \%$ ), Panthera leo (MNI $0.4 \%$ ), Gulo gulo (MNI $1.7 \%$ ), Rangifer tarandus (MNI $16.0 \%$ ), Mammuthus primigenius (MNI 14.8\%), Equus germanicus (MNI 7.2 \%), Coelodonta antiquitatis (MNI $0.4 \%$ ) (bold: species typical for the Holocene).

Birds: undetermined (MNI 0.8 \%) (Musil 1955, 1959, 1994b, 1997a).
Table 3. Larger and medium-sized mammals from Pavlov I (Musil 1959, 1994b, 1997a) (bold: species typical for the Holocene). NISP - number of identifiable specimens (as \%).

Tabelle 3. Große und mittelgroße Säugetiere aus der Lokalität Pavlov I (die Arten typisch für Holozän fett gedruckt). NISP die Anzahl der identifizierbare Stücke (in \%).

\begin{tabular}{|l|c|c|c|}
\hline \multirow{2}{*}{\multicolumn{1}{|c|}{ Species }} & \multicolumn{3}{|c|}{ Excavation area } \\
\cline { 2 - 4 } & $\mathbf{1 9 5 2 - \mathbf { 1 9 5 3 }}$ & $\mathbf{1 9 5 4} \mathbf{- 1 9 5 6}$ & $\mathbf{1 9 5 7} \mathbf{- 1 9 5 8}$ \\
\cline { 2 - 4 } & NISP \% & NISP \% & NISP \% \\
\hline Mammuthus primigenius & 7.5 & 10.4 & 18.9 \\
\hline Canis lupus & 12.5 & 15.5 & 14.6 \\
\hline Rangifer tarandus & 10.1 & 20.6 & 15.1 \\
\hline Equus germanicus & 4.6 & 8.9 & 9 \\
\hline Lepus sp. & 18.5 & 16.8 & 19.2 \\
\hline Vulpes lagopus & 16.9 & 12.6 & 13.9 \\
\hline Vulpes vulpes & 12.7 & 4.9 & 3.2 \\
\hline Ursus arctos arctos & 1.6 & 2.4 & 0.6 \\
\hline Gulo gulo & 4.4 & 1.5 & 2.3 \\
\hline Panthera leo & 0.5 & 0.6 & 0.3 \\
\hline Coelodonta antiquitatis & 0 & 0 & 0.9 \\
\hline Bovidae indet. & 0.5 & 0.05 & 0 \\
\hline Cervus elaphus & 0.2 & 0 & 0.3 \\
\hline
\end{tabular}

Table 4. Birds from Pavlov I - excavation area 1952 - 1958 (Bocheński et al. 2009). NISP - number of identifiable specimens, MIN - minimum number of individuals.

Tabelle 4. Vögeln aus der Lokalität Pavlov I - Grabungen 1952 - 1958. NISP - die Anzahl der identifizierbare Stücke, MIN - Mindestanzahl der Individuen.

\begin{tabular}{|l|c|c|c|c|}
\hline \multicolumn{1}{|c|}{ Species } & NISP & NISP\% & MNI & MNI \% \\
\hline Cygnus cygnus & 2 & 0.2 & 1 & 1.3 \\
\hline Cygnus cygnus/Cygnus olor & 5 & 0.5 & 1 & 1.3 \\
\hline Cygnus columbianus & 6 & 0.6 & 2 & 2.3 \\
\hline Anas querquedula & 1 & 0.1 & 1 & 1.3 \\
\hline Asio flammeus & 1 & 0.1 & 1 & 1.3 \\
\hline Haliaetus albicilla & 2 & 0.2 & 1 & 1.3 \\
\hline Gyps fulvus & 2 & 0.2 & 1 & 1.3 \\
\hline Falco cf. tinnunculus & 1 & 0.1 & 1 & 1.3 \\
\hline Falco cf. peregrinus & 2 & 0.2 & 1 & 1.3 \\
\hline Lagopus lagopus & 312 & 29.9 & 31 & 40.3 \\
\hline Lagopus muta & 21 & 2.0 & 4 & 5.2 \\
\hline Lagopus sp. & 58 & 5.6 & 0 & 0 \\
\hline Tetrao tetrix & 62 & 5.9 & 5 & 6.5 \\
\hline Tetrao tetrix/Lagopus sp. & 56 & 5.4 & 0 & 0 \\
\hline Perdix perdix & 1 & 0.1 & 1 & 1.3 \\
\hline Charadriiformes indet. & 1 & 0.1 & 1 & 1.3 \\
\hline Turdus sp. & 1 & 0.1 & 1 & 1.3 \\
\hline Passeriformes indet. & 1 & 0.1 & 1 & 1.3 \\
\hline cf. Pica pica & 1 & 0.1 & 0 & 0 \\
\hline Pica pica/Garrulus glandarius & 1 & 0.1 & 1 & 1.3 \\
\hline Pyrrhocorax pyrrhocorax & 7 & 0.7 & 1 & 1.3 \\
\hline Pyrrhocorax/Corvus monedula & 9 & 0.9 & 1 & 1.3 \\
\hline Corvus monedula & 12 & 1.1 & 2 & 2.6 \\
\hline Corvus corax & 442 & 42.6 & 18 & 23.4 \\
\hline
\end{tabular}


Pavlov I (open-air, Southern Moravia), research 1952 1971.

Dating: 26.65-25.2 ka BP (Svoboda et al. 2001b).

Lists of fossil mammals and birds are presented in Tables 3 and 4. Ecological analysis of birds from events 9 and 11 are presented in Table 5.

Table 5. Ecological analysis of birds in events 9 and 11. The number of stars indicates the quantity of finds (for determination of birds see Bocheński et al. 2009).

Tabelle 5. Ökologische Analyse der Vögel in den Eventen 9 und 11.

\begin{tabular}{|l|c|c|c|}
\hline \multirow{3}{*}{$\begin{array}{c}\text { Aves (sedentary) } \\
\text { palaeoecology }\end{array}$} & MIS & $\mathbf{3 . 2}$ & $\mathbf{2}$ \\
\cline { 2 - 4 } & time (ka) & $\mathbf{2 9 - 1 8}$ & $\mathbf{1 4 - 1 2}$ \\
\cline { 2 - 4 } & event & $\mathbf{9}$ & $\mathbf{1 1}$ \\
\hline warmer area & $*$ & $*$ \\
\hline colder area & $*$ & $*$ \\
\hline tolerance to temperature & $*$ & $*$ \\
\hline tundra and forest-tundra 1 & $* *$ & $* *$ \\
\hline taiga & $* * *$ & $* * *$ \\
\hline forest of temperate climate & $*$ & $*$ \\
\hline forest steppe & $* * * *$ & $* * * *$ \\
\hline steppe & $* * * *$ & $* * *$ \\
\hline alpine altitudes & $*$ & \\
\hline marsh, peatbog & $* *$ & $* *$ \\
\hline greater range of flights & $*$ & $* *$ \\
\hline
\end{tabular}

Table 6. Larger and medium-sized mammals and birds from Pavlov - without distinction between settlements (Musil 2003b, c) (bold: species typical for the Holocene). NISP - number of identifiable specimens, MIN - minimum number of individuals (as \%).

Tabelle 6. Große und mittelgroße Säugetiere und Vögeln aus der Lokalität Pavlov - alle Siedlungen zusammen (die Arten typisch für Holozän fett gedruckt). NISP - die Anzahl der identifizierbare Stücke, MIN - Mindestanzahl der Individuen (in \%).

\begin{tabular}{|l|c|c|}
\hline \multicolumn{1}{|c|}{ Species } & NISP/\% & MNI \% \\
\hline Rangifer tarandus & $423 / 20.6$ & 16.0 \\
\hline Lepus sp. & $345 / 16.8$ & 23.0 \\
\hline Canis lupus & $318 / 15.5$ & 13.9 \\
\hline Vulpes lagopus & $260 / 12.6$ & 17.7 \\
\hline Vulpes vulpes & $100 / 4.9$ & 3.0 \\
\hline Mammuthus primigenius & $213 / 10.4$ & 14.8 \\
\hline Equus germanicus & $184 / 8.9$ & 7.2 \\
\hline Ursus arctos arctos & $50 / 2.4$ & 0.4 \\
\hline Gulo gulo & $31 / 1.5$ & 1.7 \\
\hline Panthera leo & $3 / 0.15$ & 0.4 \\
\hline Panthera pardus & $3 / 0.15$ & 0.4 \\
\hline Lynx lynx & $3 / 0.1$ & 0.4 \\
\hline Capra ibex & $2 / 0.1$ & 1.0 \\
\hline Castor fiber & $2 / 0.1$ & 1.0 \\
\hline Alces alces & $1 / 0.05$ & - \\
\hline Bovidae indet. & $1 / 0.05$ & - \\
\hline Cervus elaphus & (a few bones $)$ & - \\
\hline Coelodonta antiquitatis & - & 0.4 \\
\hline Birds undetermined & - & 0.8 \\
\hline
\end{tabular}

Pavlov VI (open-air site, Southern Moravia) (Musil 1959, 1994b, 1997a). Gravettian (Pavlovian) (Svoboda et al. 2009).

Dating: $28,930 \pm 270 \mathrm{cal} \mathrm{BP}, 29,070 \pm 270 \mathrm{cal} \mathrm{BP}, 25,950$ \pm 110 BP, 26,110 \pm 130 BP (Svoboda et al. 2009).

Larger and medium-sized mammals (NISP 5334): Mammuthus primigeniuus (NISP $70 \%$, MNI 2), Canis lupus (NISP $6 \%$ ), Equus germanicus (NISP $3 \%$ ), Rangifer tarandus (NISP $3 \%$ ), Vulpes lagopus (NISP $1 \%$ ), Gulo gulo (NISP $0.2 \%$ ), Ursus sp. (NISP $0.1 \%$ ), Lepus sp. (NISP $0.1 \%$ ) (Svoboda et al. 2009).

Pavlov (open-air, Southern Moravia) (without distinction between settlements) (Musil 2003b, c).

Frequency of mammalian remains is presented in Table 6.

Dolní Věstonice II (open-air, Southern Moravia), Gravettian (Pavlovian) (Svoboda 2001b, Adovasio et al. 2001).

Dating:

Mammoth dump $24 \pm 0.5 \mathrm{ka}$ cal BP $(22,250 \pm 570 \mathrm{BP})$, $24 \pm 0.6 \mathrm{ka}$ cal BP $(22,368 \pm 749 \mathrm{BP}), 28 \pm 0.6 \mathrm{ka}$ cal BP $(26,100 \pm 200 \mathrm{BP})$.

Settlement 3: $25 \pm 0.3 \mathrm{ka}$ cal BP $(22,630 \pm 420 \mathrm{BP}), 29 \pm$ $0.9 \mathrm{ka}$ cal BP $(27,070 \pm 300 \mathrm{BP})$.

Settlement 2: $29 \pm 0.9 \mathrm{ka}$ cal BP $(26,920 \pm 250 \mathrm{BP}), 28 \pm$ $0.5 \mathrm{ka}$ cal BP $(25,740 \pm 210 \mathrm{BP})$.

Settlement 1: $28 \pm 0.6 \mathrm{ka}$ cal BP $(26,390 \pm 272 \mathrm{BP})$.

Human burials: $28 \pm 1.1 \mathrm{ka}$ cal BP $(25,570 \pm 280 \mathrm{BP}$, burial XV), $29 \pm 0.6 \mathrm{ka}$ cal BP $(26,640 \pm 110 \mathrm{BP}$, triple burial).

Miscellaneous data (Musil 2003b, c): $30 \pm 0.4 \mathrm{ka}$ cal BP $(27,660 \pm 80 \mathrm{BP}), 28 \pm 1.1 \mathrm{ka}$ cal BP $(25,950+630 /-580$ $\mathrm{BP}), 28 \pm 0.5 \mathrm{ka}$ cal BP $(25,820 \pm 170 \mathrm{BP}), 29 \pm 0.9 \mathrm{ka}$ cal $\mathrm{BP}(27,250+590 /-550 \mathrm{BP})$.

Larger and medium-sized mammals: dominant species: Lepus sp., Canis lupus, Vulpes lagopus; numerous species: Gulo gulo, Mamuthus primigenius; sporadic species: Castor fiber, Lynx lynx, Panthera leo, Vulpes vulpes, Ursus arctos arctos, Coelodonta antiquitatis, Equus germanicus, Rangifer tarandus, Bos sp. or Bison sp. (Musil 2003b, c) (bold: species typical for Holocene).

Milovice (open-air, Southern Moravia), Gravettian (Pavlovian).

Dating Milovice IV: $25,940 \pm 160$ BP $(30,920-31,041$ cal BP), 24,250 \pm 110 BP (29,347-29,447 cal BP), 26,470 \pm $120 \mathrm{BP},(31,174-31,254$ cal BP), 25,710 $\pm 130 \mathrm{BP}(30,681-$ 20,881 cal BP) (Svoboda et al. 2011).

Larger and medium-sized mammals ([NISP]/[MNI as \%]): Panthera leo (7/0.19), Canis lupus (37/0.52), Vulpes vulpes (-10.9), Mammuthus primigenius (6,748/95.25), Rangifer tarandus (135/1.9) (Musil 1997b, 2010a) (bold: species typical for Holocene).

Jarošov-Podvršt’a (open-air, Central Moravia), Gravettian (Pavlovian).

Datings: $27 \pm 1.3 \mathrm{ka}$ cal BP $(25,020 \pm 600 \mathrm{BP}), 28 \pm 1.2$ ka cal BP $(25,530 \pm 600 \mathrm{BP}), 28 \pm 0.6 \mathrm{ka}$ cal BP $(25,780+$ $240 /-250 \mathrm{BP}), 26 \pm 0.8 \mathrm{ka}$ cal BP $(25,110+230 /-240 \mathrm{BP})$, $28 \pm 0.8 \mathrm{ka}$ cal BP $(26,220+360 /-390 \mathrm{BP}), 28 \pm 0.6 \mathrm{ka}$ cal $\mathrm{BP}(26,340 \pm 180 \mathrm{BP}), 29 \pm 0.9 \mathrm{ka}$ cal BP $(26,950 \pm 200 \mathrm{BP})$ (Musil 2003, 2010a).

Jarošov-Kopaniny: $26,860 \pm 430 \mathrm{BP}$ and 27,930 \pm 240 BP (Škrdla et al. 2006). 
Larger and medium-sized mammals: Canis lupus (rare), Lynx lynx (isolated find), Vulpes lagopus (most frequent), V. vulpes (rare), Gulo gulo (several small fragments), Mammuthus primigenius (several small fragments), Equus sp. (very few), Lepus sp. (second most frequent species) (Škrdla and Musil 1999, Musil 2005b, 2010a) (bold: species typical for Holocene).

The publication by Škrdla and Kruml (2000), only a preliminary report from a small area of the site, gives the following species (NISP as \%): Rangifer tarandus (58\%), Mammuthus primigenius (4.2\%), Equus germanicus (4.2\%), Vulpes sp. (16.6\%), Canis lupus (12.50\%), Gulo gulo $(4.2 \%)$, Lepus sp. (4.2\%).

Boršice-Chrástka (open-air site, Central Moravia), Gravettian (Pavlovian).

Dating: $29,970 \pm 330$ cal BP $(25,004 \pm 300$ BP $)$ (Nývltová-Fišáková et al. 2006).

Larger and medium-sized mammals: (NISP/MNI) Mammuthus primigenius (197/3), Coelodonta antiquitatis (4/1), Equus germanicus (22/1), Rangifer tarandus (8/1), Canis lupus (4/1) (Nývltová-Fišáková et al. 2006).

Petřkovice (open-air site, Northern Moravia), Gravettian (Pavlovian).

Dating: $23 \pm 0.4 \mathrm{ka}$ cal BP $(20,790 \pm 270 \mathrm{BP}), 25 \pm 0.2$ ka cal BP (23,370 \pm 160 BP) (Jarošová 1999, Musil 2003b).

Larger and medium-sized mammals: Mammuthus primigenius (27 teeth only) (Klíma 1955), Equus sp., Rangifer sp. (Jarošová 1999). Bones of all species were destroyed due to highly unfavourable local conditions.

Recapitulation: All of the above mentioned sites belong to the Gravettian. The communities from the individual sites differ, however, not only in their species diversity, but also in terms of the number of individuals of each species. Radiometric data indicate that this culture existed in Moravia for quite a long period, about 9,000 years. The faunistic difference between these localities could therefore have been caused by the fact that some of localities originated from the time before the LGM, others existed as early as in the LGM. It is also possible that local conditions at sites could play a role. Another reason is that the sites are from all over the territory of Moravia, and the environment was not identical in each place.

This period can be characterized as an extremely favourable environment for fauna development. The assemblage diversity is unprecedentedly high. There are a large number of individuals of each game species. The basic species and, in terms of the number of individuals, the most common species are typical representatives of glacial fauna. In close proximity, however, at most sites also appear (even though rare findings) representatives of the species which are typical for the Holocene (brown bear, lynx, wildcat, deer, roe deer, beaver, present day lion Panthera leo). They apparently penetrated into this area from the south along the Danube River and its tributaries.

The climate in Moravia at this time was already so favourable that the migration of these species was possible. We can therefore conclude that the first presence of typically Holocene species does not begin at the beginning of the Holocene itself but much earlier, in the Last Glacial $29 \mathrm{ka}$ years ago. This favourable period with many animal species had an effect on the origin of the large and culturally rich settlements in Central and Southern Moravia.

These species typical for the Holocene did not, however, survive the LGM in the Moravian region, during this time they disappeared from the area. From the following Epigravettian period (event 10) they are no longer recorded. This means that the relatively favourable period for fauna soon changed with the arrival of an extremely unfavourable climate.

Plant cover was at this time extremely differentiated, not only on the grassy steppe, but particularly around rivers, the forests were dominated by conifers, but also mixed with deciduous trees. This differentiation was the basis for a similar differentiation of animals.

A sudden faunistic turnover between events 9 and 10. The end of the glacial community with sporadic presence of species typical for the Holocene (event 9). A completely glacial commmunity only (event 10).

\section{Event 10, MIS 2}

19-15 ka BP. The end of LGM sensu lato, Epigravettian.

Dating: 18.89 ka BP, 18.92 ka BP, 19.38 ka BP, 15.06 ka cal BP (Brandtner 1996, Musil 2000b).

Palaeocenosis: Rangifer tarandus-Equus germanicus.

Palaeolithic sites of this age are scarce in Moravia and they are always small and of little significance. There is a huge difference in comparison with the previous period. This is clearly reflected in the limited presence of Palaeolithic people in the area of Moravia. A good example of this period, however, can be seen in the Austrian locality of Grubgraben (Brandtner 1996, Musil 2000b), which is located near the Moravian border. It clearly documents the period of the LGM (27-15 ka cal BP sensu lato, 25-23 ka cal BP sensu stricto) (Barron et al. 2003). This time corresponds with a substantial change in the composition of the faunistic community and with a reduction in its diversity.

Velké Pavlovice (open-air, Southern Moravia), Epigravettian.

Dating: 15.06 ka cal BP $(14,460 \pm 230$ BP) (Svoboda 2003a).

Larger and medium-sized mammals: Equus sp., Mammuthus primigenius (Svoboda et al. 2002b).

Stránská skála IV (open-air site, Central Moravia), Epigravettian.

Dating: (18.22 $\pm 0.12 \mathrm{ka} \mathrm{BP}), 17.74 \pm 0.09$ ka BP (Svoboda 2003a).

Larger and medium-sized mammals: Equus sp. (dominant), Coelodonta antiquitatis, Rangifer tarandus, ?Bos primigenius, Mammuthus primigenius (Musil 2003e).

Brno-Štýřice III, Vídeňská street (open-air, Central Moravia), Epigravettian.

Dating: $14,450 \pm 90 \mathrm{BP}, 14,820 \pm 120 \mathrm{BP}$ (Nerudová et al. 2012). These data are more typical for the Magdalénian, $11,960 \pm 70 \mathrm{BP}$ (data not reliable) the fauna however appears much older.

Larger and medium-sized mammals: Mammuthus primigenius (dominant), Equus germanicus (sporadic), Coelodonta antiquitatis (one specimen, possibly this 
species), Rangifer tarandus (sporadic), Canis lupus, Vulpes sp. Mostly small fragments of bone up to $20 \mathrm{~mm}$ in size (82.5\% reflecting human activity). The assemblage is different to other Epigravettian sites and it appears more similar to Gravettian sites, but certainly not Magdalénian.

Plants: Pollen analysis AP $52 \%$, NAP $49 \%$. Pinus sylvestrtis, Pinus limba, Betula sp., Alnus sp., Corylus sp. (sporadic). Charcoal: Betula sp. (33\%), Salix sp. (25\%), Padus sp. (23\%), Hypophae sp. (5\%), Pinus/Larix (12\%), Vacciniaceae (1\%).

Climatically extreme conditions, the steppe vegetation outweighs sparse woodland and scrub (Nerudová et al 2012).

Grubgraben (open air site), Lower Austria, Epigravettian.

Dating: $18,380 \pm 130 \mathrm{BP}, 18,890 \pm 140 \mathrm{BP}, 18,920 \pm 180$ BP, 19,380 \pm 90 BP (Brandtner 1996, Musil 2002b).

Notes: It is located near the border with Moravia and belongs to the same climate province as South Moravia. I describe the faunistic findings at this point, because no site of the same age in South Moravia has such a large quantity of findings. The site is used only for comparison with Moravian sites and also shows the larger community of animals from this time.

Larger and medium-sized mammals: Rangifer tarandus strongly prevails (dominant, MNI approximately $73 \%$ ), Equus germanicus (MNI $22 \%$ ), Capra ibex (MNI $2.4 \%$ ). All other species are only sporadic: Bos primigenius (a few teeth), Vulpes lagopus (a fragment of lower jaw and several canine teeth), Gulo gulo (fragment), Mammuthus primigenius (fragment of tusk, according to Brandtner probably from carrion), Ursus arctos, Lepus sp. (Brandtner 1996, Musil 2002b).

Recapitulation: The above-mentioned composition of the community is markedly different from the previous Gravettian (event 9). The species structure of event 10 was fairly similar to the following event 11 (Magdalénian), but without the species which are typical for the Holocene. At this time there seems to have been an extremely rapid reduction in the earlier high species diversity and at the same time the number of individuals of each species. Certain species typical for the Holocene which appeared previously but sporadically in Moravia during the LGM were dying out. All of these major changes in the biota were caused by the onset of extreme cold and probably by the variation between the extremely dry and humid climate (LGM). This was reflected in the plant cover and in the rapid decrease in faunistic species diversity. This is a period of relatively rapid and significant change, the greatest known at this time.

After event 10 there was a drastic faunistic turnover. Event 11 represents the beginning of a new community. Most of the glacial species were dissappearing or a substantial reduction in the number of individuals occured.

\section{Event 11, MIS 2}

14-12 ka BP, Magdalénian of the Moravian Karst (more caves, $13.93 \mathrm{ka}-11.45 \mathrm{ka}$ BP) (Valoch 2001, Valoch and Neruda 2005).

Palaeocenosis: Rangifer tarandus-Equus germanicusSaiga tatarica.
The Magdalénian occurred mainly in karst regions, particularly in the Moravian Karst and to a lesser extent in karst areas of northen Moravia. It is nearly always found in the entrance sediments of caves. It should be noted that with regard to the Moravian Karst, this area had a climatically different environment vertically over a relatively short distance. There was a significantly colder climate throughout the whole year in the deep and relatively narrow valleys and on their northern slopes throughout the whole year. On the other hand, the upper part of the insolation slopes were mainly covered with grass, with isolated trees and bushes, and the average annual temperature was much higher than in the valleys. This was reflected of course in the fauna, mainly in the microfauna or gastropods.

The altitude of the Magdalénian sites ranged between 300-500 $\mathrm{m}$ above see level. Findings of this culture occur in two separate layers at times. The basal layer is made up of a typical yellow aeolian loess. This loess sedimentation forms the last layer of the Last Glacial in Moravia. The overlying layer is formed by a brown-coloured loessic loam reflecting a weaker pedogenetic process. With regard to game animals, there was not a great difference between the two layers in the number of species, only in the number of individuals of each species. Certain species typical for the following Holocene period (marked in bold type) already occurred in small numbers in glacial communities. They penetrated during this time from southern Europe along the major rivers (Danube, Morava, Svratka) to the north. The glacial species which were disappearing at this time, are underscored. They could be considered as endemic at this time.

Pekárna Cave, Southern part of the Moravian Karst, brown loessic loam (layer g) (Absolon and Czižek 1926, 1928, 1932, Musil 1958, 2002a).

Larger and medium-sized mammals: Lepus sp., Castor fiber, Meles meles, Panthera leo, Ursus arctos, Vulpes vulpes, Vulpes lagopus, Cervus elaphus, Rangifer tarandus, Alces alces, Bos primigenius, Bison priscus, Capra ibex, Capra sp., Mammuthus primigenius, Coelodonta antiquitatis, Equus sp. (Musil 1958, 2002a) (bold: typical Holocene species, underlined: surviving typical glacial species).

Small mammals (Magdalénian layers g and h): Mustela nivalis, Sorex araneus, Spermophilus citellus, Myodes rutilus, Myodes glareolus, Arvicola terrestris, Arvicola sherman, Chionomys nivalis, Microtus oeconomus, Microtus gregalis, Microtus arvalis/agrestis, Microtus oeconomus, Lemmus lemmus, Dicrostonyx torquatus, Dicrostonyx gulielmi, Cricetus cricetus, Ochotona pusilla (Musil 1958, 2002a).

Layer $6(=\mathrm{g})$ : Sorex cf. araneus, Spermophilus cf. major, Apodemus sp., cf. Cricetulus migratorius, Myodes sp., Arvicola amphibius, Chionomys nivalis, Microtus oeconomus, M. gregalis, M. arvalis/agrestis, Dicrostonyx cf. gulielmi (Horáček in Svoboda et al. 2000a).

Birds: Lyrurus tetrix, Lagopus mutus, Lagopus lagopus, Aquila sp., Tetrao urogallus (Musil 1958, 2002a).

Pekárna Cave, Southern part of the Moravian Karst, loess layer in an underlayer of brown loessic loam, layer $h$ (Musil 1958, 2002a). 
Table 7. Species distribution of large and medium-sized mammals in Moravia during the Last Glacial. A - anomalous finds, $\mathrm{S}$ - sporadic finds, $\mathrm{P}$ - paucity of finds, $\mathrm{M}$ - medium number of finds, L - lots of finds, D - dominant species, Q - quantity unknown, first first occurrence, last - last occurrence.

Tabelle 7. Verteilung der Arten von großen und mittelgroßen Säugetieren in Mähren während der Letzten Eiszeit.

A - anomale Funde, $S$ - sporadische Funde, $P$ - kleine Menge, $M$ - mittlere Menge, $L$ - viele Funde, D - dominante Arten, $Q$ - Menge unbekannt, first - erste Entdeckung, last - letzte Entdeckung.

\begin{tabular}{|c|c|c|c|c|c|c|c|c|c|c|c|c|}
\hline \multirow{3}{*}{ Taxon } & event & $1,2,3$ & 4 & 5 & 6 & 7 & 8 & 9 & 10 & 11 & 12,13 & 14 \\
\hline & MIS & 5 & 4 & 4 & 3 & 3 & 3 & $3+2$ & 2 & 2 & 1 & 1 \\
\hline & Time (kaBP) & \begin{tabular}{|l|} 
?128-74 \\
\end{tabular} & $74-66$ & $66-59$ & $59-44$ & $44-38$ & $38-29$ & $29-18$ & $18-15$ & 14-12 & $12-8$ & $8-0$ \\
\hline \multicolumn{2}{|l|}{ Vulpes vulpes } & & $\mathrm{Q}$ & & $\mathrm{Q}$ & $\mathrm{Q}$ & $\mathrm{Q}$ & $\mathrm{P}$ & $S$ & $\mathrm{Q}$ & $\mathrm{Q}$ & \\
\hline \multicolumn{2}{|l|}{ Vulpes lagopus } & & & & $\mathrm{Q}$ & & $\mathrm{Q}$ & $\mathrm{L}$ & D last & & & \\
\hline \multicolumn{2}{|l|}{\begin{tabular}{|l|} 
Vulpes corsac \\
\end{tabular}} & & $\mathrm{Q}$ & & & & & & & & & \\
\hline \multicolumn{2}{|l|}{ Canis sp. } & & & & & & & & & Q & & \\
\hline \multicolumn{2}{|l|}{ Cuon europaeus } & & $\mathrm{S}$ & & & & & & & & & \\
\hline \multicolumn{2}{|l|}{ Canis lupus } & Q & $\mathrm{Q}$ & & $\mathrm{P}$ & $\mathrm{Q}$ & $\mathrm{Q}$ & $\mathrm{L}$ & $\mathrm{Q}$ & & & $\mathrm{Q}$ \\
\hline \multicolumn{2}{|l|}{ Canis lupus f.familiaris } & & & & & & & & & & & $\mathrm{Q}$ \\
\hline \multicolumn{2}{|l|}{ Ursus sp. (arctoid) } & $\mathrm{Q}$ & & & & & & & & & & \\
\hline \multicolumn{2}{|l|}{ Ursus ex gr. spelaeus } & & $\mathrm{Q}$ & & $\mathrm{D}$ & $\mathrm{Q}$ & D last & & & & & \\
\hline \multicolumn{2}{|l|}{ Ursus taubachensis } & $S$ & $S$ & & & & & & & & & \\
\hline \multicolumn{2}{|l|}{ Ursus arctos priscus } & & & $\mathrm{Q}$ & & & Q last & & & & & \\
\hline \multicolumn{2}{|l|}{ Ursus arctos arctos } & & & & & & & $\mathrm{P}$ first & $\mathrm{P}$ & Q & & $\mathrm{Q}$ \\
\hline \multicolumn{2}{|l|}{\begin{tabular}{|l|} 
Gulo gulo \\
\end{tabular}} & & & & $\mathrm{Q}$ & & & $\mathrm{M}$ & A last & & & \\
\hline \multicolumn{2}{|l|}{ Meles meles } & $\mathrm{Q}$ & $\mathrm{Q}$ & & & & & $\mathrm{A}$ & $\mathrm{Q}$ & & & \\
\hline \multicolumn{2}{|l|}{ Mustela sp. } & $\mathrm{Q}$ & & & & & & & & & & \\
\hline Mustela nivalis & & & & & & & & & $\mathrm{Q}$ & & & \\
\hline Mustela erminea & & & & & & & & & $\mathrm{Q}$ & & & \\
\hline Mustela putorius & & & & & & & $\mathrm{Q}$ & & Q & & & \\
\hline Martes martes & & & & & & & & & Q & & & \\
\hline Crocuta crocuta spelaed & & & $\mathrm{Q}$ & & $\mathrm{M}$ & $\mathrm{Q}$ & $\mathrm{Q}$ & $\mathrm{A}$ & A last & & & \\
\hline \begin{tabular}{|l|} 
Felis $\mathrm{sp}$. \\
\end{tabular} & & & & & & & & & & & & $\mathrm{Q}$ \\
\hline Felis sylvestris & & & & & & & & A & A & & & \\
\hline Lynx lynx & & & & & & & & $\mathrm{A}$ & $\mathrm{A}$ & & & \\
\hline Panthera sp. & & & & & & $\mathrm{Q}$ & & & & & & \\
\hline Panthera leo leo & & & & & & & & A first & $\mathrm{Q}$ & & & \\
\hline Panthera leo spelaea & & & $\mathrm{Q}$ & & $\mathrm{P}$ & & Q last & & & & & \\
\hline Panthera pardus & & & $\mathrm{L}$ & & $\mathrm{Q}$ & & & $\mathrm{A}$ & & & & \\
\hline Mammuthus primigeniu & & $\mathrm{Q}$ & $\mathrm{Q}$ & & $\mathrm{D}$ & $\mathrm{D}$ & $\mathrm{Q}$ & $\mathrm{L}$ & $\mathrm{A}$ & A last & & \\
\hline Equus sp. & & & $\mathrm{Q}$ & $\mathrm{Q}$ & $S$ & $\mathrm{Q}$ & $\mathrm{Q}$ & $\mathrm{D}$ & $\mathrm{Q}$ & $\mathrm{Q}$ & $\mathrm{Q}$ & $\mathrm{Q}$ \\
\hline Equus germanicus & & & & & & & & P first & $\mathrm{D}$ & & & \\
\hline Equus taubachensis & & $S$ & & & & & & & & & & \\
\hline Equus mosbachensis-ab & beli & & & $Q$ & $\mathrm{Q}$ & & $Q$ & & & & & \\
\hline Equus (Asinus) hydrunt & tinus & & & $\mathrm{Q}$ & $\mathrm{Q}$ & & & & & & & \\
\hline Coelodonta antiquitatis & & & Q & Q & Q & Q & Q & $\mathrm{A}$ & A last & & & \\
\hline Stephanorhinus kirchbe & ergensis & $\mathrm{Q}$ & $\mathrm{Q}$ & $\mathrm{Q}$ & & & & & & & & \\
\hline Rhinoceros sp. & & $\mathrm{Q}$ & & & & & & & & & & \\
\hline Sus sp. & & & $\mathrm{Q}$ & & & & & & & $\mathrm{Q}$ & & $\mathrm{Q}$ \\
\hline \begin{tabular}{|l|} 
Sus scrofa \\
\end{tabular} & & & & & & & $\mathrm{Q}$ & & & $\mathrm{Q}$ & $\mathrm{Q}$ & $\mathrm{Q}$ \\
\hline Sus scrofa f. domestica & & & & & & & & & & & & $\mathrm{Q}$ \\
\hline Capreolus capreolus & & $\mathrm{Q}$ & $\mathrm{Q}$ & & & & & $\mathrm{A}$ & & $\mathrm{Q}$ & & \\
\hline Rangifer tarandus & & & $Q$ & & $\mathrm{D}$ & $\mathrm{D}$ & $\mathrm{Q}$ & $\mathrm{L}$ & $\mathrm{D}$ & $\mathrm{L}$ & & Q last \\
\hline Cervus elaphus & & $\mathrm{Q}$ & & & $\mathrm{Q}$ & & & $\mathrm{A}$ & $\mathrm{A}$ & $\mathrm{Q}$ & $\mathrm{Q}$ & $\mathrm{Q}$ \\
\hline Cervus elaphus maral & & & $\mathrm{L}$ & & & & & & & & & \\
\hline Megaloceros giganteus & & & & & & & & $\mathrm{S}$ & & & & \\
\hline Capra sp. & & & $\mathrm{Q}$ & & & & & & $\mathrm{Q}$ & & & \\
\hline Capra ibex & & & & & $\mathrm{A}$ & & $\mathrm{Q}$ & $\mathrm{A}$ & $\mathrm{A}$ & & & \\
\hline Capra aegagrus f. hirch & & & & & & & & & & & & $\mathrm{Q}$ \\
\hline Ovibos moschatus & & & $\mathrm{Q}$ & & & & & $\mathrm{A}$ & & & & \\
\hline Ovis sp. & & & $\mathrm{Q}$ & & & & & & & & & \\
\hline Ovis ammon f. aries & & & & & & & & & & & & Q first \\
\hline
\end{tabular}


Table 8. Small mammals in Moravia during the Last Glacial. A - anomalous finds, S - sporadic finds, P - paucity of finds, M - medium number of finds, L - lots of finds, D - dominant species, Q - quantity unknown, last - last occurrence.

Tabelle 8. Kleine Säugetiere in Mähren in der Letzten Eiszeit. A - anomale Funde, S - sporadische Funde, P - kleine Menge, M - mittlere Menge, L - viele Funde, D - dominante Arten, Q - Menge nicht bekannt, last - letzte Entdeckung.

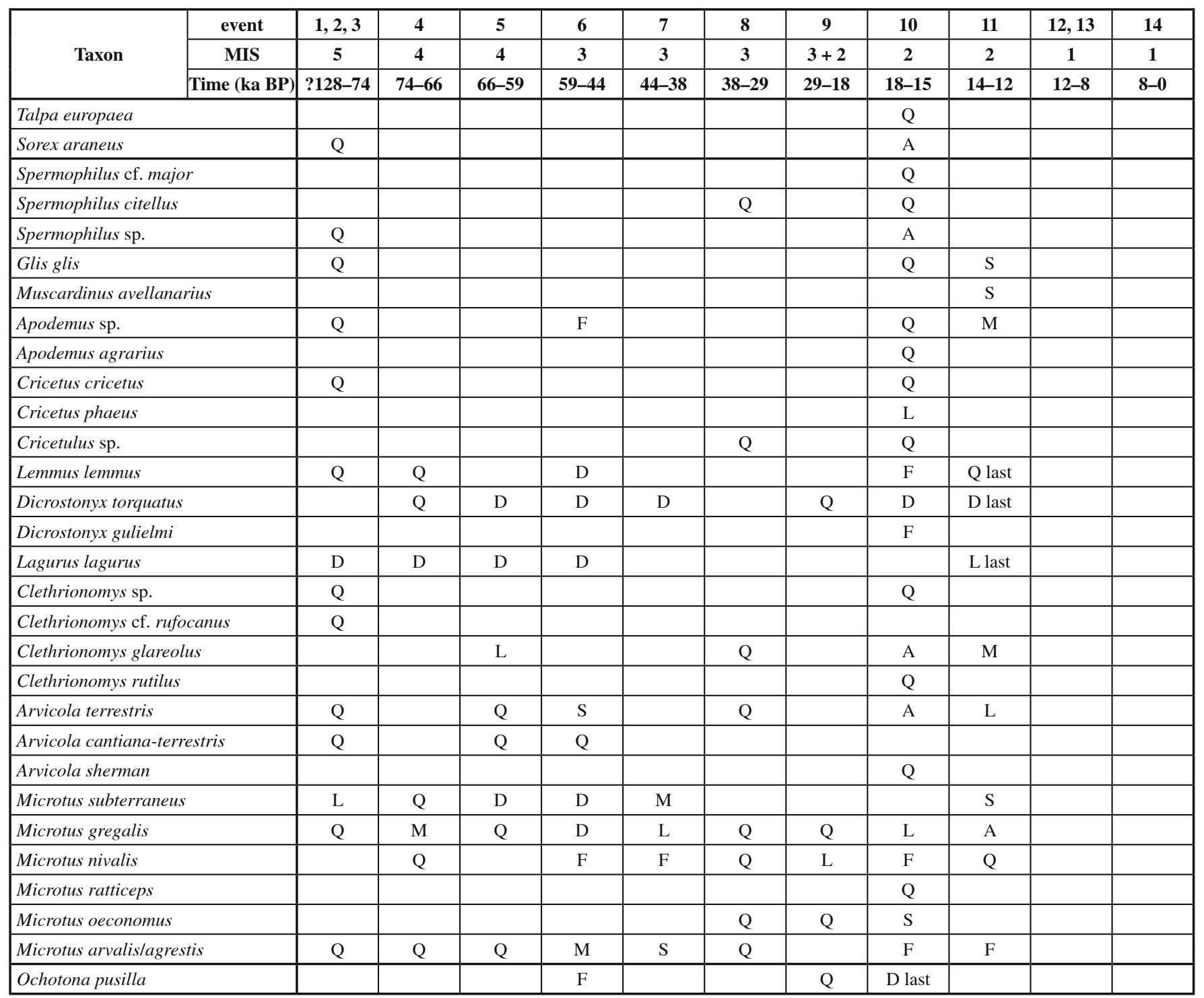

Larger and medium-sized mammals (two Magdalénian layers): Rangifer tarandus, Cervus elaphus, Bos primigenius (very few), Bos sp., Bison sp., Rupicapra rupicapra, Ursus arctos, Canis lupus, Vulpes vulpes, Vulpes lagopus, Crocuta spelaea (sporadically), Meles meles, Gulo gulo, Mammuthus primigenius (in Magdalénian culture not only at this site but also in others, always, however, an isolated find), Equus germanicus, Coelodonta antiquitatis (from more Magdalénian sites, very rare findings), Castor fiber, Lepus sp. (Musil 1958) (bold: species typical for Holocene, underlined: surviving typical glacial species).

Small mammals (two Magdalénian layers): Mustela erminea, Martes martes, Sorex araneus, Talpa europea, Ochotona pusilla, Glis glis, Dicrostonyx torquatus, Lemmus lemmus, Arvicola amphibius, Myodes glareolus, Chionomys nivalis, Microtus gregalis, Microtus oeconomus, Microtus arvalis/agrestis, Dicrostonyx gulielmi, Cricetulus sp., Cricetus cricetus, Cricetus phaeus, Apodemus agrarius (Musil 1958).
Layer $7(=\mathrm{h})$ : Spermophilus cf. major, Microtus oeconomus, Dicrostonyx cf. gulielmi, Ochotona sp. (Horáček in Svoboda et al. 2000a).

Birds: Lagopus lagopus, Tetrao tetrix, Garrulus glandarius, Turdus merula.

Pekárna Cave, Southern part of the Moravian Karst, Magdalénian.

Dating: without specifying any layer (12.5 $\pm 0.11 \mathrm{ka} \mathrm{BP,}$ $12.67 \pm 0.08 \mathrm{ka}$ BP, $12.94 \pm 0.25 \mathrm{ka}$ (Musil 1958, 2002a, Svoboda et al. 2000a), 15,701 \pm 662 cal BP, $14.8 \mathrm{ka}$ cal $\mathrm{BP}, 14.0 \mathrm{ka}$ cal BP. The average annual temperature $2.6{ }^{\circ} \mathrm{C}$, $5.7^{\circ} \mathrm{C}$ (Moravcová 2011).

Larger and medium-sized mammals: Lepus sp., Canis lupus, Vulpes lagopus, Gulo gulo, Lynx lynx, Felis silvestris, Equus germanicus, Coelodonta antiquitatis, Mammuthus primigenius, Castor fiber, Rangifer tarandus, Cervus elaphus, Alces alces, Rupicapra rupicapra, Saiga tatarica, Bos primigenius, Bison priscus (Musil 1958) (bold: species typical for Holocene, underlined: surviving typical glacial species). 
Table 9. Frequency of larger and medium-sized mammals from Pekárna Cave - layers g + h (Musil 1958, 2002a). MIN - minimum number of individuals.

Tabelle 9. Häufigkeit der große und mittelgroße Säugetiere aus der Lokalität Pekárna Höhle - Schichten g + h. MIN - Mindestanzahl der Individuen.

\begin{tabular}{|l|c|c|}
\hline \multicolumn{1}{|c|}{ Taxon } & MNI & MNI (\%) \\
\hline Lepus sp. & 60 & 36.8 \\
\hline Rangifer tarandus & 46 & 28.2 \\
\hline Equus germanicus & 31 & 19.0 \\
\hline Bos primigenius & 1 & 0.6 \\
\hline Gulo gulo & 1 & 0.6 \\
\hline Cervus elaphus & 1 & 0.6 \\
\hline Mammuthus primigenius & 1 & 0.6 \\
\hline Vulpes lagopus & 7 & 4.3 \\
\hline Vulpes vulpes & 1 & 0.6 \\
\hline Aves indet. & 14 & 8.5 \\
\hline
\end{tabular}

For frequency of selected taxa see Table 9.

Small mammals: Talpa europaea, Sorex araneus, Glis glis, Microtus gregalis, Microtus arvalis/agrestis, Ochotona pusilla, Cricetus cricetus, Cricetus phaeus, Dicrostonyx torquatus, Lemmus lemmus, Mustela putorius, Mustela erminea, Martes martes (Musil 1958).

Birds: Garrulus glandarius, Tetrao tetrix, Turdus merula, Micropus apus, Cuculus canorus, Hirundo rustica, Lagopus lagopus, Lagopus mutus, Perdix perdix, Tetrastes bonasia, Tetrao urogallus, Corvus corax, Heliaetus albicilla (Musil 1958).

Pekárna Cave, Southern part of the Moravian Karst, the last research by Svoboda et al. (2000a).

This research discovered still intact layers. The industrial remains of the Magdalénian period were located not only in layers $\mathrm{g}$ and $\mathrm{h}$ (designated herein as layers 6 and 7), but also in the upper part of layer i (layer 8). The new description of the sediments is different than that in earlier publications, loess is found only in layer 8 .

New dating of bones from the original research (layers $\mathrm{g}$ and $\mathrm{h}): 12,940 \pm 250 \mathrm{BP}$, new research from layers 6-7: $12,670 \pm 80 \mathrm{BP}$ and $12,500 \pm 100 \mathrm{BP}$. A tooth and metacarpus probably belonging to cave hyena are notable in the Magdalénian fauna.

Adlerova Cave, Southern part of the Moravian Karst, Magdalénian layer located in the loess.

Larger and medium-sized mammals, without specifying the layer: Lepus sp. (abundant), Rangifer tarandus (dominant), Equus germanicus, Canis lupus, Vulpes lagopus, Ursus sp. (Musil 2002a). In an older paper (Trampler 1897) a find of two mammoth metatarsi is presented, but these may have originated from an earlier layer.

Small mammals: Glis glis, Arvicola amphibius, Microtus gregalis, Ochotona pusilla, Talpa europea, Sorex araneus (Musil 2002a).

Birds: Garrulus glandarius, Tetrao tetrix, Turdus merula (Musil 2002a).

Balcarova Skála Cave, Northern part of the Moravian Karst, loess layer, Magdalénian (Musil 1958, 2002a), 17.2 ka cal. BP, $13.93 \pm 0.1 \mathrm{ka} \mathrm{BP}, 17.18 \mathrm{ka}$ cal BP (Neruda 2010). The average annual temperature $7.5^{\circ} \mathrm{C}$ (Moravcová 2011).

Larger and medium-sized mammals: Lepus sp. (abundant), Coelodonta antiquitatis (phalanx and scapula), Equus germanicus (abundant), Rangifer tarandus (dominant), Castor fiber, Mammuthus primigenius (vertebrae and fragments of the tusk), Vulpes lagopus (dominant), Crocuta crocuta spelaea (rare find), Ursus sp. (bold: species typical for Holocene, underlined: surviving typical glacial species).

Small mammals: Talpa europaea, Neomys fodiens, Sorex araneus, Sorex pygmaeus, Sorex alpinus, Ochotona pusilla (1,500 specimens), Cricetus phaeus (300 specimens), Dicrostonyx torquatus (8,000 specimens), Lemmus lemmus (20 specimens), Mustela erminea.

Birds: (from owls, ca. 12,000 bones), Micropus apus, Cuculus canorus, Hirundo rustica, Lagopus lagopus (4,000 bones), Lagopus mutus (1,500 bones), Perdix perdix, Bonasia bonasia, Lyrurus tetrix, Corvus corax, Corvus monedula, Falco columbarius, Falco tinnunculus, Circus cyraneus, Accipiter nisus, Nyctea scandiaca, Otus scops, Dendrocopus major, Dendrocopus leucotos, Turdus pilaris, Garrulus glandarius, Nucifraga caryocatactes, Rallus aquaticus, Crex crex, Gallinula chloropus, Otis tetrax, Vanellus vanellus, Scolopax rusticula, Tringa sp., Anser sp., Anas sp., Anas crecca (Musil 2002a).

Kůlna Cave, Northern part of the Moravian Karst, layer 5, Magdalénian, loessic loam (Musil 1958, 2002a).

Larger and medium-sized mammals: Rangifer tarandus (many), Bos primigenius, Equus germanicus (many), Mammuthus primigenius (lamellas of tusk and milk tooth), Coelodonta antiquitatis, Lepus sp. (many), Canis lupus, Vulpes lagopus, Gulo gulo (rare find), Castor fiber (rare find), Panthera leo, Meles meles, Ursus arctos, Equus sp., Cervus elaphus, Rangifer tarandus, Alces alces, Saiga tatarica (bold: species typical for Holocene, underlined: surviving typical glacial species).

Small mammals: Mustela erminea, Dicrostonyx torquatus, Arvicola amphibius (dominant), Arvicola cantiana-terrestris.

Birds: Lagopus sp.

Kůlna Cave, Northern part of the Moravian Karst, layer 6: loess, Magdalénian.

Dating: $11,590 \pm 80 \mathrm{ka} \mathrm{BP}, 11,450 \pm 90 \mathrm{ka} \mathrm{BP}$ (Svoboda et al. 2000a). The annual average temperature $6.8{ }^{\circ} \mathrm{C}$ (Moravcová 2011).

Larger and medium-sized mammals: Ursus sp., Lepus sp., Vulpes lagopus, Ursus arctos arctos, Cervus elaphus, Mammuthus primigenius, Coelodonta antiquitatis, Rangifer tarandus (Musil 1958, 2002a) (bold: species typical for Holocene, underlined: surviving typical glacial species).

Small mammals: Microtus arvalis/agrestis, Lemmus lemmus, Myodes glareolus, Arvicola amphibius, Dicrostonyx torquatus (dominant).

Birds: Aves indet.

Nová Drátenická Cave, Central part of the Moravian Karst, Magdalénian.

Dating: $13,870 \pm 140 \mathrm{ka}$ BP, $12,900 \pm 140 \mathrm{ka}$ BP and $11,670 \pm 150 \mathrm{ka} \mathrm{BP}$ (Svoboda et al. 2000a).

Larger and medium-sized mammals: Rangifer tarandus (dominant), Capra ibex (rare find) (Musil 1958, 2002a). 
Table 10. Species distribution of birds in Moravia during the Last Glacial. A - anomalous finds, $\mathrm{S}$ - sporadic finds, $\mathrm{P}$ - paucity of finds, M - medium number of finds, $L$ - lots of finds, D - dominant species, $Q$ - quantity unknown.

Tabelle 10. Verteilung der Arten von Vögeln in Mähren während der Letzten Eiszeit. A - anomale Funde, S - sporadische Funde, P kleine Menge, M - mittlere Menge, L - viele Funde, D - dominante Arten, Q - Menge unbekannt.

\begin{tabular}{|c|c|c|c|c|c|c|c|c|c|c|}
\hline \multirow{3}{*}{ Taxon } & event & $1,2,3$ & 4 & 5 & 6 & 7 & 8 & 9 & 10 & 11 \\
\hline & MIS & 5 & 4 & 4 & 3 & 3 & 3 & $3+2$ & 2 & 2 \\
\hline & Time (ka BP) & $128-74$ & $74-66$ & 66-59 & 59-44 & 44-38 & 38-29 & 24-18 & 18-15 & 14-12 \\
\hline \multicolumn{2}{|l|}{ Aves, gen. et spec. indet. } & & & & $\mathrm{Q}$ & $\mathrm{Q}$ & & & & Q \\
\hline \multicolumn{2}{|l|}{ Dafila acuta } & & & & & & $\mathrm{Q}$ & & & \\
\hline \multicolumn{2}{|l|}{ Cygnus cygnus } & & & & & & & $\mathrm{S}$ & & \\
\hline \multicolumn{2}{|l|}{ Cygnus cygnus/Cygnus olor } & & & & & & & $\mathrm{S}$ & & \\
\hline \multicolumn{2}{|l|}{ Cygnus columbianus } & & & & & & & $\mathrm{S}$ & & \\
\hline \multicolumn{2}{|l|}{ Anas crecca } & & & & & & & & & Q \\
\hline \multicolumn{2}{|l|}{ Anas sp. } & & & & & & & & & $\mathrm{Q}$ \\
\hline \multicolumn{2}{|l|}{ Anser sp. } & & & & & & & & & Q \\
\hline \multicolumn{2}{|l|}{ Anas querquedula } & & & & & & & $\mathrm{S}$ & & \\
\hline \multicolumn{2}{|l|}{ Haliaetus albicilla } & & & & & & & $\mathrm{S}$ & $\mathrm{Q}$ & \\
\hline \multicolumn{2}{|l|}{ Aquila chrysaetos } & & $\mathrm{Q}$ & & & & & & & \\
\hline \multicolumn{2}{|l|}{ Aquila sp. } & & & & & & & & Q & \\
\hline \multicolumn{2}{|l|}{ Falco cf. tinnпипсиlus } & & & & & & & $\mathrm{S}$ & & $\mathrm{Q}$ \\
\hline \multicolumn{2}{|l|}{ Falco columbarius } & & & & & & & & & $\mathrm{Q}$ \\
\hline Accipiter nisus & & & & & & & & & & $\mathrm{Q}$ \\
\hline Falco cf. peregrinus & & & & & & & & $\mathrm{S}$ & & \\
\hline Gyps fulvus & & & & & & & & $\mathrm{S}$ & & \\
\hline Tetrao urogallus & & & & & & & & & Q & \\
\hline Tetrao tetrix & & & & & & & Q & $\mathrm{P}$ & $\mathrm{Q}$ & $\mathrm{Q}$ \\
\hline Tetrao tetrix/Lagopus sp. & & & & & & & & $\mathrm{P}$ & & \\
\hline Otis tetrax & & & & & & & & & & $\mathrm{Q}$ \\
\hline Lagopus mutus & & & & & & & $\mathrm{Q}$ & $\mathrm{P}$ & $\mathrm{L}$ & Q \\
\hline Lagopus sp. & & & & & & & & $\mathrm{S}$ & $\mathrm{Q}$ & \\
\hline Perdix perdix & & & & & & & & $\mathrm{S}$ & $\mathrm{Q}$ & $\mathrm{Q}$ \\
\hline Tetrastes bonasia & & & & & & & & & $\mathrm{Q}$ & $\mathrm{Q}$ \\
\hline Charadriifomes indet. & & & & & & & & $\mathrm{S}$ & & \\
\hline Strix aluco & & & & & & & $\mathrm{Q}$ & & & \\
\hline Cuculus canorus & & & & & & & & & $\mathrm{Q}$ & $\mathrm{Q}$ \\
\hline Asio flammeus & & & & & & & & $\mathrm{S}$ & & \\
\hline Micropus apus & & & & & & & & & $\mathrm{Q}$ & $\mathrm{Q}$ \\
\hline Passeriformes indet. & & & & & & & & $\mathrm{S}$ & & \\
\hline Turdus pilaris & & & & & & & & & & $\mathrm{Q}$ \\
\hline Turdus merula & & & & & & & & & $\mathrm{Q}$ & \\
\hline Turdus sp. & & & & & & & & $\mathrm{S}$ & & \\
\hline Hirundo rustica & & & & & & & & & $\mathrm{Q}$ & $\mathrm{Q}$ \\
\hline Corvus corax & & & & & & & & $\mathrm{M}$ & Q & $\mathrm{Q}$ \\
\hline Corvus monedula & & & & & & & & $\mathrm{S}$ & & $\mathrm{Q}$ \\
\hline Otus scops & & & & & & & & & & $\mathrm{Q}$ \\
\hline Nyctea scandiaca & & & & & & & & & & $\mathrm{Q}$ \\
\hline Pica pica & & & & & & & & A & & \\
\hline Pica pica/Garrulus glanda & arius & & & & & & & $\mathrm{S}$ & & \\
\hline Circus cyraneus & & & & & & & & & & $\mathrm{Q}$ \\
\hline Dendrocopus leucotos & & & & & & & & & & $\mathrm{Q}$ \\
\hline Dendrocopus major & & & & & & & & & & Q \\
\hline Rallus aquaticis & & & & & & & & & & $\mathrm{Q}$ \\
\hline Nucifraga caryocatactes & & & & & & & & & & Q \\
\hline Crex crex & & & & & & & & & & $\mathrm{Q}$ \\
\hline Tringa sp. & & & & & & & & & & $\mathrm{Q}$ \\
\hline Gallinula chloropus & & & & & & & & & & $\mathrm{Q}$ \\
\hline Vanellus vanellus & & & & & & & & & & $\mathrm{Q}$ \\
\hline Garrulus glandarius & & & & & & & $\mathrm{Q}$ & & $\mathrm{Q}$ & $\mathrm{Q}$ \\
\hline Pyrrhocorax sp. & & $\mathrm{Q}$ & & & & & & & & \\
\hline Pyrrhocorax/Corvus monec & dula & & & & & & & $\mathrm{S}$ & & \\
\hline Pyrrhocorax pyrrhocorax & & & & & & & & $\mathrm{S}$ & & $\mathrm{Q}$ \\
\hline
\end{tabular}


Ochozská Cave, Southern part of the Moravian Karst, Magdalénian.

Dating: $12.44 \pm 0.17 \mathrm{ka} \mathrm{BP}$ (Neruda 2010).

Larger and medium-sized mammals: Lepus sp., Cervus elaphus, Rangifer tarandus, Rupicapra rupicapra, Equus germanicus (dominant) (Musil 1958, 2002a) (bold: species typical for Holocene, underlined: surviving typical glacial species).

Verunčina Cave, Northern part of the Moravian Karst, Magdalénian (Musil 1958, 2002a).

Larger and medium-sized mammals: Rangifer tarandus, Equus germanicus.

Birds: Lagopus sp.

Žitného Cave, Central part of the Moravian Karst, Magdalénian, brown loam (Musil 1957, 2002a).

Dating: $13.22 \pm 0.09 \mathrm{ka} \mathrm{BP}, 16,130 \mathrm{ka}$ cal BP (Neruda 2010), 11,425 $\pm 1,100$ BP (OxA 11352; Stuart in litt. 2002; from a woolly rhino metapodium).

Larger and medium-sized mammals: Rangifer tarandus (MNI $50 \%$ ), Equus germanicus (MNI 27.7 \%), Lepus sp., Cervus elaphus (rare find), Vulpes lagopus (a few bones), Coelodonta antiquitatis (rhino metapodium in the Magdalénian layer; for dating see above). The latter is probably the youngest woolly rhino finding in Central Europe. Bos primigenius (rare find) (bold: species typical for Holocene, underlined: surviving typical glacial species).

Small mammals: Mustela putorius.

Kolíbky Cave, Central part of the Moravian Karst, Magdalénian.

Dating: $12,680 \pm 110$ BP (Svoboda et al. 2000a), the average annual temperature $3.3^{\circ} \mathrm{C}$ (Moravcová 2011).

Larger and medium-sized mammals: Equus germanicus (many), Rangifer tarandus (abundant) (Musil 2002a) (underlined: surviving typical glacial species).

Birds: Aves indet.

Hadí Cave, Southern part of the Moravian Karst, auburn loessic loam and loess, Magdalénian (Musil 1961, 2002a).

Larger and medium-sized mammals: the findings of both layers are identical regarding species: Equus germanicus (dominant), Rangifer tarandus (dominant), Bos sp. or Bison sp.

Barová Cave, Central part of the Moravian Karst, layers 11 and 12, Magdalénian (Horáček in Svoboda et al. 2000a).

Small mammals: Layer 11 (MNI): Sorex araneus (1), Arvicola amphibius (1), Microtus oeconomus (3), Microtus gregalis (8), Microtus arvalis/agrestis (9), Dicrostonyx gulielmi (6), Ochotona sp. (1).

Layer 12: Sorex "arcticus" (2), Spermophilus sp. (1), Myodes glareolus (1), Chionomys nivalis (10), Microtus oeconomus (6), Microtus gregalis (113), Arvicola amphibius (2), Microtus arvalis/agrestis (13), Lemmus lemmus (3), Dicrostonyx gulielmi (14), Ochotona sp. (2).

Šipka Cave, Karst of Northern Moravia, yellow-brown loam, mixed possibly with an older layer (Musil, 1965a, 2002a).

Larger and medium-sized mammals: Ursus sp., Coelodonta antiquitatis (several specimens), Mammuthus primigenius (very few), Rangifer tarandus, Bison priscus, Alces alces, Vulpes vulpes, Vulpes lagopus, Lynx lynx, Equus sp. (bold: species typical for Holocene, underlined: surviving typical glacial species).
Small mammals: Ochotona pusilla, Dicrostonyx torquatus.

Birds: Tetrao urogallus, Tetrao tetrix, Lagopus lagopus, Lagopus mutus, Halietus albicilla.

Průchodice Cave, Karst of Northern Moravia, Magdalénian (Musil 1965a, 2002a).

Larger and medium-sized mammals: Rangifer tarandus, Lepus sp., Lynx lynx, Equus germanicus, Bos primigenius (bold: species typical for Holocene).

Small mammals: Talpa europea, Sorex araneus, Cricetus cricetus, Dicrostonyx torquatus.

Recapitulation: The findings of large and medium-sized fauna in each Magdalénian site varied substantially regarding the number of individuals of each species. In general, however, the species, regardless of the layer (we have two Magdalénian layers occasionally), were limited to reindeer, horses and hares with occasional saiga. This is a period when horses and reindeer were most common in large numbers, ergo animals requiring an open landscape. Only exceptionally we still find at this time mammoths, woolly rhinos and sometimes wolverine. These species were in all probability not living in this area permanently, they occasionally migrated there from the north. It was, together with the species Ochotona pusilla, their last occurrence in Moravia.

This period marked the beginning of the reappearance of deer, moose, beaver and the present species of lion (Panthera leo), bison and ox. One cannot exclude the possibility that the badger findings could be younger. Small fauna were represented mainly by Dicrostonyx torquatus (Balcarova Skála Cave, 8,000 specimens) and Ochotona pusilla (Balcarova Skála Cave, 300 specimens). The huge disproportion in the number of Dicrostonyx $(8,000$ specimens) and Lemmus (20 specimens) in one layer is important (Balcarova Skála Cave) (cause: permanently significantly cold valleys in the Moravian Karst).

The Magdalénian assemblage is a typical discordant assemblage. Its basis is made up of the still dominant species of the Last Glacial with only a slight representation of species typical for the following Holocene. Their presence and the great reduction in individuals of glacial species mean that there was a relatively significant change in climate. These findings in conjunction with the presence of loess indicate that the Magdalénian still had a cold and dry environment, but not to the same extent as in the LGM. Even if the absolute date of the individual sites does not show any great variation, the fact is that in certain sites appear mostly, or only, animals from a glacial climate. In contrast, there are additions of species typical for the Holocene. This could indicate a smaller time difference between the two groups of sites and also at the same time a relatively rapid climate change.

Faunistic turnover in event 11. Some assemblages with sporadic species typical for Holocene. The end of the Pleistocene ecosystem (event 11). The beginning of the Holocene community and the start of the Holocene ecosystem (event 12).

\section{Event 12, MIS 1}

12-10 ka BP.

Palaeocenosis: Cervus elaphus-Capreolus capreolus. 
Kůlna Cave, Northern part of the Moravian Karst, layer 3, MIS 1.

Dating: 10,070 $\pm 85 \mathrm{ka}$ BP, deep gray humic loam, Epimagdalénian (Valoch 1988, Svoboda et al. 2000a, Valoch and Neruda 2005, Nerudová 2010). According to the findings of gastropods, there was a warm humid climate and deciduous forests (Kovanda 1970). On the basis of the charcoal analysis, there was a warm forest climate (Opravil 1970).

Larger and medium-sized mammals: Canis sp., Ursus arctos, Equus sp., Sus sp., Cervus elaphus, Capreolus capreolus, Alces alces, Bos primigenius, Bos sp. (Musil 1988a).

Small mammals: Dicrostonyx torquatus (dominant, glacial relict, the last occurence of this species in the Moravian Karst), Microtus subterraneus, Microtus gregalis, Myodes glareolus (Musil 1988a) (underlined: surviving typical glacial species).

Barová Cave, Central part of the Moravian Karst, layer 10, Epimagdalénian (Horáček in Svoboda et al. 2000a).

Small mammals (MNI): Sciurus vulgaris (2), Muscardinus avellanarius (3), Glis glis (2), Apodemus sp. (17), Myodes glareolus (16), Arvicola amphibius (1), Microtus gregalis (1), Microtus arvalis/agrestis (5), Microtus subterraneus (3), Lemmus lemmus (glacial relict) (1) (underlined: typical glacial species surviving up to Holocene).

Kůlna Cave, Northern part of the Moravian Karst, layer 4.

Dating: $11,470 \pm 105 \mathrm{BP}, 11,270 \pm 80 \mathrm{BP}$ (Svoboda et al. 2000a, Neruda 2010).

Dark brown soil, occassionally large amounts of debris. Epimagdalénian (Valoch 1988, Valoch and Neruda 2005).

Larger and medium-sized mammals: Lepus sp., Castor fiber, Vulpes vulpes, Ursus arctos, Equus sp., Sus scrofa, Rangifer tarandus (many, glacial relict), Cervus elaphus, Capreolus capreolus, Alces alces, Bos primigenius, Mammuthus primigenius? (glacial relict).

Small mammals: Dicrostonyx torquatus (many, glacial relict), Arvicola amphibius (many) Chionomys nivalis, Lagurus lagurus (underlined: typical glacial species surviving up to the Holocene).

Birds: Aves indet.

The reason for the survival of the glacial species: the permanently cold valleys of the Moravian Karst (Musil 1988a).

Recapitulation: The structure of the faunistic assemblage (event 12) differs from the previous event 11. In the time between 12 and $10 \mathrm{ka} \mathrm{BP}$ a change in assemblage structure occurred. In event 12 which has a typical Holocene assemblage there are also still species typical for the end of the Last Glacial (a number of reindeerand lemmings), but in the time between about 10-8 ka BP (event 13) the structure of the community became that typical for the Holocene. In event 12 , the occurrence of lemmings ended first, but reindeer remained in existence up until the Neolithic Age (Musil 2010b). I can not explaine the finding of a mammoth in layer 4 (Kůlna Cave). In theory, this could be an anthropological reposition. The best solution would be to suggest that this finding originates from another layer. However, any evidence of such is missing. On the other hand, this layer contains a number of findings of reindeer which are representatives of arctic fauna and certainly lived here in greater numbers. The radiometric dating of layer 4 (Kůlna, Epimagdalénian) is almost identical with the Magdalénian layers. Certain limited explanations are possible: 1 . The sediments are not in situ. 2. The establishment of a new assemblage occurred so rapidly that it followed on extremely quickly. 3 . The diagnosis is incorrect or the finding does not come from this layer. However, due to the fact that layer 4 has a completely different character to the following Epimagdalénian sediment, I favour option 2. The change in the environment and fauna assemblage had to have taken place over an extremely short time.

The beginning of the Holocene community with rare glacial species. The beginning of the Holocene ecosystem (event 12). The end of the Pleistocene ecosystem (event 11).

\section{Event 13, MIS 1}

Mesolithic Age.

Palaeocenosis: Cervus elaphus-Sus scrofa.

Smolín (open-air site, Central Moravia), Mesolithic Age. Dating: 8,315 \pm 55 BP (Valoch 1989).

Larger and medium-sized mammals: Equus sp., Castor fiber, Alces alces, Sus scrofa, Vulpes vulpes, Cervus elaphus, Bovidae indet. (Musil 1978).

Recapitulation: The typical assemblage of the Holocene, quite stable new ecosystem.

At the time about 10-8 ka BP (event 13), the composition of the community was limited to that typical for the Holocene.

\section{Event 14, MIS 1}

Neolithic Age, Bronze Age.

\section{Palaeocenosis: Capra hircus-Ovis ammon f. aries}

Kůlna Cave, Northern part of the Moravian Karst, layer 2, Early Neolithic, the first appearance of domesticated animals.

Larger and medium-sized mammals: Equus caballus, Sus sp., Cervus elaphus, Bos primigenius f. taurus, Capra hircus f. egagrus, Ovis ammon f. aries (Musil 1970, 1988a).

Kůlna Cave, Northern part of the Moravian Karst, layer 1, dark to black-grey loam, limited debris, Bronze Age and younger.

Larger and medium-sized mammals: Equus caballus, Sus sp., Cervus elaphus, Bos primigenius f. taurus, Capra hircus f. egagrus, Ovis ammon f. aries, Lepus sp., Sus scrofa, Sus scrofa f. domestica, Alces alces, Bos sp. (Musil 1970, 1988a)

Kůlna Cave, Northern part of Moravian Karst, layers $1+2$.

In addition to the above species also Canis lupus, Canis lupus f. familiaris, Felis silvestris, Rangifer tarandus, Ursus arctos are still present. The last occurrence of reindeer in the Moravian Karst (underlined: typical glacial species surviving up to the Holocene).

Recapitulation: The finding of reindeer from the Neolithic Age is completely unexpected. Even if we could 


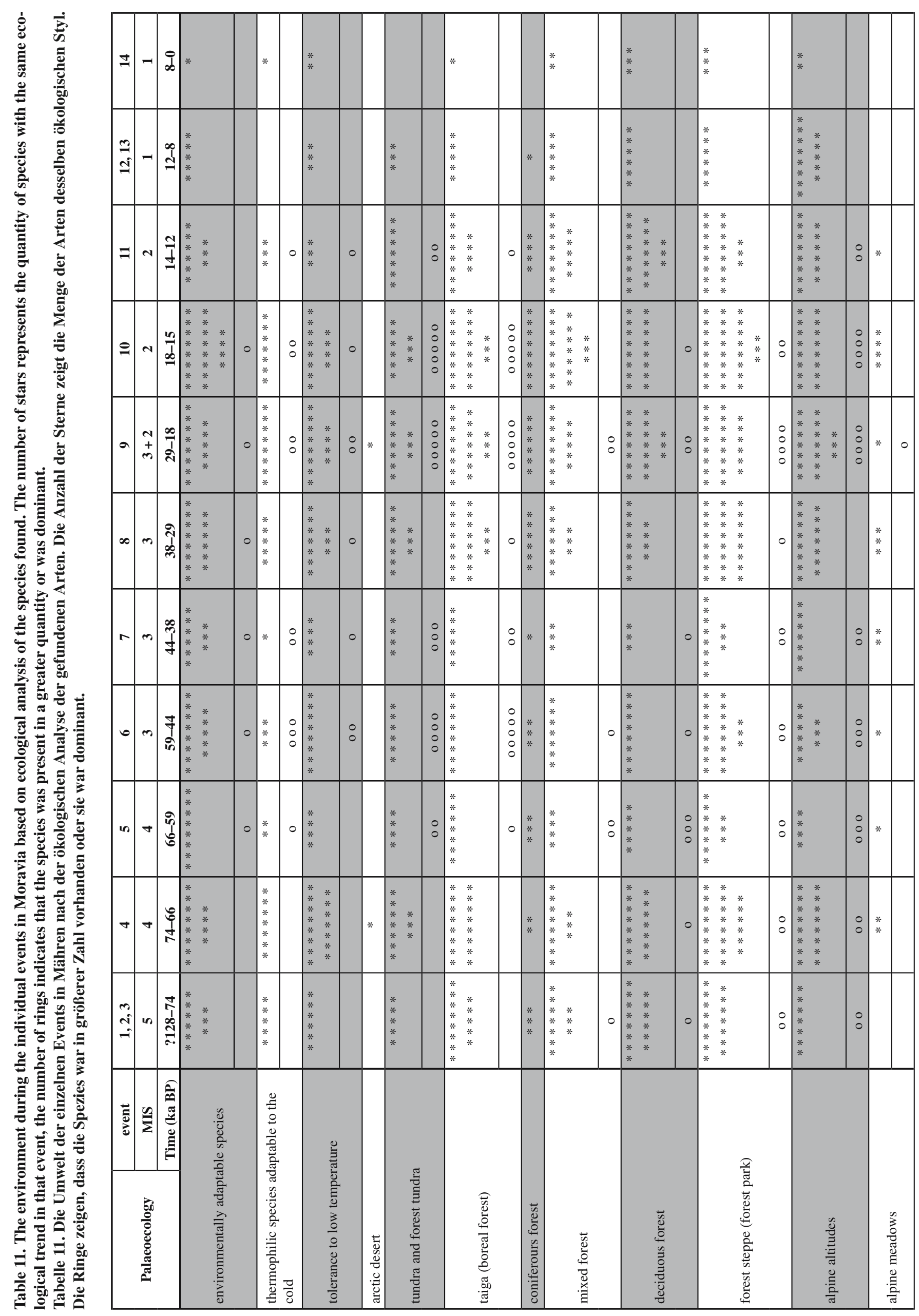




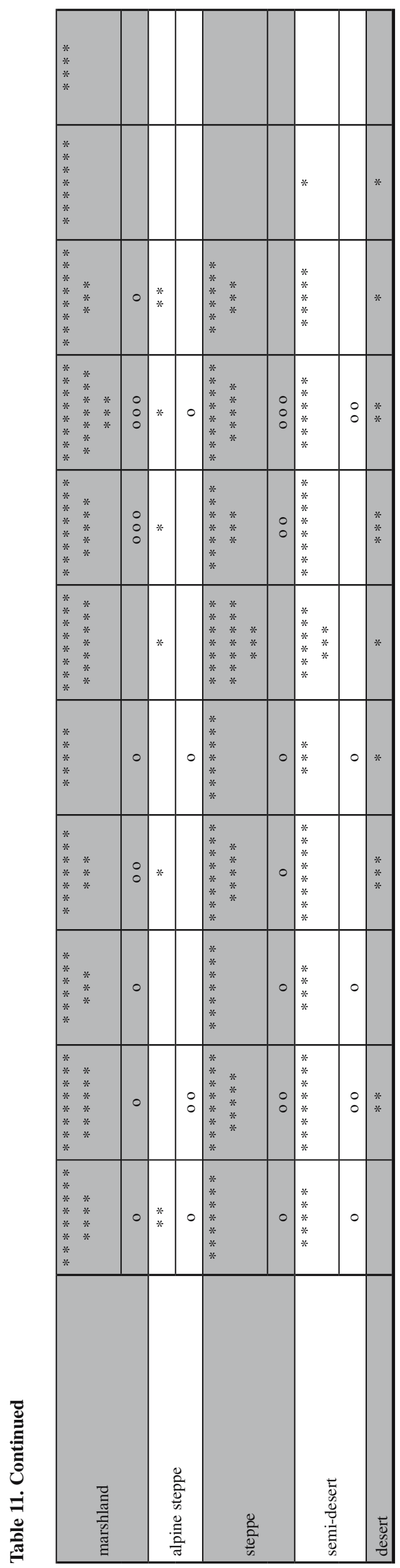

consider the possibility of a secondary location, I believe that the discovery of this species in the climatic conditions of the Moravian Karst (an extremely cold valley) may not be an isolated finding.

Domestic animals in the Neolithic Age. In a few isolated cases reindeer still found.

\section{Vertical and horizontal zonality of Moravia}

Moravia has a marked vertical zonality. Its western and eastern part are surrounded by relatively high mountains, those on the west are at an altitude of 800-1,400 $\mathrm{m}$ a.s.l. and on the east at 700-1,300 $\mathrm{m}$ a.s.l. In the middle area there are low-lying alluvial river floodplains with various levels of upland. This means that at the same time the environment was extremely different over a relatively short distance and also of course the composition of the vegetation and fauna. We can distinguish the following types of environment.

1. Alluvial floodplains around the larger water flows (rivers Morava, Dyje, Svratka, Odra), where continuous coniferous forest is assumed to have existed during the Last Glacial, with also occasionally sporadic thermophilous deciduous trees in favourable locations, mainly in south Moravia. Towards the end of the Last Glacial, there were also frequent marshy areas and peat bogs. The presence of thermophilous deciduous trees ended with the onset of the LGM (Biotope A; I use the term biotope to indicate a classification unit which is defined by the vegetation type of the plant communities).

2. Lower foothills of uplands up to a height of about $300 \mathrm{~m}$ a.s.l. extending along the flood plains. Their extent is variable, but it is probably the largest area of the described biotopes. The plant cover is dependent on the geological bedrock, the amount of precipitation (the precipitation varies significantly between the south and north of Moravia) and on the geographical orientation of the slopes. The park landscape, open grassy areas with isolated trees and shrubs is predominant, and smaller woodlands at optimal locations (Biotope B).

3. The only primarily grassy cover is assumed to have been at the higher altitude of hills (ca. 300-500 m a.s.1.). Reindeer migrated there and back during the summer months. The structure and diversity of herbivorous animals in the months when the grass was dry (all summers and later) was extremely limited due to the reduction in food value of the grass (Biotope C).

4. The top parts of the foothills and in particular on the mountains (500-1,400 $\mathrm{m}$ a.s.1.). The highest places in many areas were without grassy vegetation during the cold and dry events. Deflationary areas. From here loess originated and was deposited in the lower regions. On the basis of petrographic composition of the windblown loess, a predominance of western winds prevailed in Moravia (Musil 2010a, 2011a) (Biotope D).

The boundaries of the individual biotopes during the climate oscillations of the Last Glacial were not permanent, they could have been slightly modified. These changes in 


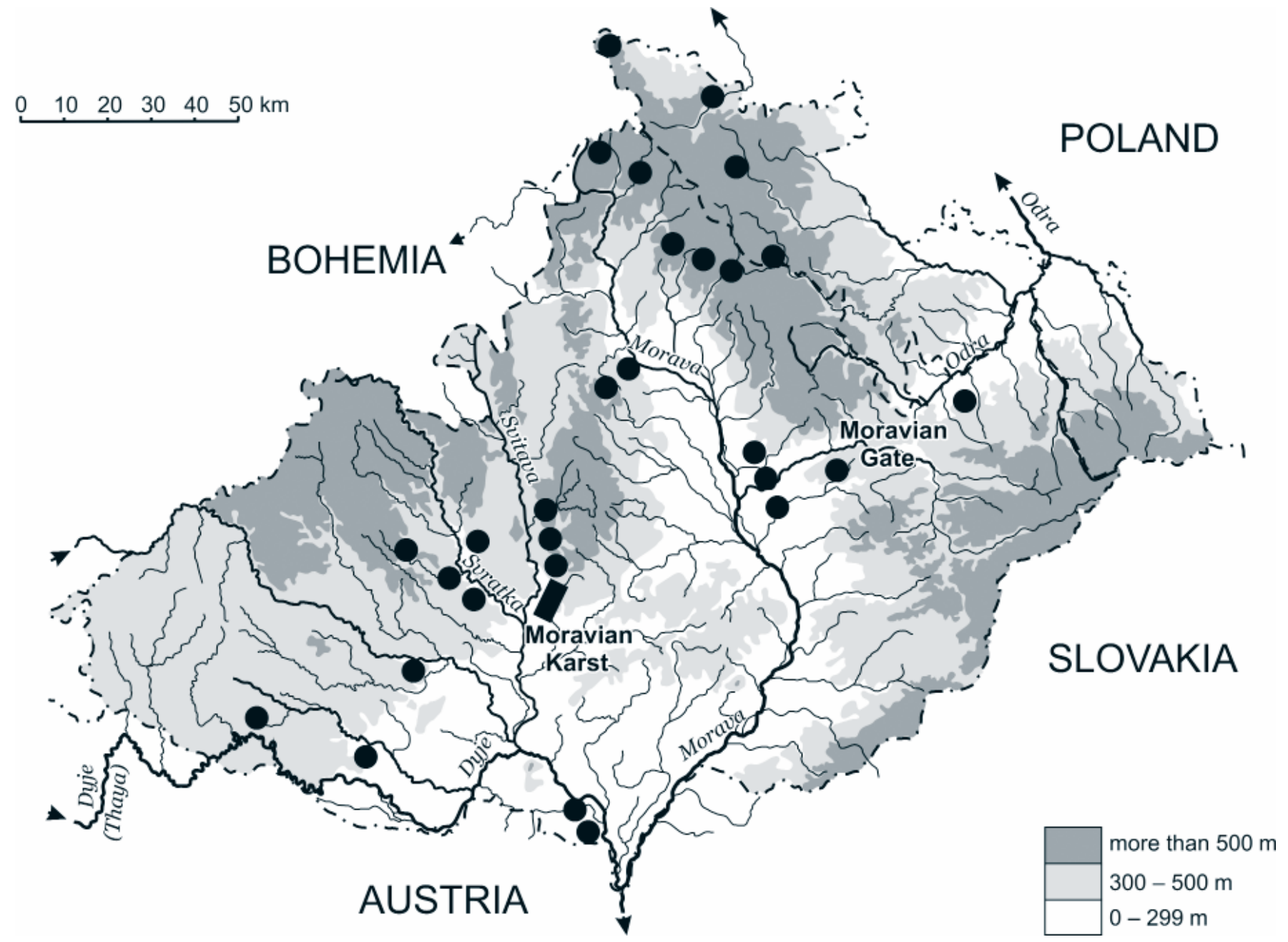

Text-fig. 2. Moravia, altitudes. Types of environment indicated by colour: 1 (white colour) - flood plain (biotope A) and lower foothills (up to $300 \mathrm{~m}$ a.s.l., biotope B), 2 (grey) - the higher areas of the foothills (300-500 m a.s.l., biotope C), 3 (dark grey) - the top part of the foothills and the mountains (500-1,400 $\mathrm{m}$ a.s.l., biotope D). Large black circles: The extension of the karst areas in Moravia. The Moravian Karst is the largest and most importan (rectangle). All other karst areas (circles) are smaller. The karst areas are important for the large number of fossil vertebrates bone finds.

Abbildung 2. Höhen von Mähren. Typen von Umwelt: 1 (weisse Farbe) - Flussaue (Biotop A) und niederes Hügelland (bis zu 300 m, Biotop B), 2 (grau) - die höheren Lagen des Hügellandes (300 bis 500 m, Biotop C), 3 (dunkelgrau) - die höchsten Höhen des Hügellandes und die Berge (500-1 400 m, Biotop D). Die Verbreitung der Karstgebiete. Das größte und wichtigste ist der Mährische Karst (Rechtgeck). Alle anderen Karstgebieten (Kreise) sind bereits kleiner. Karstgebiete sind wichtig für eine große Anzahl von Knochen fossiler Wirbeltiere.

the size of the individual biotopes during the Last Glacial were probably not caused by temperature oscillations, but most likely by different quantities of precipitation and its distribution throughout the year. Precipitation played the most important role.

\section{Analysis of sites in relation to rainfall}

A comprehensive study of the Last Glacial revealed that the area of Moravia did not have a uniform climate at any given time. The north was significantly different from the south. While the south of Moravia had a rather dry climate and with northern Austria formed a single province, the northern part of Moravia had at the same time a climate with substantially higher precipitation, quite similar to the southern part of Poland. The amount of rainfall in central Moravia at that time was roughly between the values for north and south Moravia (Musil 1985, 2005a, b, 2008, 2010a).

If we consider the list of sites containing remains of fauna, we find that they primarily come from archaeological research. And not just from open-air sites, but also from caves. Specifically palaeontologically orientated research is scarce and I consider this an interesting fact. Certain Palaeolithic cultures were mostly based in the open-air, others mainly in caves. I believe that this has nothing to do with the temperature as such, but more likely with the amount of rainfall.

Epimagdalénian: Caves only, time range: 10,070 \pm 85 BP (Kůlna, layer 3, exception) - 11,470 \pm 105 BP (3 sites).

Magdalénian: Only one open-air site which is located in front of a rock, otherwise only caves. Time range: 11,450 
$\pm 105 \mathrm{BP}$ up to $13.870 \pm 140 \mathrm{BP}(13.4-17.2 \mathrm{ka}$ cal BP) $(15$ sites). We know the average annual temperature from these sites: $2.6-7.5^{\circ} \mathrm{C}$ (Moravcová 2011).

Epigravettian: Open-air sites only. Time range: 14,450 \pm 90 BP, 14,820 \pm 129 BP (Brno, Štýřice III, exceptions), $11,960 \pm 90$ BP up to $19,380 \pm 90$ BP (5 sites).

Gravettian (Pavlovian): mostly open-air sites (11 sites investigated, but in total many tens more) and only two minor sites in caves. Time range in caves 21.26 up to 22.99 ka BP (23.03-25.02 ka cal BP), time range of the open-air site 20.79 up to $31.70 \mathrm{ka} \mathrm{BP}(22.36-29.97 \mathrm{ka}$ cal BP).

Aurignacian: only three sites, two of them dated. One of them is a cave (34.16-34.93 $\mathrm{ka} \mathrm{BP})$, and the second openair site (30.98-32.6 BP; 35.3-35.1 ka cal PB).

Bohunician: only three open-air sites. Time range: $34,440 \pm 530 \mathrm{BP}$ up to $42,900+1,700 /-1,400 \mathrm{BP}$.

Mousterian: one open air locality. Time range: 39.5 to $37.6 \mathrm{ka} \mathrm{BP}(41.5-39.65 \mathrm{ka}$ cal BP). Two cave sites: $36,750 \pm$ $800 \mathrm{BP}$ up to $42,400 \pm 550 \mathrm{BP}$.

Micoquian: Described from caves only (three caves). Time data are probably not entirely reliable, estimated as $\geq 36 \mathrm{ka} \mathrm{BP}$ up to $52,700 \pm 230 \mathrm{BP}$.

From the above information the following conclusions can be made: If people lived in caves, we can assume that it was not only cold, but also rainy as well. There was probably a humid and cool climate from 13.93 up to 10.07 ka BP (Epimagdalénian, Magdalénian), when people mainly lived in caves.

From 11.47 up to 31.70 ka BP there was a dry climate with minimum precipitation. The Epigravettian, Pavlovian and Bohunician settlements were in open country. This was a significant change in comparison with Magdalénian culture. In the culture of the Mousterian and Micoquian, people lived predominantly in caves.

\section{The Central European provinces of the Last Interglacial}

Average temperatures and average rainfall were not synchronic over the whole of Central Europe. Moravia is located in a wide European west-east loess zone and almost everywhere the typical fossil soil complex of the Last Interglacial can be found, unfortunately, without the findings of fossil mammals. It is fortunate that sediments with findings from this time were also located in caves. The situation there is, however, more complicated. We nearly always find brown to dark brown sediments at this time, which lie mostly on extremely old sterile gravels. If these brown sediments contain fossil mammals, it is mostly a large number of Ursus ex gr. spelaeus findings or in other cases a whole series of different taxa. Extremely rare findings typical for the Last Interglacial have been found only occasionally in these layers. The assemblage structure of large and medium large mammals is not typical for the Last Interglacial: Crocuta crocuta spelaa, Canis lupus, Vulpes vulpes, Meles meles, Mammuthus primigenius, Cervus elaphus, Coelodonta antiquitatis, Cervus elaphus maral, Alces alces, Rangifer tarandus, Bos primigenius, Bison priscus, Capreolus capreolus, Rupicapra rupicapra, Ovis sp., Capra sp., Marmota sp., Equus (Asinus) hydruntinus and others. Palaeolithic findings if present, were previously assigned to the Mousterian, Micoquian or Taubachian. In any case, the fauna assemblage differs greatly from the typical Eemian assemblages of Western and Central Europe.

Overall, however, the findings of some of the above listed taxa indicate a mostly warmer climate and expanding forests. We can find these species which are in principle typical for stage 5e, even in the first interstadials of the Last Glacial. These sporadic findings (Ursus taubachensis, Equus taubachensis etc.) are not therefore crucial for an exact determination of age. Sediments with these findings were previously incorporated into the Eemian interglacial at the time when the first extremely warm interstadials after the climax phase of the Eemian interglacial had occurred. According to current opinion, however, these stages were already the first interstadials of the Last Glacial. This also applies to the last extensive research programme on the Moravian Karst, in particular in Kůlna Cave.

We have no other choice but to look at the structure of the nearest typical communities of the Last Interglacial (Eemian interglacial) in the eastern part of Germany and try to compare this assemblage with the findings in Moravia. In Germany these consist of mainly travertine localities such as Burgtonna, Taubach (116 ka BP) and Weimar, all with typical Antiquus fauna (Musil 1977, 1984).

Assemblage structure of these sites (Kahlke 1958): Castor fiber, Canis lupus, Ursus taubachensis, ?Meles meles, Lutra lutra, Crocuta spelaea, Lynx lynx, Panthera pardus, P. spelaea, Palaeoloxodon antiquus, Equus taubachensis, Stephanorhinus hemitoechus, Stephanorhinus kirchbergensis (Taubach, Weimar, Ehringsdorf) (Kahlke 1958, Billia 2011), Sus scrofa, Megaloceros giganteus, Cervus elaphus, Dama dama, Alces alces, Capreolus capreolus, Bison priscus, Bos primigenius.

The characteristic species of the Last Interglacial, which are always present in large quantities, are Stephanorhinus kirchbergensis and Palaeoloxodon antiquus. Some of the featured species are also known from the Moravian Karst, others (typically Eemian species) are nearly always unknown in the Moravian Karst. Mammoths and woolly rhinos are completely absent in typical Eeminan localities of Central Europe.

At first sight the Eemian assemblage is completely different from the communities in the Moravian Karst from the layers which were previously included within the Eemian interglacial. This is not just related to species structure, but also the number of findings, in particular of Palaeoloxodon antiquus and Stephanorhinus kirchbergensis.

The issue, however, is more complicated than it seems at first sight. I predicted (Musil 2010a, 2011b) that the mean temperature in this interglacial was probably more or less the same throughout Central, Western and Eastern Europe. This was not so with the quantity of rainfall which to the east was gradually on the wane (Musil 2003b, 2005a, 2010a, 2011a, 2011b). The species Palaeoloxodon antiquus and Stephanorhinus kirchbergensis required not only a higher average temperature, but also a humid climate and corresponding soft plant food. Due to a drier climate such a composition of plant food however, was not found in Moravia. This means that these species could cross the theoretical eastern border Taubach-Weimar-Burgtonna- 


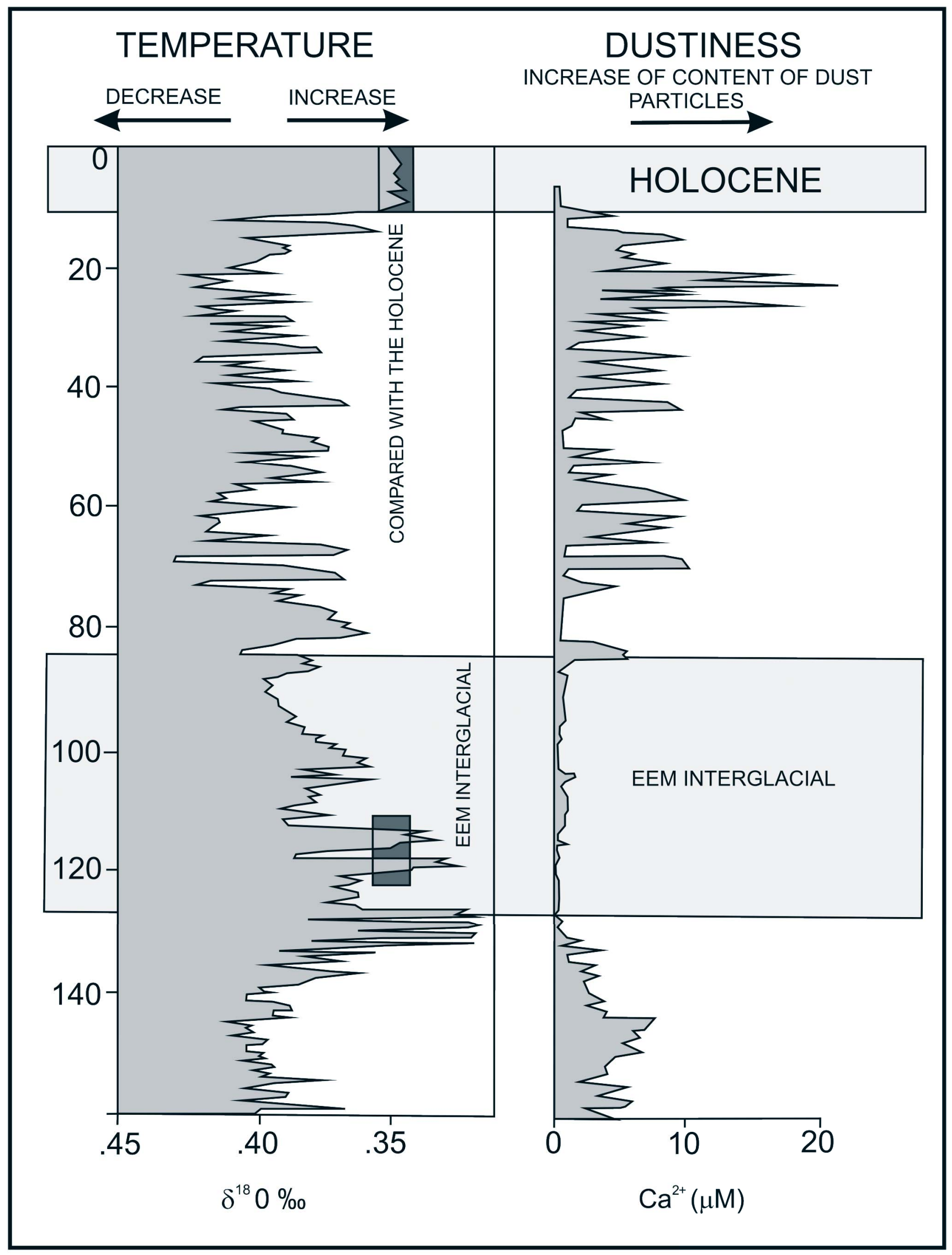


Lehringen, i.e. the border at a longitude of roughly $11^{\circ}$ east, only sporadically. Further to the east, where the climate was drier, these animals never occured in such numbers as in Western Europe or in the western part of Central Europe. In contrast to the western part of Central Europe, the meager findings of these species indicate an unsuitable climate in the eastern part of Europe (see Billia 2011).

We must take into account, therefore, in the Last Interglacial (Eemian) in Central Europe that there were two different provinces, a more humid west (oceanic weather) and a drier east (continental weather). This means for Moravia that there are two possible alternatives. The first option would include the brown loams of Kůlna Cave, Švédův Stůl Cave, Šipka Cave and some of the other caves with sporadic findings of interglacial species in the Eemian interglacial. The second option would suggest the first interstadials of the Last Glacial for these faunas. A relatively large number of species from a cold climate and the unique findings of typical interglacial species, however, indicate more likely the second alternative, which I also view as more probable. It would be, therefore, rather the first warm oscillations in the Last Glacial which were at an earlier time classified as Eemian interglacial: Herning stadial (MIS 5d), Brörup interstadial (MIS 5c), Rederstal stadial (MIS 5b) and Odderade interstadial (MIS 5a). A more detailed classification based on current knowledge is not available.

\section{Intensity of change in the diversity of faunistic assemblages}

Temporal changes in the structure of the fauna communities did not occur abruptly, they took place over an extended time period. In this respect they differ from climate change identified from marine sediments or from glaciers. They cannot reflect a short climate change even if they are intense. However, it should be noted that many species in the Last Glacial had great ecological valency, so they were not always strictly tied to only one biotope. This assumption is confirmed by the ecological analysis of currently living species (Musil 2014).

Another problem exists in the current-day publications. Taxa from individual sites are not differentiated according to those living permanently in an optimal environment (the ecological optimum) or from species which migrated from other areas and which lived there temporarily when the climate was favourable for them. This could produce waves of migration from substantial distances and additionally migration from the immediate surroundings (in-migration, great vertical zonation!). This would have to be reflected in assemblage diversity and in the number of individuals. This distinction between permanent and temporary inhabitants is important for environmental analysis of communities.

Faunistic communities associated with individual events (1-14) were not permanently the same in the Last Glacial, they changed almost constantly, and were unstable. They did not even have a linear development. They clearly mirrored all the environmental changes. I can distinguish a number of basic types of community which changed irregularly.

Despite this statement, certain changes in the Last Glacial are, however, observable. I have divided these alternations into fundamental sudden changes, which lead to a significant change in the entire community, and slower gradual changes.

The significantly cold steppe assemblage of event 1 ended quickly (rapid faunistic turnover) and in the next assemblages (events 2 and 3) we see a gradually increased number of interglacial species together with recent species. This is not the Last Interglacial, but the first interstadial of the Last Glacial, which are climatically similar to the Eemian. It is interesting that this fact corresponds to an earlier stratigraphic table, IUGS, 1996, which puts the end of the Eemian interglacial at about this time.

In event 4 , the faunistic assemblage consists of steppe climate species, plus sporadically species typical for the Holocene. This period is characterized by findings of the sized large deer Cervus elaphus maral (migration from east). This species was not present either before or after event 4 .

A fundamental change in community appears after event 4 . Event 5 reflects the beginning of a glacial steppe assemblage. This assemblage continues to event 6, but, sporadically with species typical for the Holocene. On the basis of the charcoal, there was a closed forest and slightly colder climate which is reflected in the steppe fauna with warm forest elements.

Between events 6 and 7 the structure of the community changed. The species typical for Holocene are absent. In event 7 we find only typical glacial species also as in event 8. Events 7 and 8 have therefore only glacial fauna. The species diversity remains the same, only the number of individuals changed. The dominant species (mammoths and reindeer) indicate open countryside, dry steppe and a cold climate. Thermophilous forest species still present in event 6 had completely disappeared. This is also the last time when

Text-fig. 3. The changes in temperature and dust air pollution over the past 160,000 years on the basis of the boreholes in the Greenland glacier. The length of the Eemian (right rectangle) based on earlier views. It corresponds to the extent of the interglacial species findings. A rectangle in the left column indicates the current concept of the Eemian, at the top an analogy with the Holocene climate. Unlike the glacial era in the interglacial period, dust particles are practically absent. With respect to the quantity of dust particles, the original length of the Eemian was more accurate than today's stratigrapic classification. (Compare with the findings of the interglacial species at the beginning of the Last Glacial cycle (events 2 and 3)). Based on the report from $44^{\text {th }}$ Executive Committee Meeting of International Union of Geological Sciences, January 26-30, 1998, Vienna, Austria.

Abbildung 3. Die Veränderungen von Temperatur und Staub, die Luftverschmutzung in den letzten 160000 Jahre. Anhand der Bohrungen in dem grönländischen Gletscher. Die Länge des Eem (rechts Rechteck) nach früheren Ansichten. Ein Rechteck in der linken Spalte zeigt das heutige Konzept der Letzten Warmzeit, an der Spitze dann die Analogie mit holozänem Klima. Anders als in die Eiszeit die Staubpartikeln in der Warmzeit nahezu fehlen. Angesichts der Menge der Staubpartikeln die ursprüngliche EemLänge war korrekter als heutige stratigrapische Klassifikation. Als Grundlage diente der Bericht der Kommission IUGS von 1998. 


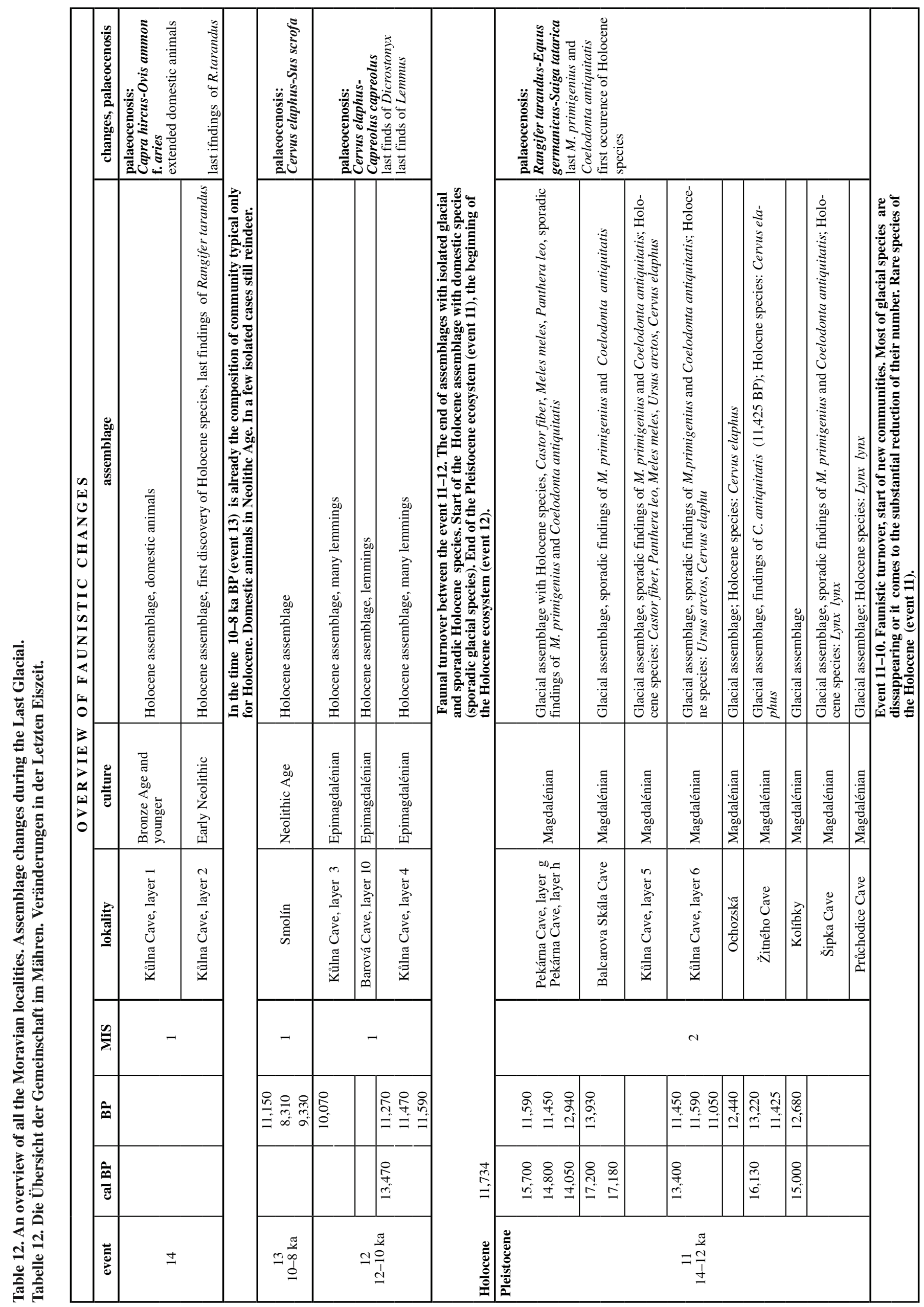




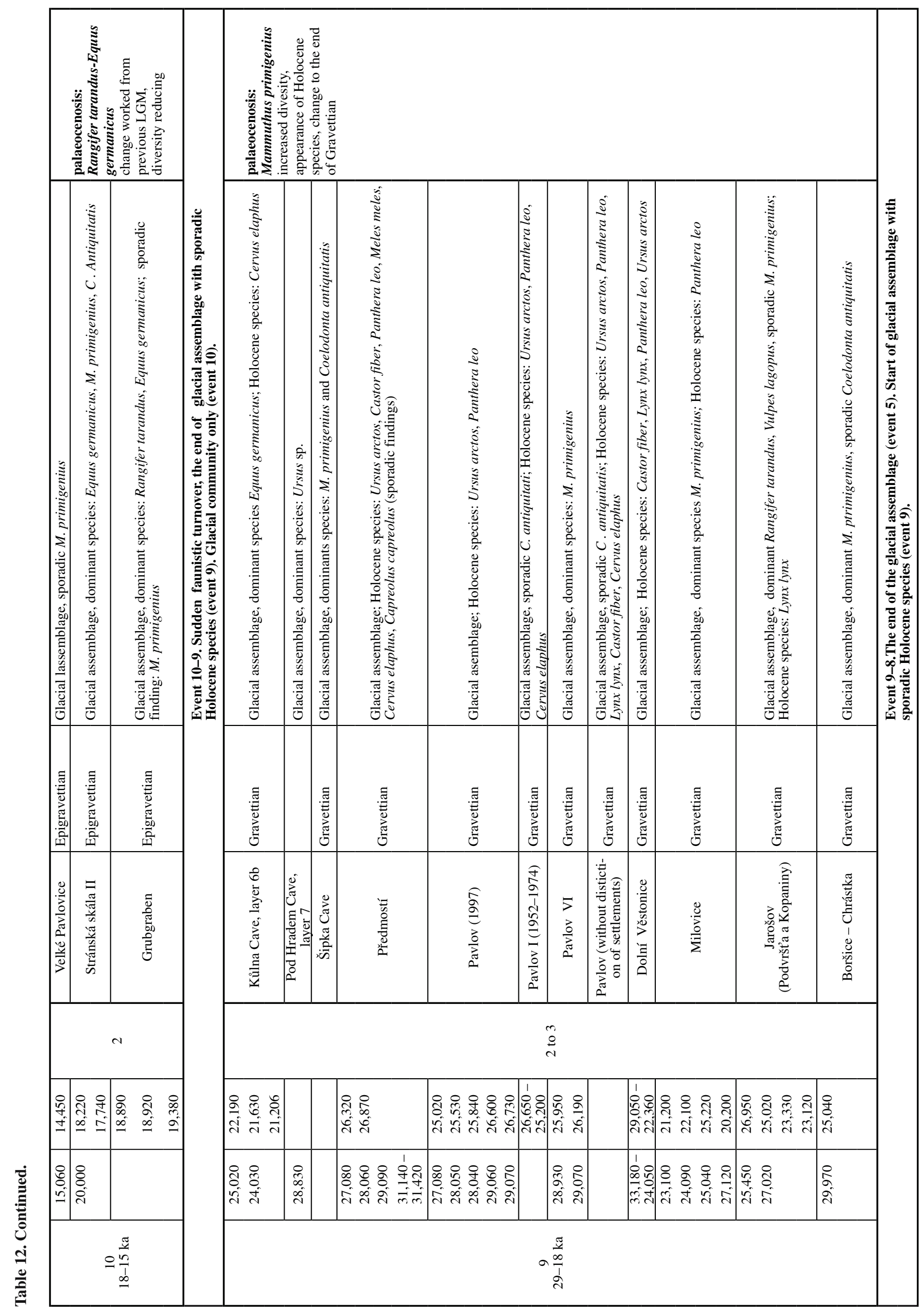




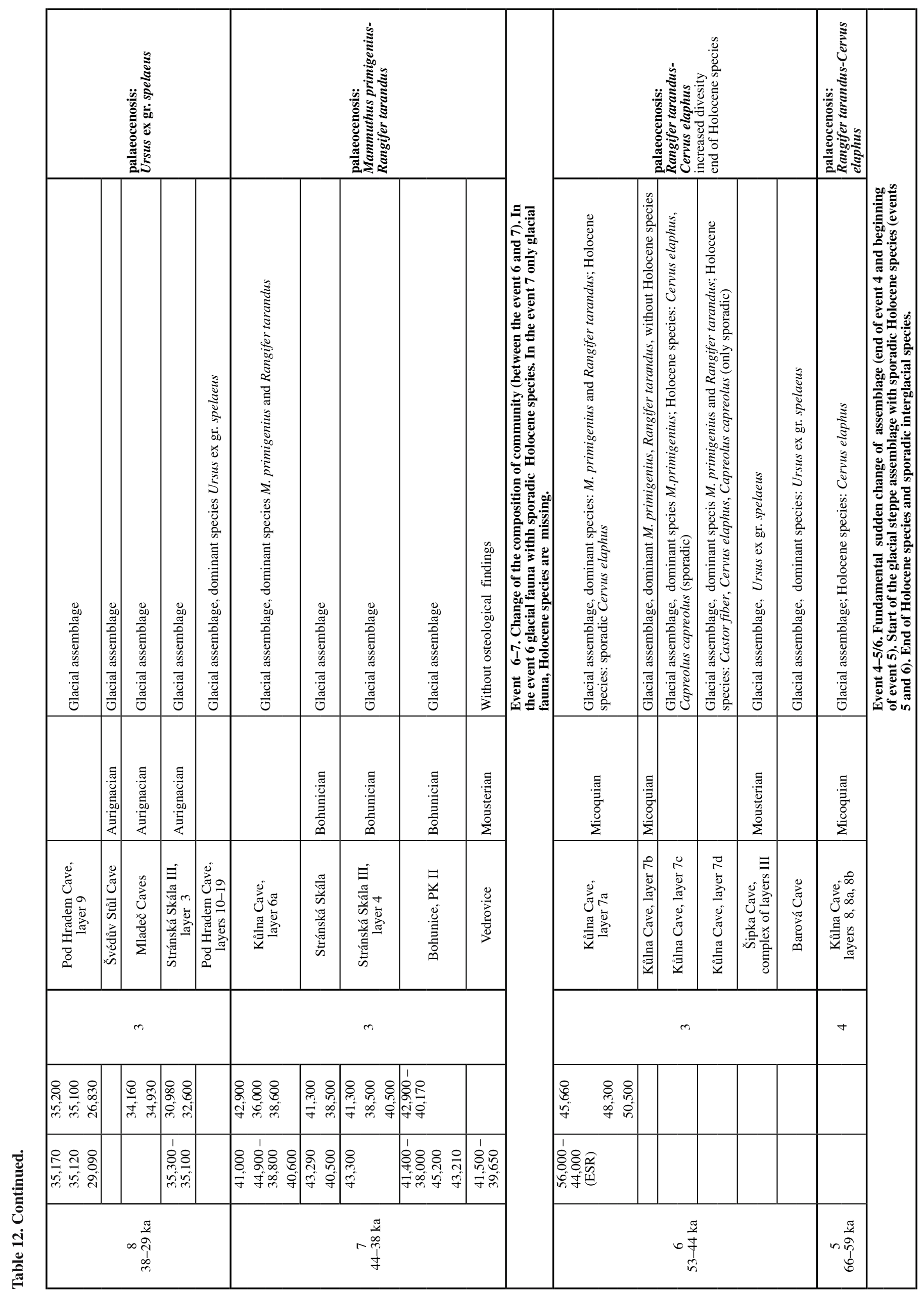




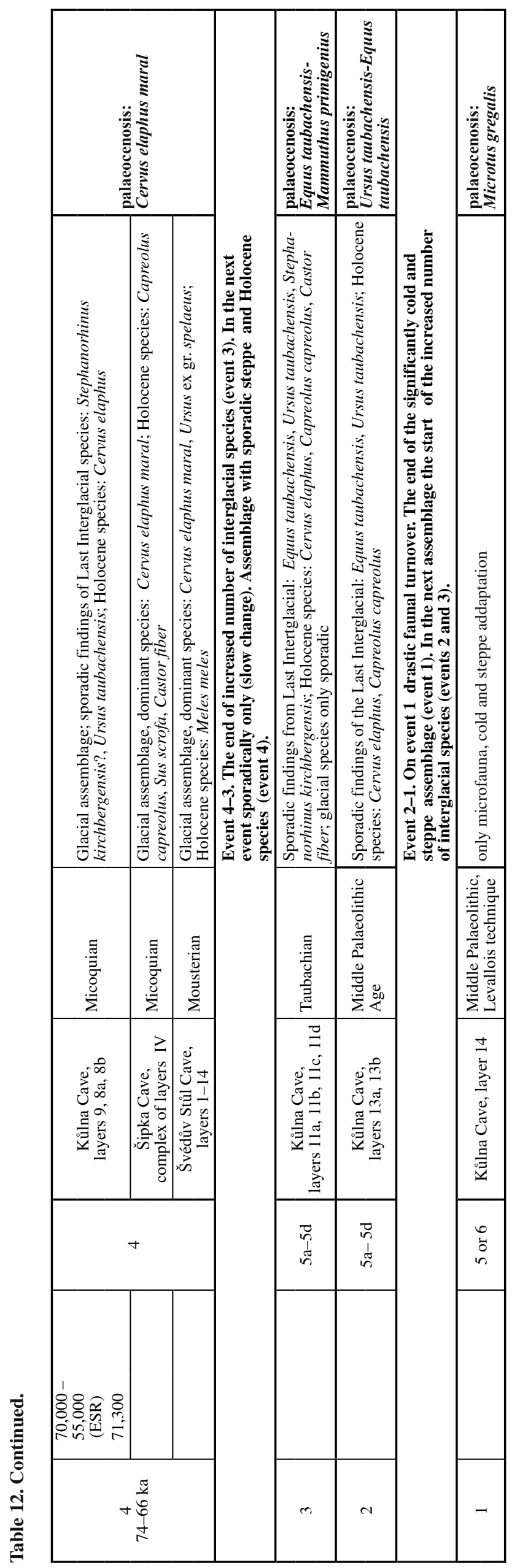

findings of cave bears in Moravia were recorded (event 8).

Event 9 can be assessed as being extremely favorable for fauna development. Assemblage diversity is unprecedentedly great. The majority of the species are typical representatives of the glacial fauna. Among them, however, there appear sporadic representatives of species which are typical for the Holocene (brown bear, lynx, wildcat, deer, roe deer, beaver, lion). They penetrated into this area apparently from the south along the Danube River and its tributaries. The environment was so favorable that it led to the migration of these species. We can therefore conclude that the first presence of typically Holocene species does not begin with the beginning of the Holocene but much earlier, at the latest at the end of the Last Glacial 29 ka years ago. Plant cover was at this time extremely differentiated, not only grassy steppe, but particularly around the rivers, coniferous forests dominated, but within them, were also sporadically deciduous trees (see Markova et al. 1995).

Towards the end of event 9 a drastic and sudden faunistic turnover occurred. The LGM includes the end of sporadic Holocene species. Some species typical for the Holocene, which appeared in Moravia sporadically in event 9, died out during the LGM and after this time did not exist. The Holocene species did not survive the LGM, they disappeared from this area. From the following period with Epigravettian (event 10) they were no longer known. This means that the relatively favourable period for fauna had changed with the arrival of an extremely unfavourable climate. The structure of the community is markedly different from the previous Gravettian before the LGM (event 9). The species structure of event 10 was fairly similar to the following event, 11 (Magdalénian). At this time there seems to have been an extremely fast reduction in the earlier large species diversity and at the same time the number of individuals of each species. This was a period of relatively rapid significant change, the greatest that we know of at present.

Event 11 represents once again a faunistic turnover: the beginning of a new community. Most of the glacial species were disappearing or exhibited a substantial reduction in their numbers. The typical animals were first and foremost reindeer, horses, and hares with also rare occurrences of saiga. This is a period when horses and reindeer were most common in large numbers, ergo animals requiring an open landscape. Surprisingly we still find at this time mammoths, woolly rhinos and even wolverine (Musil 2005a). These species were in all probability not living in this area permanently, they migrated there only occasionally from the north. This is, along with the species Ochotona pusilla their last occurrence in Moravia. They were a rare species of the Holocene, with the beginnings of the return of deer, moose, beaver and the current-day of lion, bison and ox species. Event 11 marked the end of the Pleistocene ecosystem (Markova et al. 2008).

Event 12 began with the recent community as well as sporadic glacial species. The composition of the faunistic assemblage differs from the previous assemblage in event 11. There were still quite a number of species typical for the end of the Last Glacial in a layer with a typical Holocene assemblage (a number of reindeer, lemmings, findings of mammoth?), while at the time between about 10-8 ka BP (event 13) the composition of the community was already 
Table 13. An overview of the structure of faunistic communities and their changes during the Last Glacial in Moravia (events 1-14).

Tabelle 13. Die Übersicht der faunistischen Vielfalt und ihre Veränderungen in der Letzten Eiszeit in Mähren.

\begin{tabular}{|l|}
\hline MIS 1 \\
\hline EVENT 14 \\
\hline Typical Holocene assemblage, domestic animals \\
\hline MIS 1 \\
\hline EVENT 13 \\
\hline Typical Holocene assemblage, domestic animals \\
\hline MIS 1 \\
\hline EVENT 12 \\
\hline Typical Holocene assemblage, domestic animals \\
\hline MIS 2 \\
\hline EVENT 11 \\
\hline Majority of glacial species disapperaed, sporadic Holocene species \\
\hline MIS 2 \\
\hline EVENT 10 \\
\hline Glacial fauna, Holocene species missing \\
\hline MIS 3/2 \\
\hline EVENT 9 \\
\hline Glacial fauna with sporadic Holocene species \\
\hline MIS 3 \\
\hline EVENT 8 \\
\hline End of glacial fauna assemblage \\
\hline MIS 3 \\
\hline EVENT 7 \\
\hline Glacial steppe fauna only, Holocene species missing \\
\hline MIS 3 \\
\hline EVENT 6 \\
\hline Glacial steppe, assemblage, relict of Holocene species \\
\hline MIS 4 \\
\hline EVENT 5 \\
\hline Start of glacial steppe assemblage, relict of Holocene species \\
\hline MIS 4 \\
\hline EVENT 4 \\
\hline Relict of interglacial species, above all Holocene species \\
\hline MIS 5b \\
\hline EVENT 3 \\
\hline End with increasing interglacial species \\
\hline MIS 5c \\
\hline EVENT 2 \\
\hline Assemblage with interglacial species \\
\hline MIS 5d \\
\hline EVENT 1 \\
\hline Cold assemblage \\
\hline
\end{tabular}

that typical for the Holocene. Lemmings disappeared first, while reindeer remained in existence in the Moravian Karst up until the Neolithic Age. The change in the environment and fauna assemblage had to have taken place over an extremely short time. This event marked the beginning of the Holocene ecosystem (Musil 1992a, 1993, 1994a).

The next time period saw the presence of only Holocene mammals and domestic animals. I mentioned in a few isolated cases the surprising findings of reindeer in the layers of Early Neolithic Age.

Faunistic communities of individual events (1-14) were not constant over the duration of the Last Glacial, they changed frequently and were, not stable. Their development was not linear but clearly mirrored all the environmental changes which occurred. We can distinguish a few basic types which irregularly changed. The changes in community had different intensities and different time scales. In some cases, they had a very fast time course (e.g. events 1-2 or 11-12), others took place more gradually.

During the Last Glacial I note the main faunistic types:

1. A relatively long period at the beginning of the Last Glacial with a gradually increasing number of certain interglacial species. At this time Holocene species were also found.

2. Stages of various lengths in which we find only or mostly species of a typical glacial assemblage.

3. Several times recurrent stages in which glacial species appear together with sporadically occurring species characteristic for the Holocene.

4. The LGM brought about an exceptionally major change in the diversity of the community. All the Holocene species disappeared and a gradual decline in the number of individuals of the glacial species took place.

5. Significant climate changes at the end of the Last Glacial. The assemblage consisted of only typical Holocene species. Initially still some of the glacial relicts (reindeer and lemmings) sporadically occured. Event 12 meant the end of the Pleistocene ecosystem and the beginning of the Holocene ecosystem.

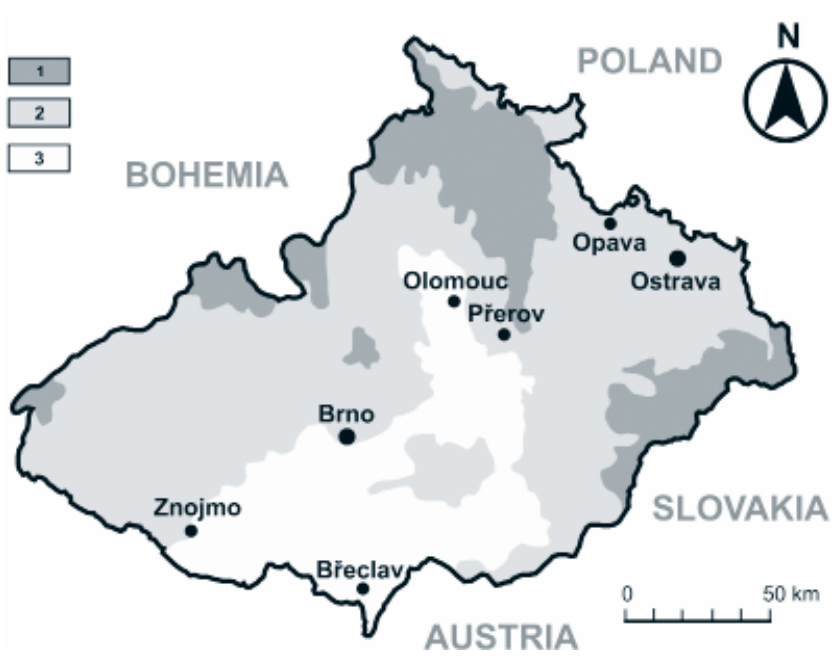

Text-fig. 4. Recent climate provinces in Moravia (the Czech Republic). 1 - cold regions, 2 - moderate warm regions, 3 warm region. The boundaries of each area during the Last Glacial roughly correspond to today's provinces (taken from maps of climatic areas of the Czech Republic (Quitt 2001; highly simplified)).

Abbildung 4. Heutige klimatische Provinzen im Mähren. 1 Gebiete mit dem kalten, 2 - milden und 3 - warmen Klima. Die Grenzen der einzelnen Bereiche der Letzten Eiszeit entsprechen etwa den heutigen Provinzen (genommen von Karten der Klimazonen der Tschechischen Republik (Quitt 2001; stark vereinfacht)). 


\section{Palaeoecological characteristic of the individual events}

For this analysis I used published information on various themes (details of all papers in bibliography) connected with the environment in the Moravian territory. The list of animals was created from findings of game at Palaeolithic sites, and from findings in natural deposits, particularly from karst caves. The individual species were divided up according to individual events. A relatively broad ecological variability is provided for each species. The quantity of findings of each species are not identical, it is actually related to the length of their existence in the Last Glacial, which is at times dependent on the number of sites. Despite these difficulties, a quantitative representation of species in the different biotopes in the individual events is presented.

During any given event, we may find at times species adapted to several different environments. This points to the extensive ecological range of certain species or the diversity of vegetation cover, maybe also to the vertical diversity over a relatively short distance. A larger number of short-term climate oscillations in a single event is also possible. An interesting finding is that within the borders of the provinces in Moravia (southern, central and northern) the temperatures at that time correspond to today's average temperature to a certain extent, of course, with different averages.

The situation is more complicated in terms of the bird findings. We know only a limited number of sites with bird findings. Most are limited to events 7, 8 and 11 (Musil 2002a, Bocheński et al. 2009). Their ecological analysis shows a similarity with mammals in terms of the great diversity of vegetation cover.

The largest number of species was connected to a parkor open landscape (steppe), which probably developed over a substantial part of the studied area. Moist to boggy biotope, peat bogs or slow running water were not rare environments for bird findings. These places were mainly in the valleys of larger rivers. Also of interest is the large number of species found in the lowlands which at present live only in high mountains.

\section{Daily, seasonal and global migration of animals}

The life style of the animals, the size of home territory, in connection with other changes would require further independent detailed processing. These factors are also marginally connected with the time of hunting in Palaeolithic settlements.

Up until now, little attention has been paid to migration and in-migration to this area (Moravia), which can be both seasonal and as well as large-scale. In both forms of migration, the distances that animals may travel during the course of one day and over a longer time period should be taken into account.

Considering a north-south migration of animals in Moravia, only one possibile route was available, through the Moravian Gate (see Text-fig. 3). This form of migration could therefore relate particularly to the fauna communities of Moravia, southern Poland and northern Austria. The area occupied by the various species is, according to current knowledge, extremely variable. Our European fox (Vulpes vulpes) were found, for example, in an area between 5-50 $\mathrm{km}^{2}$, mostly, however, on an average about $10 \mathrm{~km}^{2}$. For wolves (Canis lupus) in North America the smallest territory was $33 \mathrm{~km}^{2}$, some, however, were considerably larger. The area for the wolverine males (Gulo gulo) is larger than for females, and is more than $620 \mathrm{~km}^{2}$, for females only 130-260 $\mathrm{km}^{2}$. One could continue, but this is enough to emphasise the importance of population density of each species (Musil 2014).

Let us now look at the migration distance of certain species during the Last Glacial, to investigate the possible instability of the assemblage in a given territory over the course of one year. The arctic fox (Vulpes lagopus) at present lives in the tundra of the far north duing the spring and summer. They only move to more favourable areas in the autumn. An annual migration for them, is up to a distance of 2,000 km. The wolf pack (Canis lupus) has a stable and nomadic period. The stable period is in the spring and summer when wolves live in pairs. Only in winter they create packs and each pack has its own area. The pack size depends on the amount of food available. If a greater number of reindeer (their main food) live in the surroundings, the wolve packs are larger. In the winter wolves can migrate large distances, particularly when the main prey are migrant animals such as reindeer. The daily distance travelled can be up to $200 \mathrm{~km}$ (Musil 2014).

This is similar for wolverines (Gulo gulo). Their presence is linked mainly to reindeer, if the prey is on the move, wolverines also disappear. These animals are extremely mobile, they may travel up to $800 \mathrm{~km}$ during a month, and daily up to $50 \mathrm{~km}$.

Considering other animals such as elk (Alces alces) which in the late summer and autumn travel up to $100 \mathrm{~km}$ from their original location, migration of a distance up to $600 \mathrm{~km}$ is no exception. The daily movements of lynx (Lynx lynx) are significantly shorter, only about $25 \mathrm{~km}$. The same is true for horses (Equus sp.), the daily migration of a herd is about $5-10 \mathrm{~km}$.

Migration of the musk ox (Ovibos moschatus) in the summer can reach up to $200 \mathrm{~km}$, in the winter it is much shorter, with a maximum of up to $70 \mathrm{~km}$.

A long migration distance can be observed in reindeer (Rangifer tarandus) and their seasonal migrations were repeated regularly. Their herds were always on the move. During migration the size of the herd increased to thousands of individuals. Early on at the beginning of the summer when the number of insects was high, reindeer migrated from the lower areas to higher areas, returning in August. The annual migration can be up to $500 \mathrm{~km}$. The longest daily migration is in the spring months, between $19-55 \mathrm{~km} /$ day (Musil 2014).

The furthest migration among mammals is found in saiga (Saiga tatarica). In the Last Glacial they came from the Eastern European steppes as far as the Pyrenees. The daily migration length is $80-120 \mathrm{~km}$ and occurs mainly in the autumn and early winter. In the summer, if there is enough food, they do not migrate. The migrations are not repeated every year, if food is sufficient, they remain in one place (Musil 2014). 
The way of life of animals, the size of the territory occupied and the length of migration are in direct relationship to the length of sojourn of the hunting groups of the Palaeolithic people in a specific location. It would be necessary to study the game animals from Palaeolithic settlements for a more indepth understanding of the situation. Moravia has a length of approximately $180 \mathrm{~km}$ between the north and south borders and this represents a relatively small territory compared to the migration distance of individual species. This means that it is not possible to make meaningful analyses from only the territory of Moravia, the Austrian Danube region and the southern region of Poland should also be taken into account.

\section{Conclusions}

Moravia, in the eastern part of the Czech Republic, is a relatively small territory, which is, however, extremely important for possible migration of flora and fauna. Its importance lies in its location in Central Europe, and it forms the only possible connection between the north and south. To the north it is connected to the relatively narrow Moravian Gate. Streams flow northwards to Poland and southwards to the Danube River.

Moravia has a remarkable vertical zonality. Its western and eastern parts are surrounded by relatively high mountains, on the west to an altitude of $800-1,400 \mathrm{~m}$ a.s.l. and to the east 700-1,300 $\mathrm{m}$ a.s.1., in the middle part there are lowlying alluvial floodplains of rivers with uplands of various heights. This means that the environment was at the same time, over a relatively short distance extremely variable and also of course the composition of the vegetation and fauna. We can distinguish the following types of environment:

1. Alluvial floodplains around the larger waterways. Favourable areas in the Last Glacial with permanent coniferous forest, mainly in south Moravia with occasionally sporadic thermophilous deciduous trees (Biotope A).

2. Lower foothills of uplands up to about $300 \mathrm{~m}$ in height around rivers. Their extent was variable, but it was probably the largest area of any given biotope. The plant cover was dependent on the geological bedrock. Predominant were: park landscape, open grassy areas with isolated trees and shrubs, at the optimal locations smaller woodlands (Biotope B).

3. Higher altitudes of hills (approx. 300-500 m a.s.1.) mainly with grassy cover only (Biotope C).

4. The top parts of the foothills and mainly in the mountains (500-1,400 $\mathrm{m}$ a.s.l.). The highest places during the cold and dry events, maybe areas without grassy vegetation. Deflationary areas (Biotope D).

A comprehensive study of the Last Glacial indicated that in Moravia the climate was not totally uniform over any given time period (Musil 2008, 2010a). The north was significantly different from the south. The south had a rather dry climate and formed a single province together with northern Austria. The northern part of Moravia, with substantially higher precipitation, was at this time similar to the southern part of Poland.

The border provinces at that time had a similar average temperature to today's temperature, of course, with different temperature averages in the different provinces.
We also discovered an interesting fact. Certain Palaeolithic sites were open-air and others were located in caves. We believe that this division had nothing to do with the temperature but more likely with the amount of precipitation. In my opinion a rainy climate, rather than a dry one predominated during the period when the majority of Palaeolithic sites were located in caves. This is the case particularly during the Magdalénian, Epimagdalénian, Gravettian and Epigravettian cultures.

During the Last Interglacial (Eemian) in Central Europe, we must assume that there were two completely different areas, in the west it was more humid (oceanic weather) and in the east it was more arid (continental weather). The question is how significant the differences were between some provinces and to what extent it impacted on the vegetation cover and fauna. The interglacial assemblage of the classical sites of East Germany always had the typical Antiquus fauna in which species typical for the north of Europe were missing. Such an assemblage was not known in Moravia. Apart from a reduction in the number of species during this Interglacial, certain species reflecting a cold climate were absent, which therefore indicates the time of the first warm oscillations in the Last Glacial.

Faunistic communities of the Last Glacial in Moravia were divided into individual events (1-14). The composition of the communities was not permanently the same, they changed constantly, and were not stable. They did not even have a linear development. They clearly mirrored all the environmental changes. The intensity and the duration of the different conditions varied. There were fundamental changes (sudden changes, collapse of the community) as well as slow changes (gradual changes in the structure of the community). By the end of the Last Glacial the duration of the changes were accelerating.

At the same time we find animals together that were tolerant to both low and higher average temperatures, sometimes species adapted to a different environment. It indicates the great diversity of vegetation cover, perhaps with vertical diversity over a relatively short distance and finally a larger number of short-term climate oscillations within a single event. The largest number of species, however, originated from park or open landscape (steppe), which apparently extended over a substantial part of the studied territory (Ábelová 2008).

We can distinguish the following faunistic types in the Last Glacial in Moravia:

1. A relatively long period with gradually increasing numbers of some interglacial species.

2. A variety of long stages in which we find only species from a typical glacial assemblage.

3. Stages in which glacial species appear together with sporadically occurring species characteristic for the Holocene.

4. The LGM experienced an exceptionally significant change in the flora and in the diversity of the faunistic community.

5. Large changes at the end of the Last Glacial. Several glacial relics (reindeer and lemmings) occurred sporadically in only a few Holocene sites.

The basic composition of the communities was always the same during the Last Glacial, but the length and the 
intensity of changes were different. Changes of the first order were not local, but covered a larger area. Changes of the second order were gradual, mostly on a local scale.

\section{Zusammenfassung}

Das Land Mähren, der östliche Teil der Tschechischen Republik, hat ein relativ kleines Gebiet, jedoch wichtig von dem Standpunkt der nordsüdlichen Migration von Flora und Fauna. Die Bedeutung liegt in der Tatsache, dass es in diesem Teil Mitteleuropas, die einzig mögliche Verbindung zwischen Nord und Süd vorstellt. Mit Norden ist es mit der relativ schmalen Mährischen Pforte vereinigt. Alle mährische Flüsse fliesen entweder nördlich nach Polen oder südlich zur Donau.

Mähren hat auf einem geringen Abstand relativ große Höhenunterschiede der Oberfläche. In der Mitte und im Süden befinden sich entlang der Flüsse recht umfangreiche Talauen, die östlich und westlich von Hügelland und hohen Bergen umgeben sind. Dies bedeutet, dass die Umwelt in der gleichen Zeit bei einer relativ kleinen Entfernung sehr unterschiedlich war, was wir natürlich auch für die Flora und Fauna beziehen können. In dieser Publikation sind die folgenden Typen der Umwelt der Letzten Eiszeit unterschieden:

1. Auen entlang der größeren Flüssen. In der Letzten Eiszeit mit zusammenhangendem Nadelwald, in den günstigen Lagen, vor allem in Südmähren gelegentlich sporadische wärmeliebende Laubbäume (Biotop A).

2. In unmittelbarer Nähe der Auen niedrigeres Hügelland zu einer Höhe von ca. 300 m. Verschiedener Umfang, jedoch in Mähren wahrscheinlich der größte aus allen Biotopen. Die Pflanzendecke war abhängig vom geologischen Untergrund. Dominieen: Parklandschaft, offene Grasflächen mit vereinzelten Bäumen und Sträuchern, an den optimalen Stellen kleinere Wälder (Biotop B).

3. Höhere Teile des Hügellandes (approx. 300-500 m) hauptsächlich nur mit Grasabdeckung (Biotop C).

4. Die obersten Teile des Hügellandes und vor allem Berge (500-1400 m). Die höchsten Stellen im kalten und trockenen Zeitraum an manchen Stellen wahrscheinlich ohne Grasbedeckung. Die Räume woher Löss kommt (Biotop D).

Eine detaillierte Studie der Letzten Eiszeit hat gezeigt, dass Mähren in gleicher Zeit nicht ganz gleichmäßiges Klima hatte. Der nördliche Teil von Mähren unterscheidet sich sehr von dem südlichen. Im Süden war eher trockenes Klima ähnlich wie in Niederösterreich, mit welchem das Südmähren eine klimatische Provin bildete. Zum Unterschied von Südmähren der nördliche Teil war niederschlagsreicher und klimatisch ziemlich ähnlich dem Südpolen.

In der Letzten Warmzeit (Eemian) müssen wir in Mitteleuropa mit zwei völlig verschiedenen Bereichen rechnen, mit dem feuchteren West (ozeanisches Wetter) und trockenerem Ost (kontinentales Wetter). Es ist nur eine Frage, wie bedeutsam dieser Unterschied zwischen den beiden Provinzen war und in welchem Ausmass die Pflanzendecke und Fauna beeinflusst. Die interglaziale Gemeinschaft der klassischen Fundstätten von östlichen Teil Deutschlands hatte immer die typische Antiquus Fauna, in der typische glaziale Arten fehlen. Eine solche Gemeinschaft kennen wir in Mähren nicht. Neben einer ganz unbedeutenden Anzahl von Arten dieser Warmzeit, einige Säugetiere zeigen auf kaltes Klima, daher zeigen sie eher den Zeitraum der ersten warmen Interstadialen der Letzten Eiszeit.

Alle faunistische Gemeinschaften der Letzten Eiszeit aus allen bedeutenden mährischen Fundstellen haben wir mit einer kurzen klimatischen Charakteristik in 14 Eventen unterteilt. Einzelne Events behandeln faunistische Vielfalt und daraus dann die resultierende Breite der Umwelt.

Die Analyse der Gemeinschaften zeigt, dass sie während des Letzten Glazials nicht gleich waren. Die Veränderungen waren von zweierlei Art: Grundsätzliche und plötzliche und dann allmähliche. Zum Ende der Letzten Eiszeit alle Veränderungen zeitlich beschleunigen.

Im Letzten Glazial könnten wir in Mähren diese Zyklen feststellen:

1. Relative langen Zeitraum mit allmählich zunehmendem Zahl von einigen interglazialen Arten.

2. Unterschiedlich lange Phasen, in der wir finden nur typische Arten der glazialen Gemeinschaft.

3. Phasen, in der diese typischen glazialen Arten zusammen mit den sporadisch auftretenden für das Holozän charakteristischen Arten vorkommen.

4. Die LGM steht außergewöhnlich große Änderung in der Flora und in der faunistischen Gemeinschaft.

5. Große Veränderungen zum Ende der Letzten Eiszeit. Am Anfang des Holozäns in wenigen Fundstellen noch einige glaziale Relikte (Rentier und Lemminge).

Die Zusammensetzung der Gemeinschaften war nicht in der Letzten Eiszeit stabil, die Länge und die Intensität der Veränderungen waren different. Die Änderungen des ersten Ranges sind nicht lokal, sie decken gewiss einen größeren Bereich. Die Änderungen des zweiten Ranges sind allmähliche, die meistens in dem lokalen Massstab. Bei dem Vergleich der heutigen durchschnittlichen Temperaturen mit Temperaturen aus dem Letzten Glazial stieß ich auf eine interessante Tatsache. Die Grenzen der einzelnen damaligen klimatischen Provinzen mit der gleichen Durchschnittstemperaturen entsprechen einigermassen den heutigen, natürlich mit anderen Temperaturdurchschnitten. Diese Erkenntnis braucht in Zukunft eine Details-Studie.

Gleichzeitig haben wir eine interessante Tatsache gefunden. Irgendeine paleolithische Siedlungen waren entweder im Freien, andere in Höhlen. Ich glaube, dass dieseTrennung nichts mit der Temperatur zu tun hatte, sondern nur mit der Niederschlagsmenge. Ich nehme an, in den Höhlenfundstellen regnerisches Klima vorherrschte, außen dann eher trocken. Besonders deutlich kennen wir es in Kulturen von Magdalénien, Epimagdalénien, Gravettien und Epigravettien.

In gleicher Zeit finden wir zusammen Tiere, die tolerant sind $\mathrm{zu}$ niedrigen und zugleich $\mathrm{zu}$ den höheren Durchschnittstemperaturen. Manchmal handelt es sich um Tiere die an mannigfaltige Umwelt angepasst sind. Das zeigt auf große Vielfalt der Vegetation, an mögliche Höhenunterschiede bei einem relativ kleinen Abstand und schließlich vielleicht auch auf eine größere Anzahl von kurzfristigen Klimaschwankungen in den einzelnen Events. 
Die größte Zahl der Arten stammte jedoch aus offener Landschaft (Steppe), die offenbar zu einem erheblichen Teil der untersuchten Gegend ausgedehnt wurde.

\section{References}

Ábelová, M. (2008): Zánik ekosystému pleistocénneho a vznik ekosystému holocénneho [Extinction of the Pleistocene ecosystem and origin of the Holocene one]; Dizertačná práca $[\mathrm{PhD}$ thesis]. - MS, Masaryk University, Faculty of Science, Brno, Czech Republic, 180 pp. (in Slovak) (copy in library of Department of Geological Sciences, Faculty of Science, Masaryk University)

Absolon, K., Czižek, R. (1926): Paleolithický výzkum jeskyně Pekárny na Moravě. (První zpráva) [Palaeolithic Research at Pekárna Cave, Moravia. (First Report)]. - Časopis Moravského zemského muzea, 24: 1-59. (in Czech)

Absolon, K., Czižek, R. (1928): Paleolithický výzkum jeskyně Pekárny na Moravě. (Druhá zpráva za rok 1926) [Palaeolithic Research at Pekárna Cave, Moravia. (Second Report, for year 1926)]. - Časopis Moravského zemského muzea, 25: 112-201. (in Czech)

Absolon, K., Czižek, R. (1932): Paleolithický výzkum jeskyně Pekárny na Moravě. (Třetí předběžná zpráva za rok 1927) [Palaeolithic Research at Pekárna Cave, Moravia. (Third Preliminary Report, for year 1927)]. Časopis Moravského zemského muzea, 26-27: 479-598. (in Czech)

Adovasio, J. M., Soffer, O., Hyland, D. C., Illingworth, J. S., Klíma, B., Svoboda, J. (2001): Perishable Industrie from Dolní Věstonice I: New Insights into the Nature and Origin of the Gravettian. - Archaeology, Ethnology and Anthropology of Eurasia, 2(6): 48-65.

Barron, E., van Andel, T. H., Pollard, D. (2003): Glacial Environments II. Reconstructing the Climate of Europe in the Last Glaciation. - In: van Andel, T. H., Davies, W. (eds), Neanderthals and Modern Humans in the European Landscape During the Last Glaciation. McDonald Institute for Archaeological Research, Cambridge, pp. 131-146.

Billia, M. E. (2011): Occurrences of Stephanorhinus kirchbergensis (Jäger, 1839) (Mammalia, Rhinocerotidae) in Eurasia - an account. - Acta Palaeontologica Romaniae, 7: $17-40$.

Bocheński, Z. M., Tomek, T., Wilczynski, J., Svoboda, J., Hertz, K. (2009): Fowling during the Gravettian: the avifauna of Pavlov I, the Czech Republic. - Journal of Archaeological Science, 36: 2655-2665. https://doi.org/10.1016/j.jas.2009.08.002

Bocherens, H., Drucker, D. G., Germonpré, M., Lazničková-Galetová, M., Naito, Y. I., Wissing, Ch., Brůžek, J., Oliva, M. (2015): Reconstruction of the Gravettian food-web at Předmostí I using multi-isotopic tracking $\left({ }^{13} \mathrm{C},{ }^{15} \mathrm{~N},{ }^{34} \mathrm{~S}\right)$ of bone collagen. - Quaternary International, 359-360: 211-228. http://dx.doi.org/10.1016/j.quaint.2014.09.044

Brandtner, F. (1996): Zur geostratigaphischen und kulturellen Zuordnung der Paläolithstation Grubgraben bei Kammern, NÖ. - Spisy Archeologického ústavu AV ČR v Brně, 5: 121-145.
Huntley, B., Allen, J. R. M. (2003): Glacial Environments III. Palaeo-vegetation Patterns in Last Glacial Europe. In: van Andel, T. H., Davies, W. (eds), Neanderthals and Modern Humans in the European Landscape During the Last Glaciation. McDonald Institute for Archaeological Research, Cambridge, pp. 79-102.

Jarošová, L. (1999): Nové výkumy paleolithické lokality v Ostravě-Petřkovicích v letech 1994-1995 [New excavation at the Paleolithic site of Ostrava-Petrrkovice in 1994-1995]. - Archeologické rozhledy, 51: 26-57.

Kahlke, H. D. (1958): Die jungpleistozänen Säugetierfaunen aus dem Travertingebiet von Taubach-Weimar-Ehringsdorf. - Alt-Thüringen, 3: 97-130.

Klíma, B. (1955): Výsledky archeologického výzkumu na tábořišti lovců mamutů $\mathrm{v}$ Ostravě Petřkovicích $\mathrm{v}$ roce 1952 a 1953 [Results of archaeological exploration of mammoth-hunter's settlement in Ostrava Petřkovice in years 1952 and 1953]. - Časopis Slezského muzea, 4: 1-35. (in Czech)

Kovanda, J. (1970): Fossile Mollusken aus den Ablagerungen der Kůlna-Höhle. - In: Valoch, K., Pelíšek, J., Musil, R., Kovanda, J., Opravil, E.: Die Erfroschung der KůlnaHöhle bei Sloup im Mährischen Karst (Tschechoslowakei). Quartär, 20(1969): 21-25.

Lisá, L., Neruda, P., Nerudová, Z., Nejman, L. (2018): Podhradem Interstadial; A critical review of the middle and late MIS 3 (Denekamp, Hengelo) in Moravia, Czech Republic. - Quaternary Science Review, 182: 191-201. http://dx.doi.org/10.1016/j.quascirev.2017.12.024

Markova, A. K., Kolfschoten, T. van, Bohncke, S., Kosintsev, P. A., Mol, J., Puzachenko, A. Yu., Simakova, A. N., Smirnov, N. G., Verpoorte, A., Golovachev, I. B. (2008): Evolyutsiya ekosystem Evropy pri perechode ot pleystotsena k golotsenu (24 - 8 tis. 1. n.) [Evolution of European Ecosystems during Pleistocene - Holocene Transition (24 - 8 kyr BP)]. - KMK Scientific Press, Moscow, 556 pp. (in Russian)

Markova, K. A., Smirnov, N. G., Kozharinov, A. V., Kazantseva, N. E., Simakova, A. N., Kitaev, L. M. (1995): Late Pleistocene Distribution and Diversity of Mammals in Northern Eurasia. - Palaeontologia i Evolucia, 28(2): 5-142.

Meese, D. A., Gow, A. J., Alley, R. B., Zielinsky, G. A., Grootes, P. M., Ram, M., Taylor, K. C., Mayewski, P. A., Bolzan, J. F. (1997): The Greenland Ice Sheet Project 2 depth-age scale: methods and results. - Journal of Geophysical Research, 102(C12; 26): 411-423. https://doi.org/10.1029/97JC00269

Mook, W. G. (1976): Groningen Radiokarbondaten von Bohunice. - In: Valoch, K. (ed.), Die altsteinzeitliche Fundstelle in Brno-Bohunice. Studie Archeologického ústavu ČSAV v Brně, 4(1): 84.

Mook, W. G. (1988): Radiokarbon-Daten aus der KůlnaHöhle. - In: Valoch, K. (ed.), Die Erforschung der KůlnaHöhle 1961-1976. Anthropos, 24(N.S. 16): 285-286.

Moravcová, M. (2011): Izotopové analýzy biominerálov a interpretácia paleoprostredia na území Slovenska a Moravy v období Vislanského glaciálu a holocénu [Isotopic analyses of biominerals and interpretation of paleoenvironment on the territory of Slovakia and Moravia during 
Weichselian and Holocene]; Rigorózní práce [Rigorous thesis]. - MS, Prírodovedecká fakulta, Univerzita Komenského v Bratislave, Bratislava, Slovak Republic, 73 pp. (in Slovak) (copy in library of Faculty of Sciences, Comenius University in Bratislava)

Musil, R. (1955): Osteologický materiál z paleolithického sídliště v Pavlově [The osteological material from Palaeolithic settlement in Pavlov]. - Práce Brněnské základny ČAV, 27(6): 279-320. (in Czech with German summary)

Musil, R., (1957): Magdalénská fauna Žitného jeskyně [Madalénian fauna from Žitný's Cave]. - Práce Brněnské základy ČAV, 29(12): 559-572. (in Czech with German summary)

Musil, R. (1958): Fauna moravských magdalénských stanic [Fauna of Moravian Magdalénian Stations]. - Anthropozoikum, 7(1957): 7-26. (in Czech with German summary)

Musil, R. (1959): Osteologický materiál z paleolithického sídliště v Pavlově. Část II [Osteological material from Palaeolithic settlement in Pavlov. Part II]. - Anthropozoikum, 8(1958): 83-106. (in Czech with German summary)

Musil, R. (1960a): Die pleistozäne Fauna der Barová-Höhle. - Anthropos, 10(N.S. 3): 5-37.

Musil, R. (1960b): Paläontologische Funde in Sedimenten des Letzten Zwischeneiszeit. - Acta Musei Moraviae, Scientiae naturales, 45: 99-136.

Musil, R. (1961): Magdalénská fauna Hadí jeskyně [Magdalénian Fauna from Hadí Cave]. - Acta Musei Moraviae, Scientiae naturales, 46: 51-66. (in Czech with German summary)

Musil, R. (1962): Die Höhle Švédův stůl, ein typischer Höhlenhyänenhorst. - Anthropos, 13(N.S. 5): 97-260.

Musil, R. (1965a): Zhodnocení dřívějších palaeontologických nálezů u Šipky [Evaluation of previous palaeontological finds from Šipka Cave]. - Anthropos, 17(N.S. 9): 127-134. (in Czech)

Musil, R. (1965b): Die Bärenhöhle Pod hradem. Die Entwicklung der Höhlenbären im letzten Glazial. - Anthropos, 18(N.S. 10): 7-92.

Musil, R. (1967): Die interglaziale Fauna aus der Höhle Nr. 4 in Vratíkov. - Acta Musei Moraviae, Scientiae naturales, 52: 93-120.

Musil, R. (1970): Die Entwicklung der Tiergesellschaft im Laufe der Sedimentation in der Kůlna-Höhle. - In: Valoch, K., Pelíšek, J., Musil, R., Kovanda, J., Opravil, E.: Die Erfroschung der Kůlna-Höhle bei Sloup im Mährischen Karst (Tschechoslowakei). Quartär, 20(1969): 8-20.

Musil, R. (1976): Pferdefunde aus der Zeit zwischen dem Alt- und Mittelwürm. - In: Valoch, K. (ed.), Die altsteinzeitlichen Fundstelle in Brno-Bohunice. Studie Archeologického ústavu ČSAV v Brně, 4(1): 76-83.

Musil, R. (1977): Die Equidenreste aus den Travertinen von Taubach. - Quartärpaläontologie, 2: 237-264.

Musil, R. (1978): Die endpaläolithische (mesolithische) Faunagemeinschaft in Smolín. - In: Valoch, K. (ed.), Die endpaläolithische Siedlung in Smolín. Studie Archeologického ústavu ČSAV v Brně, 6: 90-100.

Musil, R. (1980): Fázovité vymírání savců v pleistocénu [Phases of Mammal Extinction during Pleistocene]. Scripta Facultatis Scientarum Naturalium Universitatis
J. E. Purkynianae Brunensis, Geologica, 10(7): 361-353. (in Czech)

Musil, R. (1984): Die Equiden-Reste aus dem Travertin von Weimar. - Quartärpaläontologie, 5: 369-380.

Musil, R. (1985): Palaeobiography of terrestrial communities in Europe during the Last Glacial. - Acta Musei Nationalis Pragae, Series B - Historia Naturalis, 41(1-2): 1-84.

Musil, R. (1988a): Ökostratigraphie der Sedimente in der Kůlna-Höhle. - In: Valoch, K. (ed.), Die Erforschung der Kůlna-Höhle 1961-1976. Anthropos, 24(N.S. 16): 215-256.

Musil, R. (1988b): Změny klimatu v Evropě v posledním glaciálu na základě analýzy změn společenstev obratlovců [Climate changes in Europe during the Last Glacial on the basis of vertebrate assemblages changes]. - In: Vztahy Slunce - Země [Relations between Sun and Earth]; 3rd meeting, Prague, May 1988. Jednota československých matematiků a fyziků, Praha, pp. 217-219. (in Czech)

Musil, R. (1992): Changes in mammalian communities at the Pleistocene-Holocene boundary. - Annales Zoologici Fennici, 28: 241-244.

Musil, R. (1993): Die Ursachen der Veränderungen der Großsäugergemeinschaften im letzten Glazial und am Anfang des Holozäns: Tatsachen und Hypothesen. Quartär, 43/44: 191-197.

Musil, R. (1994a): Migration and extinction of mammals at the turn of Pleistocene and Holocene. - Acta Universitatis Carolinae, Geologica, 1992(1-2): 159-163.

Musil, R. (1994b): Hunting game of the culture layer of Pavlov. - In: Svoboda, J. (ed.), Pavlov I. Excavations 19521953 (The Dolní Věstonice Studies, vol. 2). ERAUL, 66: 169-196.

Musil, R. (1997a): Hunting game analysis. - In: Svoboda, J. (ed.), Pavlov I-Northwest. The Dolní Věstonice Studies, 4: 443-468.

Musil, R. (1997b): Klimatická konfrontace terestrických a marinních pleistocenních sedimentů [Climatic Comparison of Terrestrial and Marine Pleistocene Sediments]. In: Hladilová, Š. (ed.), Dynamika vztahů marinního a kontinentálního prostředí [Dynamic of relationships between marine and terrestrial environment]. Masarykova univerzita v Brně, Brno, pp. 93-167. (in Czech)

Musil, R. (1999a): The Environment in Moravia during the Stage 3. - In: Central and Eastern Europe from 50.00030.000 BP. International Workshop in the Neanderthal Museum, March18-21, 1999, Abstracts, pp. 23-27.

Musil, R. (1999b): Životní prostředí v posledním glaciálu na území Moravy [The environment in the Last Glacial on the territory of Moravia]. - Acta Musei Moraviae, Scientiae geologicae, 84: 161-186. (in Czech)

Musil, R. (1999c): The environment in Moravia during the Stage 3. - In: State of the Stage Project at the Start of its fourth Phase. News, Cambridge, 7: 69-78.

Musil, R. (2000a): The environment in Moravia during the stage OIS 3. - In: Orschiedt, J., Weniger, G.-C. (eds), Neanderthals and Modern Humans - discussing the Tradition. Central and Eastern Europe from 50 000-30 000 BP. Wissenschaftliche Schriten des Neanderthal Museums, 2: 68-75.

Musil, R. (2000b): Natural environment. - Anthropologie, 38(3): 307-310. 
Musil, R. (2002a): Fauna moravských jeskyní s paleolithickými nálezy [The fauna from Moravian Palaeolithic cave deposits]. - In: Svoboda, J. (ed.), Prehistorické jeskyně. Katalogy, dokumenty, studie [Prehistoric Caves. Catalogues, Documents, Studies]. The Dolní Věstonice Studies, 7: 53-101. (in Czech)

Musil, R. (2002b): Das Studium der Pferde aus der Lokalität Grubgraben. - Acta Musei Moraviae, Scientiae geologicae, 87: 165-219.

Musil, R. (2003a): Das Aussterben der pleistozänen Großsäuger. - In: Hansch, W. (ed.), Katastrophen in der Erdgeschichte - Wendezeiten des Lebens. Museo, Städtische Museen Heilbronn, 19: 154-165.

Musil, R. (2003b): The Middle and Upper Palaeolithic Game Suite in Central and Southeastern Europe. - In: van Andel, T., Davies, W. (eds), Nenderthals and modern humans in the European landscape during the last glaciation. McDonald Institute for Archaeological Research, Cambridge, pp. 167-190.

Musil, R. (2003c): The environment in Moravia during the stage OIS 3. - In: Orschiedt, G., Weniger, C. (eds), Neanderthals and Modern Humans. Discussing the Transition: Central and Eastern Europe from 50 000-30 000. Neanderthal Museum, Mettman, pp. 68-75.

Musil, R. (2003d): Die Umweltanalyse und ihre Interpretation: ein anderer Weg. - Praehistoria Thuringica, 9: 80-85.

Musil, R. (2003e): The Early Upper Paleolithic Fauna from Stránská skála. - In: Svoboda, J. A., Bar-Yosef, O. (eds), Stránská skála. Origins of the Upper Paleolithhic in the Brno Basin, Moravia, Czech Republic (The Dolní Věstonice Studies, vol. 10). American School of Prehistoric Research Bulletin, 47: 213-218.

Musil, R. (2005a): Klima v posledním glaciálu [The climate of the Last Glacial]. - Acta Musei Moraviae, Scientiae geologicae, 90: 223-246. (in Czech)

Musil, R. (2005b): Jarošov-Podvršt’a. A Faunal Anomaly among Gravettian sites.Osteological Material Analysis. - In: Škrdla, P. (ed.), The Upper Palaeolithic on the Middle Course of the Morava River. The Dolní Věstonice Studies, 13: 203-216.

Musil, R. (2008): The Palaeoclimatic and Palaeoenvironmental Conditions at Předmostí. - In: Velemínská, J., Brůžek, J. (eds), Early Modern Humans from Předmostí. A new reading of old documentation. Academia, Praha, pp. 15-20.

Musil, R. (2010a): Palaoenvironment at Gravettian Sites in Central Europe with emphasis on Moravia (Czech Republic). - Quartär, 57: 95-123.

Musil, R. (2010b): Das Aussterben der Megafauna am Ende des Pleistozäns. - In: Meller, H. (ed.), Elephantenreich. Eine Fossilwelt in Europa. Landesamt für Denkmalpflege und Archäologie Sachsen-Anhalt, Halle an der Saale, pp. 613-624.

Musil, R. (2011a): The Environment of Pavlov and its surrounding area during the Pavlovian. - In: Svoboda, J. (ed.), Pavlov Excavations 2007-2011. The Dolní Věstonice Studies, 18: 76-114.

Musil, R. (2011b): Gravettian Environmental Changes in a $\mathrm{N}-\mathrm{S}$ Transect of Central Europe. - Central European Journal of Geosciences, 3(2): 147-154.

https://doi.org/10.2478/s13533-011-0015-5
Musil, R. (2014): Morava v době ledové. Prostředí posledního glaciálu a metody jeho poznávání [Moravia during th Ice Age. Environment of the Last Glacial and methods of its understanding]. - MuniPress, Brno, 228 pp. (in Czech)

Musil, R., Karásek, J., Valoch, K. (1999): Pleistocén. Historie výzkumů na území bývalého Československa [Pleistocene. History of its reserch on the territory of the former Czechoslovakia]. - Folia Historica, 69: 5-175.

Nejman, L., Rhodes, E., Škrdla, P., Tostevin, G., Neruda, P., Nerudová, Z., Valoch, K., Oliva, M., Kaminská, L., Svoboda, J. A., Grün, R. (2011): New chronological evidence for the Middle to Upper Palaeolithic transition in the Czech Republic and Slovakia: new optically stimulated luminiscence dating results. - Archaeometry, 53(5): 1044-1066. https://doi.org/10.1111/j.1475-4754.2011.00586.x

Neruda, P. (2010): Chronologická pozice paleolithitického osídlení jeskyně Balcarky ve středoevropském kontextu [Chronological position of Palaeolithic settlement of Balcarka Cave in the Central European Context]. - In: Nerudová, Z. (ed.), Jeskyně Balcarka v Moravském krasu. Interdisciplinátní studie. [Balcarka Cave in the Moravian Karst. Interdisciplinary Study]. Athropos, 31(N.S. 23): 83-95. (in Czech with German summary)

Neruda, P., Nerudová, Z. (2013): The Middle-Upper Palaeolithic transition in Moravia in the context of the Middle Danube region. - Quaternary International, 294: 3-19. https://doi.org/10.1016/j.quaint.2011.08.035

Nerudová, Z. (ed.) (2010): Jeskyně Balcarka v Moravském krasu. Interdisciplinární výzkum [Blacarka Cave in the Moravian Karst. Interdisciplinary Study]. - Anthropos, 31(N.S.23): 1-177. (in Czech with German summary)

Nerudová, Z., Neruda, P., Lisá, L., Roblíčková, M. (2012): Záchranný výzkum mladopaleolitických lokalit v BrněŠtýřicích v kontextu osídlení Brněnska [Rescue excavation on the Upper Palaeolithic sites in Brno-Štýřice in the context of Brno region]. - Archeologické rozhledy, 44: 591-627. (in Czech)

Nývltová-Fišáková, M., Nývlt, D., Škrdla, P. (2006): Geoarcheologický výzkum lokality Boršice u Buchlovic [Geoarchaeological research of Boršice near Buchlovice Palaeolithic site]. - Zprávy o geologických výzkumech v roce 2005: 82-84. (in Czech with English Abstract)

Opravil, E. (1970): Die Ergebnisse der Holzkohlenanalyse aus der Kůlna-Höhle. - In: Valoch, K., Pelíšek, J., Musil, R., Kovanda, J., Opravil, E.: Die Erfroschung der KůlnaHöhle bei Sloup im Mährischen Karst (Tschechoslowakei). Quartär, 20(1969): 25-29.

Opravil, E. (1988): Ergebnisse der Holzkohlenanalyse aus der Kůlna-Höhle. - In: Valoch, K. (ed.): Die Erforschung der Kůlna-Höhle 1961-1976. Anthropos, 24(N.S. 16): 211-214.

Quitt, E. (2001): Recent climate provinces in Moravia (the Czech Republic).

Rink, W. J., Schwarz, H. P., Valoch, K., Seitl, L., Stringer, C. B. (1996): ESR Dating of Micoquian Industry and Neanderthal Remains at Kůlna Cave, Czech Republic. - Journal of Archaeological Science, 23: 889-901. https://doi.org/10.1006/jasc.1996.0084

Seitl, L. (1988): Ökologisch-ökonomische analyse des osteologischen materials aus dem Magdalenien und 
aus dem Gravettien in der Kůlna-Höhle. - In: Valoch, K. (ed.): Die Erforschung der Kůlna-Höhle 1961-1976. Anthropos, 24(N.S. 16): 257-259.

Seitl, L., Valoch, K. (1998): Stanice gravettienských lovců mamutů $v$ Jarošově (Uherské Hradiště-Jarošov, okr. Uherské Hradiště) [Gravettian settlement of Mammoth Hunters in Jarošov]. - Acta Musei Moraviae, Scientiae socieles, 83: 67-81. (in Czech with German summary)

Sommer, R. S., Nadachowski, A. (2006): Glacial refugia of mammals in Europe: evidence from fossil records. Mammal Review, 36: 251-265. https://doi.org/10.1111/j.1365-2907.2006.00093.x

Stewart, J. R., Kolfschoten, T. van, Markova, A., Musil, R. (2003): The Mammalian Fauna of Europe durting Oxygen Isotope Stage Three. - In: van Andel, T. H., Davies, W. (eds), Neanderthals and Modern Humans in the European Landscape During the Last Glaciation. McDonald Institute for Archaeological Research, Cambridge, pp. 103-130.

Svoboda, J. (ed.) (2001a): Pavlov excavations 2007-2011. The Dolní Věstonice Studies, 18: 1-287.

Svoboda, J. (2001b): The Pavlov Site and the Pavlovian. A Large Hunters' Settlement in Context. - Prehistoria, 2: 97-115.

Svoboda, J. (2003a): Gravettian and Epigravettian chronologies in the middle Danube area. - In: Widemann, F., Taborin, Y. (eds), Chronologies géophysiques et archéologiques du Paléolithique supérieur: comptes rendus du Colloque international de Ravello (3-8 mai 1994)/Geophysical and archaeological chronologies for the upper Palaeolithic: proceedings of the international colloquium of Ravello (3rd-8th May 1994). Edipuglia, Bari, pp. 273-282.

Svoboda, J. (2003b): The Bohunician and the Aurignacian. - In: Zilhão, J., d'Errico, F. (eds), The Chronology of the Aurignacian and of the Transitional Technocomplexes. Dating, Stratigraphies, Cultural Implications. Trabalhos de Arqueologia, 33: 123-131.

Svoboda, J. A. (2003c): Chronostratigraphic background, environment, and formation of the archaeological layers. - In: Svoboda, J. A., Bar-Yosef, O. (eds), Stránská skála. Origins of the Upper Paleolithhic in the Brno Basin, Moravia, Czech Republic (The Dolní Věstonice Studies, vol. 10). American School of Prehistoric Research Bulletin, 47: 15-26.

Svoboda, J. A. (2006): The Danubian Gate to Europe: Patterns of Chronology, Settlement Achaeology, and Demography of Late Neandertals and Early Modern Humans on the Middle Danube. - In: Conard, N. J. (ed.), When Neandertals and Modern Humans Met (Tübingen Publications in Prehistory). Kerns Verlag, Tübingen, pp. 233-267.

Svoboda, J., Bocheński, Z. M., Čulíková, V., Dohnalová, A., Hladilová, Š., Hložek, M., Horáček, I., Ivanov, M., Králík, M., Novák, M., Pryor, A. J. E., Sázelová, S., Stevens, R. E., Wilczyński, J., Wojtal, P. (2011): Palaeolitic Hunting in a Southern Moravian Lansdscape: The Case of Milovice IV, Czech Republic. - Geoarchaeology, 26: 838-866. https://doi.org/10.1002/gea.20375

Svoboda, J., Havlíček, P., Ložek, V., Macoun, J., Musil, R., Přichystal, A., Svobodová, H., Vlček, E. (2002a): Paleo- lit Moravy a Slezska [Palaeolithic of Moravia and Silesia]. - The Dolní Věstonice Studies, 8: 3-303.

Svoboda, J., Horáček, I., Ložek, V., Svobodová, H., Šilar, J. (2000a): The Pekárna Cave. Magdalenian stratigraphy, environment, and the termination of the loess formation in Moravian Karst. - Sborník geologických věd, Antropozoikum, 24: 61-79.

Svoboda, J., Klíma, B., Jarošová, L., Škrdla, P. (2000b): The Gravettian in Moravia: climate, behavior and technological complexity. - In: Roebroeks, W., Mussi, M., Svoboda, J., Fennema, K. (eds), Hunters of the Golden Age: the Mid Upper Palaeolithic of Eurasia 30,000 - 20,000 BP. Analecta Praehistorica Leidensia, 31(1999): 197-217.

Svoboda, J., Králík, M., Čulíková, V., Hladilová, Š., Novák, M., Nývltová-Fišáková, M., Nývlt, D., Zelinková, M. (2009): Pavlov VI: an Upper Palaeolithic living unit. Antiquity, 83: 282-295. https://doi.org/10.1017/S0003598X00098434

Svoboda, J., Plicht, J. van der, Kuželka, V. (2002b): Upper Palaeolithic and mesolithic human fossils from Moravia and Bohemia (Czech Republic): some new ${ }^{14} \mathrm{C}$ dates. Antiquity, 76: 957-962. https://doi.org/10.1017/S0003598X00091754

Svobodová, H. (1987): Pylová analýza půdního horizontu ze Stránské skály II [Pollen analysis of the soil horizon of Stránská skála II]. - Archeologické rozhledy, 39: 383385. (in Czech)

Switsur, V. R. (1976): Cambridge Radiocharcoaldaten von Bohunice. - In: Valoch, K. (ed.), Die altsteinzeitliche Fundstelle in Brno-Bohunice. Studie Archeologického ústavu ČSAV v Brně, 4(1): 85-86.

Škrdla, P. (2002): Uherské Hradiště (k.ú. Jarošov u Uherského Hradiště, okr. Uherské Hradiště) [Archeological Research in Uherské Hradiště district]. - Přehled výzkumů, Archeologický ústav AV ČR, Brno, v. v. i., 42: 122-126. (in Czech).

Škrdla, P., Nývltová- Fišáková, M., Nývlt, D. (2006): Sídelní cluster Jarošov II. Výsledky výzkumu v roce 2005 [Jarošov II settlement cluster. Results of the 2005 excavation]. - Archeologické rozhledy, 58: 207-236. (in Czech)

Škrdla, P., Kruml, O. (2000): Uherské Hradiště (k.ú. Jarošov u Uh.Hradiště) [Archeological Research in Uherské Hradiště district]. - Přehled výzkumů, Archeologický ústav AV ČR, Brno, v. v. i., 41: 88-92. (in Czech)

Škrdla, P., Musil, R. (1999): Jarošov II: nová stanice gravettienu na Uherskohradištsku [Jarošov II: a new Gravettian station in Uherské Hradiště district]. - Přehled výzkumů AÚ AV ČR Brno, 39(1995-1996): 47-62. (in Czech)

Šroubek, P., Diehl, J. F., Kadlec, J., Valoch, K. (1996): Preliminary study on the mineral magnetic properties of sediments of Kůlna Cave (Moravian Karst), Czech Republic. - Studia Geophysica et Geodaetica, 40: 301-312. https://doi.org/10.1007/BF02300745

Trampler, R. (1897): Meine Grabungen in den mährischen Karsthöhlen. - Reprint from Mittheilungen und Vorträgen des fachtechnischen Club der Beamten und Factoren der k. k. Hof- und Statsdruckerei, 15 pp.

Valoch, K. (1988): Die Erforschung der Kůlna-Höhle 19611976. - In: Valoch, K. (ed.), Die Erforschung der KůlnaHöhle 1961-1976. Anthropos, 24(N.S. 16): 7-199. 
Valoch, K. (1989): The Mesolithic Site of Smolín, South Moravia. - In: Bonsall, C. (ed.), The Mesolithic in Europe. John Donald Publishers Ltd., Edinbourgh, pp. 461-470.

Valoch, K. (1996): Př́spěvek k ekologii pozdního glaciálu v Moravském krasu [Contribution to the Late Glacial environment in Moravian Kras]. - Acta Musei Moraviae, Scientiae sociales, 81: 61-71. (in Czech)

Valoch, K. (2001): Das Magdalenien in Mähren. - Jahrbuch des Römisch-Germanischen Zentralmuseums, 48: 103159.

Valoch, K. (2002): Eine Notgrabung in der Kůlna-Höhle im Mährischen Karst. - Acta Musei Moraviae, Scientiae geologicae, 87: 3-34.

Valoch, K. (2008): Brno-Bohunice. Eponymous Bohunician Site: new data, new ideas. - In: Sulgostowska, Z., Tomaszewski, A. J. (eds), Man-Millennia-Environment. Studies in Honour of Romuald Schild. Institute of Archaeology and Ethnology PAS, Warszawa, pp. 225-236.

Valoch, K., Neruda, P. (2005): K chronologii moravského magdalénienu [On the chronology of the Moravian Mag- dalénian]. - Archeologické rozhledy, 57: 459-476. (in Czech with English abstract)

Valoch, K., Pelíšek, J., Musil, R., Kovanda, J., Opravil, E. (1970): Die Erforschung der Kůlna-Höhle bei Sloup im Mährischen Karst (Tschechoslowakei). - Quartär, 20(1969): 1-45.

van Andel, T. (2003): Glacial environments I: the Weichselian Climate in Europe between the End of the OIS-5 Interglacial and the Last Glacial Maximum. - In: van Andel, T. H., Davies, W. (eds), Neanderthals and Modern Humans in the European Landscape During the Last Glaciation. McDonald Institute for Archaeological Research, Cambridge, pp. 9-29.

van Andel, T., Davies, W. (eds) (2003): Nenderthals and modern humans in the European landscape during the last glaciation (McDonald Institute Monographs). McDonald Institute for Archaeological Research, Cambridge, 265 pp. 